\author{
Universidade de São Paulo - USP \\ Escola de Engenharia de São Carlos - EESC \\ Departamento de Engenharia Elétrica
}

\title{
Estudo de Esquemas de Amplificação para Redes PON de Longo Alcance
}

Getúlio Eduardo Rodrigues de Paiva

Dissertação de mestrado apresentada à Escola de Engenharia de São Carlos, Departamento de Engenharia Elétrica da Universidade de São Paulo, como parte dos requisitos para obtenção do título de Mestre em Ciências, Programa de Engenharia Elétrica - Área de concentração: Telecomunicações.

Orientador: Prof. Dr. Murilo Araujo Romero

São Carlos

2012

Trata-se da versão corrigida da dissertação. A versão original se encontra disponível na EESC/USP que aloja o Programa de Pós-Graduação de Engenharia Elétrica. 
AUTORIZO A REPRODUÇÃO E DIVULGAÇÃO TOTAL OU PARCIAL DESTE TRABALHO, POR QUALQUER MEIO CONVENCIONAL OU ELETRÔNICO, PARA FINS DE ESTUDO E PESQUISA, DESDE QUE CITADA A FONTE.

Ficha catalográfica preparada pela Seção de Tratamento da Informação do Serviço de Biblioteca - EESC/USP

\begin{tabular}{|c|c|}
\hline \multirow[t]{3}{*}{ P149e } & $\begin{array}{l}\text { Paiva, Getúlio Eduardo Rodrigues de. } \\
\text { Estudo de esquemas de amplificação para redes PoN de } \\
\text { longo alcance. / Getúlio Eduardo Rodrigues de Paiva ; } \\
\text { orientador Murilo Araujo Romero. São Carlos, } 2012 \text {. }\end{array}$ \\
\hline & $\begin{array}{l}\text { Dissertação - Mestrado (Programa de Pós-Graduação em } \\
\text { Ciências em Engenharia Elétrica e Área de Concentração em } \\
\text { Telecomunicações)-- Escola de Engenharia de São Carlos da } \\
\text { Universidade de São Paulo, } 2012 \text {. }\end{array}$ \\
\hline & $\begin{array}{l}\text { 1. LR-PON. 2. Redes ópticas passivas estendidas. } 3 . \\
\text { Amplificação óptica. 4. SOA. 5. EDFA. 6. Amplificação } \\
\text { Raman. I. Título. }\end{array}$ \\
\hline
\end{tabular}




\section{FOLHA DE JULGAMENTO}

\section{Candidato: Bacharel GETÚLIO EDUARDO RODRIGUES DE PAIVA}

Título da dissertação: "Estudo de esquemas de amplificação para redes PON de longo alcance".

Data da defesa: 12/04/2012

\section{Comissão Julgadora:}

Prof. Titular Murilo Araujo Romero (Orientador)

(Escola de Engenharia de São Carlos/EESC)

\section{Dr. João Batista Rosolem}

(Centro de Pesquisa e Desenvolvimento/CPqD)

Msc. Atilio Eduardo Reggiani

(Centro de Pesquisa e Desenvolvimento/CPqD)

Coordenador do Programa de Pós-Graduação em Engenharia Elétrica:

Prof. Titular Denis Vinicius Coury

Presidente da Comissão de Pós-Graduação:

Prof. Associado Paulo Cesar Lima Segantine $\underline{\text { Resultado: }}$
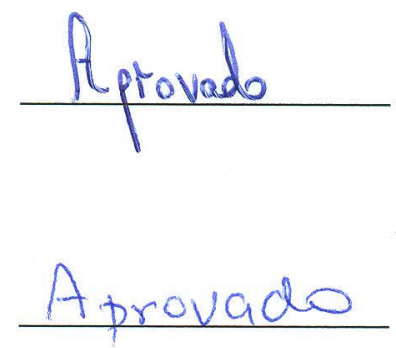

Amovado 

"A ciência humana de maneira nenhuma nega a existência de Deus. Quando considero quantas e quão maravilhosas coisas o homem compreende, pesquisa e consegue realizar, então reconheço claramente que o espirito humano é obra de Deus, e a mais notável."

Galileu Galilei 



\section{Agradecimentos}

Agradeço a Deus, por permitir que concluísse mais essa etapa.

Agradeço ao meu orientador, Prof. Dr. Murilo Araujo Romero, por ter me dado a oportunidade de ser seu aluno, onde aprendi muito através das riquíssimas discussões e sugestões. Muitíssimo obrigado!

Agradeço à Profa. Dra. Regiane Ragi, por ter me incentivado desde a primeira reunião a realizar este trabalho, por seus conselhos de aprimoramento durante os colóquios. Muito obrigado!

Agradeço ao meu supervisor de estágio e grande amigo, Dr. João Batista Rosolem, que foi um verdadeiro guia não somente para a conclusão deste trabalho, mas para um aprimoramento contínuo, através de seus valiosos ensinamentos. Muitíssimo obrigado.

Agradeço aos professores do Departamento de Engenharia Elétrica da Escola de Engenharia de São Carlos, por contribuir imensamente para minha formação. Muito obrigado

Agradeço à CAPES, Coordenação de Aperfeiçoamento de Pessoal de Nível Superior, pela bolsa de estudos e ao CPqD, Centro de Pesquisa e Desenvolvimento em Telecomunicações, pela vaga de estágio e, posteriormente, pela contratação. Muito obrigado.

Agradeço infinitamente aos meus pais, Eli e Silma, por sempre terem apoiado minhas escolhas e me amparado nas horas mais difíceis. Sem vocês, nunca teria conseguido.

Serei eternamente grato a minha namorada, Lilian, que há oito anos me acompanha em todas as jornadas e me ergue sempre que fraquejo. Seu carinho e compreensão foram os combustíveis indispensáveis para mais esta realização.

Agradeço às minhas avós, Laura e Terezinha, por seus ensinamentos de humildade e perseverança, que foram, e continuarão sendo, muito úteis.

Agradeço também a Leonardo e Rosemeiri Rondina, por terem me acolhido de forma tão carinhosa e generosamente durante o período de estágio no $\mathrm{CPqD}$ e, principalmente, durante minha mudança para Campinas. Sem seu apoio jamais teria sido possível. Muitíssimo obrigado!

Agradeço ao Rafael Nóbrega, o gordassa original, por ter me apresentado ao grupo de telecomunicações, ainda em 2008. Muito obrigado!

Agradeço também ao Ulysses Rondina Duarte, a inconfundível Porca Rosa, por ter me lembrado da matrícula de acompanhamento e, principalmente, por pedir a seus tios em Campinas que me acolhessem também. Muito obrigado!

Agradeço aos amigos de Uberlândia: Bruno, Carlos Henrique, Júlio Servo, Luiz Henrique, Marcus Vinícius, prof. Reinaldo e Rafael Rodrigues. Muito obrigado!

Agradeço aos amigos de São Carlos: Ailton, Dengo (Alex), Penadinho (Anderson), Aníbal, kdu (Carlos Eduardo), Carlão (Carlos Rocha), Clebão (Cléber), Cleide, Daiane, Dimas, Diogo, Ed, Pumba (Eduardo), Du (Eduardo Meakawa), Emerson, Guilherme, Gustavo, Codorna (Helvécio), Hígor, Inês, Ingrid, Josy, Leonardo, Lucas, Japa (Luciano), Maria (Marcelo), Mariama, Mariana, Miguel, Pedrão (Pedro), Mufasa (Otávio), Paranhos (Rafael), Osama (Raul), GiGi (Reginaldo), Rodrigão (Rodrigo), Romel, Ronald, Rosirene, Dr. Bactéria (Samuel), Devassa (Thiago), Vinícius, Valdemir, Wanda, Wilma.

Agradeço aos amigos de Campinas: Alexandre, Amauri, Anderson, Bruno, Dom Floridia (Claudio), Dimitri (Eduardo Magalhães), Rosa (Eduardo Rosa), Edson Bezerra, Edson Porto, Fábio, Felipe, Glutão (Glauco), Juliano, Júlio Diniz, Júlio Oliveira, Maurilio, Turco (Júlio Said), Lívia, Rafael, Reginaldo, Rivael, Roberto, Vitor Ribeiro, Vitor Parahyba, Uiara.

Agradeço àqueles que indiretamente contribuíram para a realização deste trabalho. 



\section{Resumo}

O surgimento de novos serviços que requerem uma largura de banda cada vez maior, bem como o crescente número de usuários de tais serviços, têm introduzido desafios às empresas operadoras de telecomunicações em sua capacidade de atender a estas demandas sem perda apreciável da qualidade de serviço e mantendo, ainda assim, os custos num nível aceitável pelos usuários. Neste contexto, redes ópticas passivas (PONs) vêm atraindo grande interesse em anos recentes. Na sua variante de longo-alcance, as redes PON permitem uma consolidação do uso dos equipamentos e centrais de serviço requeridos, reduzindo custos operacionais e de instalação. Uma das formas de atingir este maior alcance dá-se por meio da inserção de amplificadores ópticos nas redes de acesso. Neste trabalho, portanto, estudaram-se alguns tipos de amplificadores ópticos e suas possíveis aplicações em redes de acesso, levando a topologias de longo alcance e alta capacidade. Foram realizadas avaliações experimentais de um extensor, baseado em amplificadores ópticos semicondutores (SOAs), na rede GPON do $\mathrm{CPqD}$, sob a Meta 3 do Projeto GIGA, possibilitando a obtenção de uma topologia do tipo Fiber-to-the-Building (FTTB) com 80km de extensão e 128 usuários atendidos por uma única central de serviço. Além dessas validações experimentais, foram simulados computacionalmente SOAs com características otimizadas bem como sistemas que utilizam fibras dopadas com érbio bombeadas remotamente, sendo que nestes últimos, atingiram-se distâncias superiores a 100km. 


\begin{abstract}
The emergence of new services which require an increasing bandwidth, as well as the growing number of users of such services, have introduced challenges to the network operators in regard to their capacity of supporting these demands with no penalty on the required quality of service, while keeping the costs at an acceptable level for the users. In this context, passive optical networks (PONs) have attracted a great deal of interest in recent years. In the long-reach configuration, PON networks allow for a consolidation of equipament usage, reducing operational and installation costs. One way to achieve this longer reach is by the insertion of optical amplifiers in the access network. Therefore, in our work, we have investigated several optical amplifier configurations, as well as their application in access networks, leading to longreach and high capacity network topologies. Experimental evaluations of an extender, based on semiconductor optical amplifiers, were carried out in the CPqD GPON network, under Goal 3 of GIGA Project, allowing the achievement of a Fiber-to-the-Building (FTTB) topology with $80 \mathrm{~km}$ of extension and 128 users served by a single central office. Besides these experimental validations, were simulated computationally SOAs with optimized characteristics as well as systems using remotely pumped erbium-doped fibers, whereas in the latter were reached distances exceeding $100 \mathrm{~km}$.
\end{abstract}




\section{Sumário}

Lista de Tabelas $\quad$ iv

Lista de Figuras $\quad$ v

1 Introdução 1

1.1 Redes Ópticas Passivas . . . . . . . . . . . . . . . . . . . . . . . . . . 4

1.1.1 Multiplexação por Divisão de Tempo . . . . . . . . . . . . . . . . . . 5

1.1.2 Multiplexação por Divisão de Comprimento de Onda . . . . . . . . . . . . 6

2 Extensores de Redes Ópticas $\quad 8$

2.1 Regeneradores Optoeletrônicos . . . . . . . . . . . . . . . . . . 8

2.2 Amplificadores Ópticos . . . . . . . . . . . . . . . . . . . . . . . . . . . 10

2.2.1 Princípios Básicos de Amplificação Óptica . . . . . . . . . . . . . . . . . . . . . 10

2.2.2 Características dos Amplificadores Ópticos . . . . . . . . . . . . . . . . . . 12

2.2.3 Amplificadores utilizados em Extended PONs . . . . . . . . . . . . . . . . 17

2.2.4 Amplificadores Ópticos utilizados nas LR-PONs . . . . . . . . . . . . . 27

2.2.5 Posicionamento dos Amplificadores Ópticos . . . . . . . . . . . . . . . . 33

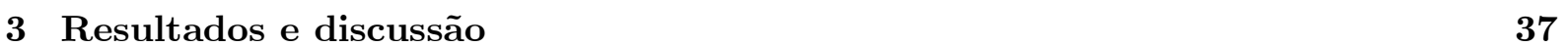

3.1 Extensores para sistemas do padrão GPON . . . . . . . . . . . . . . . . 37

3.1.1 Simulação Computacional dos Parâmetros dos Amplificadores Ópticos Semicondutores ......................... 60

3.2 EDFAs como Extensores . . . . . . . . . . . . . . . . . . . 64

4 Conclusões $\quad 82$

Referências Bibliográficas $\quad 84$ 


\section{Lista de Tabelas}

3.1 Principais parâmetros utilizados na simulação da fibra dopada com érbio. . . . . 67

3.2 Parâmetros dos componentes utilizados na caracterização da fibra dopada com érbio mostrada nas Figuras 3.26 e 3.27 . . . . . . . . . . . . . . . . 67 


\section{Lista de Figuras}

1.1 Gráfico representando o aumento anual no número de usuários de internet atendidos, segundo pesquisa publicada em 2008, disponível em [8] . . . . . . . . . . .

1.2 Gráfico representando o crescimento no fluxo de dados pela internet. A pesquisa realizada pela Cisco [11] estima que no ano de 2014 serão transmitidos 42 exabytes, sendo que $56 \%$ serão resultantes do tráfego de vídeo e $27 \%$ são referentes ao compartilhamento ponto-a-ponto de arquivos. . . . . . . . . . . . . . .

1.3 Simplificação da rede a partir da unificação de nós remotos [12]. A partir da redução na quantidade de equipamentos necessários, há uma redução no consumo energético requerido. . . . . . . . . . . . . . . . .

1.4 Representação esquemática da transmissão com multiplexação por divisão no tempo. A Figura 1.4 (a) representa a transmissão downstream, que é feita em broadcast. A Figura 1.4 (b) mostra o tráfego upstream, que é feito a partir da divisão de tempo, para que cada usuário envie seus dados no instante correto. . .

1.5 Representação esquemática de uma rede WDM-PON (Wavelength Division MultiplexingPassive Optical Network). Deve-se observar que os tráfegos nos dois sentidos utilizam comprimentos de onda específicos, sendo que cada usuário possui um par dedicado.

2.1 Ilustração representando a integração de um esquema DWDM com o padrão GPON, a partir da utilização de regeneradores optoeletrônicos presentes no conversor GPON-DWDM. . . . . . . . . . . . . . . . . .

2.2 Esquema representando o princípio da emissão estimulada. Na figura (a), um elétron presente no estado fundamental, $\mathrm{E}_{0}$, absorve o fóton, representado em azul, e atinge o nível de excitado $\mathrm{E}_{1}$, como pode ser visto em (b). A energia do fóton corresponde à diferença de energia entre os dois níveis, $\mathrm{E}_{0}$ e $\mathrm{E}_{1}, h v=$ $E_{1}-E_{0}$. Em (c), o elétron, no nível $E_{1}$, decai espontaneamente emitindo um fóton idêntico ao absorvido em (a). Finalmente, em (d) ocorre o processo de emissão estimulada, no qual a presença de um fóton estimula o decaimento de um elétron presente no nível mais energético, levando à emissão de outro fóton. Como conseqüência, os dois fótons, o incidente e o emitido, são coerentes, ou seja, possuem a mesma fase e amplitude. . . . . . . . . . . . . .

2.3 Ganho de um amplificador em função da potência de entrada do sinal. À medida que a potência do sinal de entrada aumenta, a amplificação ainda ocorre, porém, em menor intensidade, quando comparada à amplificação de pequenos sinais, que é a amplificação em baixos níveis de potência óptica. . . . . . . . . . . . . . . . 
2.4 Ganho de um amplificador de fibra dopada com érbio em função do comprimento de onda do sinal de entrada. Nota-se que para diferentes valores do comprimento de onda, há diferentes valores do ganho $[35] \ldots \ldots \ldots \ldots \ldots$

2.5 Espectro típico da ASE proveniente de um amplificador de fibra dopada a érbio, obtido no software OptiSystem. As emissões espontâneas ocorrem independentemente da passagem de sinal óptico, bastando apenas a presença do bombeio. . .

2.6 Ganho óptico de um SOA em função da corrente de injeção. Observa-se que com a elevação da corrente de injeção a potência de saída do amplificador aumenta, partindo de uma região em que a perda é maior que o ganho até uma região em que o ganho é superior à perda, onde ocorre a amplificação óptica. . . . . . . . . . .

2.7 Ganho óptico de um SOA em função do comprimento de onda do sinal de entrada. Deve-se notar que esta figura de ganho é diferente daquela mostrada na Figura 2.4, que se referia a um amplificador de fibra dopada com érbio. Estes dispositivos possuem larguras de banda óptica de 30 a 80nm [38] - [42] . . . . . . . . . . . .

2.8 Arquitetura proposta pela ACTS-PLANET [48]. A central de serviço é conectada ao Amplified Splitter (AS) por meio das duas fibras da região de alimentação, que contém um repetidor localizado no centro do enlace. No AS, os sinais de downstream e upstream são amplificados. A conexão entre a rede de distribuição e o AS é realizada pelo WDM, que torna possível a utilização de uma única fibra distribuidora para cada uma das 2048 ONUs. . . . . . . . . . . . . . . .

2.9 Esquema de PON de longo alcance proposto pela British Telecom. As taxas utilizadas são de 10Gbps e são atendidas 1024 ONUs. Novamente, uma seção de alimentação de $90 \mathrm{~km}$ conecta a central de serviço ao chamado Local Exchange (LE), que é onde a amplificação é feita. Os sinais de up e downstream são mutliplexados na fibra de distribuição por meio do dispositivo CDWM conectado à rede de distribuição, que possui um comprimento máximo de $10 \mathrm{~km}$, entre o LE e

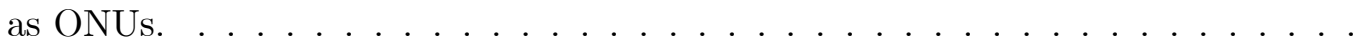

2.10 Perfil de ganho Raman em função da diferença de freqüências entre o bombeio e o sinal, para a silica. O ganho máximo ocorre em torno de $13 \mathrm{THz}$. Os demais picos ocorrem devido aos modos de vibração das moléculas de silica [51] . . . . . .

2.11 Amplificação multicanal utilizando a amplificação Raman distribuída. Em (a), os quatro canais, representados em vermelho, laranja, verde e azul, propagam-se pela fibra sem serem amplificados, sofrendo atenuações diferentes. Em (b), é utilizado um bombeio para a amplificação do canal vermelho. Este canal é amplificado com o ganho máximo proveniente do bombeio, ao passo que os demais podem ser amplificados, porém em diferentes intensidades. Por fim, a parte (c) mostra que utilizando um conjunto de bombeios é possível ter um ganho homogêneo para todos os canais. . . . . . . . . . . . . . . . . . .

2.12 Representação esquemática de um sistema GPON utilizando amplificação Raman para aumentar o orçamento de potência. A análise desta extensão é realizada para o tráfego upstream, já que é ele o responsável pela limitação da extensão da rede.

2.13 Enlace óptico ponto-a-ponto utilizando bombeio remoto, garantindo que a rede permaneça passiva. O EDFA está localizado ao longo do enlace e o laser de bombeio está posicionado junto do transmissor óptico. Como o sinal óptico e o de bombeio se propagam na mesma direção, o esquema é bombeio co-propagante. A inserção dos dois sinais na fibra dopada é feita pelo acoplador de bombeio. . . 
2.14 Enlace óptico ponto-a-ponto utilizando bombeio remoto, garantindo que a rede permaneça passiva. O EDFA está localizado ao longo do enlace e o laser de bombeio está posicionado junto do transmissor. Como o sinal óptico e o de bombeio se propagam em direções opostas, o esquema é bombeio contra-propagante. A inserção do sinal de bombeio na fibra óptica é feita pelo acoplador de bombeio.

2.15 Esquema da topologia híbrida DWDM-TDM proposta em [19]. A secção alimentadora possui $88 \mathrm{~km}$ e é DWDM-PON. Já a região de distribuição possui comprimento máximo de $12 \mathrm{~km}$, sendo TDM-PON. Cada TDM-PON, com suas 256 ONUs, está conectada a um dos canais DWDM. . . . . . . . . . . . . . .

2.16 Representação esquemática da topologia PIEMAN [58]. Ela é semelhante à proposta híbrida DWDM-TDM feita por Talli em [19]. Deve-se notar que na secção metropolitana, os tráfegos up e downstream são separados em duas fibras, enquanto na região de acesso, há apenas uma fibra transmitindo os dois fluxos de informação.

2.17 Representação esquemática da topologia em anel SARDANA. A arquitetura de um anel com tráfego WDM bidirecional com taxas de 10Gbps downstream e 1,25/2,5Gbps upstream, conforme a tecnologia utilizada na Colorless ONU [63]. .

2.18 Esquema representando o efeito do aumento da distância de propagação sobre a informação transmitida. São utilizados transmissores e receptores idênticos nos dois casos. Na parte superior da figura, o receptor é capaz de identificar corretamente a informação transmitida. Já na parte inferior, a elevação no comprimento do enlace faz com que a potência incidente sobre o receptor esteja abaixo do limite que o fotodetector é capaz de identificar corretamente, levando, portanto, à perda da informação transmitida. . . . . . . . . . . . . . . . . . .

2.19 Representação esquemática da amplificação de potência. Posicionando o amplificador após a saída do laser: configura-se a amplificação de potência, cujo objetivo é aumentar o comprimento do enlace a partir da injeção de um sinal de alta potência na fibra. Por receber um sinal de alta potência, o amplificador utilizado na amplificação de potência deve operar em regime de saturação. . . . . . . . . . . .

2.20 Esquema da pré-amplificação. Ao posicionar o amplificador exatamente antes do receptor óptico, tem-se a pré-amplificação, cujo objetivo principal é elevar a potência recebida no fotodetector. Como o sinal sairá do pré-amplificador para o receptor, o amplificador utilizado determinará o ruído que incidirá sobre o fotodetector, podendo levar a elevações nas taxas de erro de bit. Assim, deve possuir uma pequena figura de ruído ou filtros ópticos bastante finos devem ser utilizados, reduzindo o ruído detectado. . . . . . . . . . . . . . . . . . . .

2.21 Representação esquemática da amplificação de linha, cuja principal função é aumentar o comprimento do enlace. . . . . . . . . . . . . . . .

2.22 Esquema representando a divisão de potência óptica ao longo da rede. O aumento no número de usuários conectados a uma mesma estrutura de rede requer que a potência do sinal óptico seja dividida entre eles. Para garantir que todos os usuários recebam uma potência óptica adequada, insere-se um amplificador antes de realizar a divisão. . . . . . . . . . . . . . . . . . . . . .

3.1 Foto do aparato experimental, em laboratório do $\mathrm{CPqD}$, utilizado no estudo de um extensor baseado em SOAs. . . . . . . . . . . . . . . . . .

3.2 Foto do extensor baseado em SOAs desenvolvido no $\mathrm{CPqD}$, contendo os amplificadores de $1490 \mathrm{~nm}$ e $1310 \mathrm{~nm}$ e os acopladores $1310 \mathrm{~nm} / 1490 \mathrm{~nm}$. . . . . . . . . . 
3.3 Ganho e figura de ruído, do SOA de 1300nm, em função do comprimento de onda do sinal para potências de entrada de $-25 \mathrm{dBm},-20 \mathrm{dBm}$ e $-15 \mathrm{dBm}$. A corrente de injeção do dispositivo é de $180 \mathrm{~mA}$. . . . . . . . . . . . . . . . . . .

3.4 Ganho e figura de ruído, do SOA 1500nm, em função do comprimento de onda para potências de entrada de $-23 \mathrm{dBm},-17 \mathrm{dBm},-11 \mathrm{dBm}$ e $-7 \mathrm{dBm}$. A corrente de

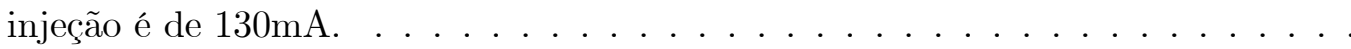

3.5 Espectro de ASE proveniente do SOA de $1310 \mathrm{~nm}$ polarizado com $200 \mathrm{~mA}$ de corrente de injeção. Observa-se que o pico de ASE ocorre aproximadamente em

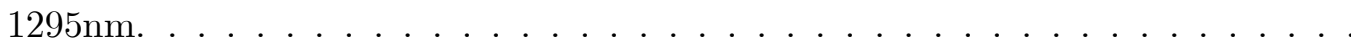

3.6 Espectro de ASE gerada pelo SOA de $1490 \mathrm{~nm}$ alimentado com corrente de $200 \mathrm{~mA}$. Nota-se que o pico do perfil de ASE ocorre em torno de 1462nm. . . . . . . . . . .

3.7 Potência de saída do SOA de 1310nm em função da corrente de injeção, para as potências de entrada de $-20 \mathrm{dBm}$ e $-30 \mathrm{dBm}$. As linhas tracejadas mostram o limite para o qual o ganho é positivo, para as duas potências de entrada. . . . . .

3.8 Potência de saída do SOA de 1490nm em função da corrente de injeção, para as potências de entrada de $-20 \mathrm{dBm}$ e $-30 \mathrm{dBm}$. As linhas tracejadas mostram o limite para o qual o ganho é positivo, para as duas potências de entrada. . . . . . . . .

3.9 Representação esquemática das formas de amplificação investigadas para o SOA de $1310 \mathrm{~nm}$, utilizado no upstream. As duas formas investigadas são a pré-amplificação e amplificação de linha. . . . . . . . . . . . . . . . . . . . . . . . . 46

3.10 Representação esquemática das formas de amplificação para o SOA de 1490nm, utilizado no downstream. As duas formas de amplificação investigadas são a amplificação de linha e de potência. . . . . . . . . . . . . . . . . . .

3.11 Taxa de erro de bit em função da potência incidente em um receptor do tipo PIN, para o SOA de 1310nm. São considerados dois regimes de amplificação de linha com potência de entrada de $-20 \mathrm{dBm}$ e $-25 \mathrm{dBm}$, além da pré-amplificação. . . . .

3.12 Taxa de erro de bit em função da potência incidente em um receptor do tipo APD, para o SOA de 1310nm. São considerados dois regimes de amplificação de linha com potência de entrada de $-20 \mathrm{dBm}$ e $-25 \mathrm{dBm}$, além da pré-amplificação. . . . .

3.13 Taxa de erro de bit em função da potência recebida na entrada do SOA de 1490nm para um fotodetector do tipo PIN. Além da amplificação de potência, foram consideradas duas potências de entrada, $-20 \mathrm{dBm}$ e $-25 \mathrm{dBm}$, para a amplificação de linha. . . . . . . . . . . . . . . . . . . . . . .

3.14 Taxa de erro de bit em função da potência recebida na entrada do SOA de 1490nm para um fotodetector do tipo APD. Além da amplificação de potência, foram consideradas duas potências de entrada, $-20 \mathrm{dBm}$ e $-25 \mathrm{dBm}$, para a amplificação

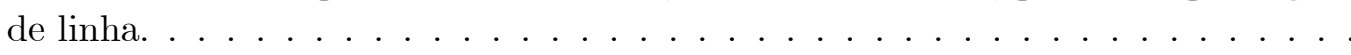

3.15 Ilustração do esquema utilizando a Extender Box para a extensão de um enlace do sistema GPON. . . . . . . . . . . . . . . . . . . .

3.16 Taxa de erro de bit em função da potência recebida no fotodetector para um sistema de 2,5Gbps simétricos. No cenário descrito na Figura 3.15, o comprimento L1 possui $40 \mathrm{~km}$ de extensão enquanto o comprimento L2 tem $20 \mathrm{~km}$. O splitter utilizado foi de $1 \times 32 \ldots \ldots \ldots \ldots \ldots \ldots \ldots$

3.17 Taxa de erro de bit em função da potência recebida no fotodetector para um sistema de 2,5Gbps simétricos. No cenário descrito na Figura 3.15, o comprimento L1 possui $40 \mathrm{~km}$ de extensão enquanto o comprimento L2 tem $20 \mathrm{~km}$. O splitter utilizado foi de $1 \times 32$. Para o tráfego upstream, foi transmitido apenas um comprimento de onda de cada vez. . . . . . . . . . . . . . . . . . 
3.18 Foto do equipamento GPON do $\mathrm{CPqD}$ e aparato experimental utilizados na avaliação do extensor baseado em SOAs.

3.19 Representação esquemática do sistema GPON com os SOAs localizados ao longo do enlace (amplificação de linha). Os pontos numerados de 1 a 5 representam posições em que foram medidas as potências nos dois sentidos e que são mostradas na tabela abaixo da do esquema. . . . . . . . . . . . . . . . . .

3.20 Representação esquemática mantendo a distância diferencial de $20 \mathrm{~km}$ e a taxa de divisão de potência óptica de $1 \times 32$. A fibra de tronco foi fixada em $60 \mathrm{~km}$. . . . . 58

3.21 Utilização do extensor como um mid-span extender para GPON. A distância total obtida foi de $84 \mathrm{~km}$ e a taxa de divisão da potência foi $1 \mathrm{x} 64$. . . . . . . . . . .

3.22 Representação esquemática do uso da EB num sistema GPON. Como todos os usuários estão a uma mesma distância do splitter, é possível a inserção do divisor de potência e do extensor num sistema do tipo FTTB (Fiber-to-the-Building). . .

3.23 Janelas de transmissão de cada uma das ONUs. Foram atribuídas janelas temporais iguais a cada uma das ONUs. . . . . . . . . . . . . . . .

3.24 Espectros de ASE experimental e simulado para o SOA de 1310nm, sob corrente de $200 \mathrm{~mA} \ldots \ldots \ldots \ldots \ldots \ldots \ldots$

3.25 Espectros de ASE experimental e simulado para o SOA de 1490nm, alimentado com corrente de $200 \mathrm{~mA} . \ldots \ldots \ldots \ldots \ldots$

3.26 Componente, disponível no programa, representando uma fibra dopada com érbio. A caixa de diálogo ao lado do componente mostra os principais parâmetros utilizados pelo software para proceder as simulações. Estes parâmetros são os mesmos indicados em [35]. . . . . . . . . . . . . . . . . .

3.27 Representação esquemática de um amplificador de fibra dopada com érbio. O esquema de bombeio é co-propagante. O transmissor emite no comprimento de onda de 1550nm e o laser de bombeio pode emitir em $980 \mathrm{~nm}$ ou $1480 \mathrm{~nm}$, conforme

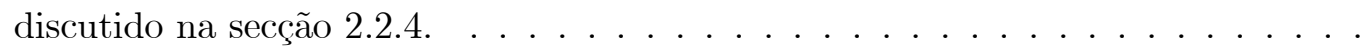

3.28 Representação esquemática de um amplificador de fibra dopada com érbio. O esquema de bombeio é contra-propagante. O transmissor emite no comprimento de onda de $1550 \mathrm{~nm}$ e o laser de bombeio pode emitir em $980 \mathrm{~nm}$ ou $1480 \mathrm{~nm}$, conforme discutido na seç̧ão $2.2 .4 \ldots \ldots \ldots \ldots \ldots \ldots$

3.29 Ganho óptico e figura de ruído da fibra dopada com érbio bombeada em função da potência de entrada do sinal. A EDF é bombeada em esquema co-propagante por um laser de bombeio de $980 \mathrm{~nm}$. O comprimento de onda do sinal é de 1550nm. 68

3.30 Ganho óptico e figura de ruído da fibra dopada com érbio bombeada em função da potência de entrada do sinal. A EDF é bombeada em esquema co-propagante por um laser de bombeio de 1480nm. O comprimento de onda do sinal é de 1550nm. 69

3.31 Ganho óptico e figura de ruído da fibra dopada com érbio bombeada em função do comprimento de onda do sinal. A EDF é bombeada em esquema co-propagante por um laser de bombeio de $980 \mathrm{~nm}$. O potência óptica do sinal é de $-15 \mathrm{dBm}$. . .

3.32 Ganho óptico e figura de ruído da fibra dopada com érbio bombeada em função do comprimento de onda do sinal. A EDF é bombeada em esquema co-propagante por um laser de bombeio de 1480nm. O potência óptica do sinal é de $-15 \mathrm{dBm}$.

3.33 Ganho óptico e figura de ruído da fibra dopada com érbio bombeada em função da potência de bombeio. A EDF é bombeada em esquema co-propagante por um laser de bombeio de $980 \mathrm{~nm}$. O comprimento de onda do sinal é de $1550 \mathrm{~nm}$. . . . 
3.34 Ganho óptico e figura de ruído da fibra dopada com érbio bombeada em função da potência de bombeio. A EDF é bombeada em esquema co-propagante por um laser de bombeio de 1480nm. O comprimento de onda do sinal é de 1550nm. . .

3.35 Representação esquemática da topologia utilizando amplificação por fibra dopada com érbio bombeada remotamente em esquema co-propagante. O componente representado pela letra $\mathrm{X}$ representa a posição onde a fibra compensadora de dispersão [81] ou atenuador óptico serão introduzidos, a fim de se comparar a influência da dispersão. . . . . . . . . . . . . . . . . . . . .

3.36 BER vs. Comprimento da Fibra Alimentadora para um sistema de 1,25Gbps com receptor baseado em APD. Observa-se que o melhor desempenho é produzido pela configuração que não utiliza nem DCF nem atenuador no transmissor. . . . . . . .

3.37 BER vs. Comprimento da Fibra Alimentadora para um sistema de 1,25Gbps com receptor baseado em PIN. Novamente, observa-se que o melhor desempenho é produzido pela configuração que não utiliza nem DCF nem atenuador no trans-

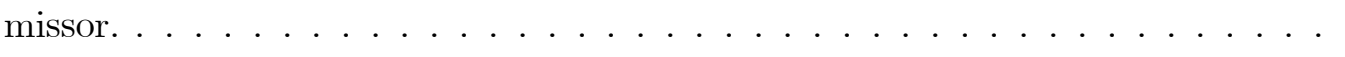

3.38 Taxa de erro de bit em função do comprimento da fibra alimentadora para receptores do tipo APD, para o sistema de 2,5Gbps. Novamente, nota-se que o cenário que atinge o maior comprimento é aquele em que não há nenhuma atenuação adicional no transmissor. . . . . . . . . . . . . . . . . .

3.39 Taxa de erro de bit em função do comprimento da fibra alimentadora para receptores do tipo PIN, para o sistema de 2,5Gbps. Novamente, nota-se que o cenário que atinge o maior comprimento é aquele em que não há nenhuma atenuação adicional no transmissor. . . . . . . . . . . . . . . . . .

3.40 BER vs. Comprimento da Fibra Alimentadora para receptores baseados em APD, considerando uma taxa de 10 Gbps. Diferentemente dos cenários obtidos até o momento, aquele contendo a fibra compensadora de dispersão apresentou o melhor desempenho para uma mesma BER. . . . . . . . . . . . . . . . . .

3.41 BER vs. Comprimento da Fibra Alimentadora para receptores com fotodetector do tipo PIN, em sistemas de 10Gbps. Nota-se, mais uma vez, que o cenário contendo a compensação da dispersão, através da DCF, atingiu um comprimento maior que aqueles que não possuíam nenhuma compensação. . . . . . . . . . . . . 


\section{Lista de Acrônimos}

\begin{tabular}{|c|c|}
\hline ACTS-PLANET & $\begin{array}{l}\text { Advanced Communication Technologies and } \\
\text { Services-Photonic Local Access } \boldsymbol{N e t w o r k}\end{array}$ \\
\hline $\mathrm{AON}$ & Active Optical Network \\
\hline APD & Avalanche Photo Diode \\
\hline APON & A TM Passive Optical Network \\
\hline ASE & A mplified Spontaneous Emission \\
\hline ATM & Asynchronous Transfer Mode \\
\hline AWG & A rrayed Waveguide $\boldsymbol{G r a t i n g}$ \\
\hline BER & B it Error Rate \\
\hline $\mathrm{BtB}$ & $\mathbf{B} a c k-\boldsymbol{t} o-\boldsymbol{B} a c k$ \\
\hline $\mathrm{CAD}$ & Computer Aided Design \\
\hline CAPEX & Capital Expenditure \\
\hline CDR & Clock and Data Recovery \\
\hline $\mathrm{CE}$ & Core Exchange \\
\hline $\mathrm{CO}$ & Central Office \\
\hline CWDM & Coarse Wavelength Division Multiplexing \\
\hline $\mathrm{DCF}$ & Dispersion Compensation Fiber \\
\hline DFA & Doped Fiber Amplifier \\
\hline DFB & D istributed $\boldsymbol{F}$ eedback $\boldsymbol{L}$ aser \\
\hline $\mathrm{DOP}$ & Divisor Óptico Passivo \\
\hline DWDM & Dense Wavelength Division Multiplexing \\
\hline EAM-SOA & $\begin{array}{l}\text { Electro-Absorption Modulator- } \\
\text { Semiconductor } \boldsymbol{O} \text { ptical } \boldsymbol{A} \text { mplifier }\end{array}$ \\
\hline EB & Extender $\boldsymbol{B}$ ox \\
\hline EDFA & Erbium-Doped Fiber Amplifier \\
\hline FTTB & Fiber-to-the-Building \\
\hline GPON & Gigabit Passive $\boldsymbol{O}$ ptical Network \\
\hline HDV & $\mathbf{H}$ igh Definition Video \\
\hline $\mathrm{LE}$ & Local Exchange \\
\hline LR-PON & Long $\boldsymbol{R}$ each-Passive $\boldsymbol{O}$ ptical $\boldsymbol{N}$ etwork \\
\hline MAC & Medium Access Control \\
\hline MAP & Medium Access Point \\
\hline
\end{tabular}




\section{Lista de Acrônimos}

\begin{tabular}{|c|c|}
\hline ODN & $\mathbf{O}$ ptical Distribution Network \\
\hline $\mathrm{OEO}$ & Óptico-Elétrico-Óptico \\
\hline OLT & Optical Line Terminal \\
\hline $\mathrm{ONU}$ & Optical Network Unit \\
\hline OPEX & Operational Expenditure \\
\hline OSA & $\mathbf{O}$ ptical $\boldsymbol{S}$ cpectrum Analyzer \\
\hline OTL & Optical Trunk Line \\
\hline$\overline{\mathrm{PDG}}$ & $\mathbf{P}$ olarization Dependent Gain \\
\hline PIEMAN & $\begin{array}{l}\text { Photonic Integrated Extended } \\
\text { Metro and Access Network }\end{array}$ \\
\hline PIN & $\mathbf{P}$-intrinsec- $\mathbf{N}$ \\
\hline $\mathrm{PON}$ & $\mathbf{P}$ assive Optical Network \\
\hline$\overline{\text { PRBS }}$ & $\mathbf{P}$ seudo-Random Bit Sequence \\
\hline QoS & $\mathbf{Q}$ uality of Service \\
\hline $\mathrm{RBF}$ & $\mathbf{R}$ ed-Blue Filter \\
\hline $\mathrm{RN}$ & Remote Node \\
\hline $\mathrm{RPCO}$ & Roteador Passivo de Comprimento de Onda \\
\hline RTD & $\mathbf{R}$ ound Trip Delay \\
\hline SARDANA & $\begin{array}{l}\text { S calable Advanced } \boldsymbol{R} \text { ing-based Passive } \\
\mathbf{D} \text { ense } \boldsymbol{A} \text { ccess } \boldsymbol{N} \text { etwork } \boldsymbol{A} \text { rchitecture }\end{array}$ \\
\hline SNR & Signal-to-Noise Ratio \\
\hline $\mathrm{SOA}$ & Semiconductor Optical A mplifier \\
\hline SRS & Stimulated $\boldsymbol{R}$ aman $\boldsymbol{S}$ cattering \\
\hline TDM & Time Division Multiplexing \\
\hline TDMA & Time Division Multiplexing Access \\
\hline TWA & Travelling Wave Amplifier \\
\hline VoD & Video on Demand \\
\hline WDM & W avelength Division Multiplexing \\
\hline WDMA & W avelength Division Multiplexing Access \\
\hline
\end{tabular}




\section{Capítulo 1}

\section{Introdução}

Os sistemas de telecomunicações evoluíram imensamente nos últimos anos, passando de uma era em que a transmissão de informação entre dois pontos era, predominantemente, realizada por ondas de rádio ou por cabos metálicos a uma era em que os sistemas de comunicações ópticas têm fundamental importância [1], [2].

A invenção da fibra óptica de baixas perdas [3], [4] configura uma das mais importantes realizações científicas do século XX, fato reconhecido em 2009, quando os cientistas que a demonstraram, Kao e Hockham [3], foram laureados com o prêmio Nobel de Física [5] e o grupo de pesquisadores da Corning, Dr. Robert Maurer, Dr. Peter Schultz e Dr. Donald Keck, [4] recebeu a National Medal of Technology, nos Estados Unidos em 2000 [6]. Além disto, estima-se que em torno de $80 \%$ das comunicações mundiais sejam realizadas através de sistemas de fibra óptica [7].

Decorrentes da importância destes sistemas surgem dois desafios enfrentados atualmente pelas empresas operadoras de telecomunicações. O primeiro deles é o atendimento ao vertiginoso aumento no número de usuários conectados às redes, conforme pode ser visto na Figura 1.1, obtida a partir de [8].

Já o segundo é o atendimento à crescente demanda por taxas de transmissão mais elevadas, necessárias para o suporte adequado aos novos serviços oferecidos, dentre eles, transmissão de vídeo em alta definição (High Definition Video - HDV), transferência (compartilhamento) ponto-a-ponto de arquivos, vídeo sob demanda (Video on Demand - VoD), jogos on-line interativos e outros [9], [10]. O crescimento no fluxo de dados circulados pela internet pode ser visto na Figura 1.2, retirada de uma pesquisa realizada pela empresa Cisco [11]. Observa-se, a partir da Figura 1.2, que os serviços que mais requerem largura de banda são a transmissão de vídeo 
e o comparti-lhamento de arquivos.

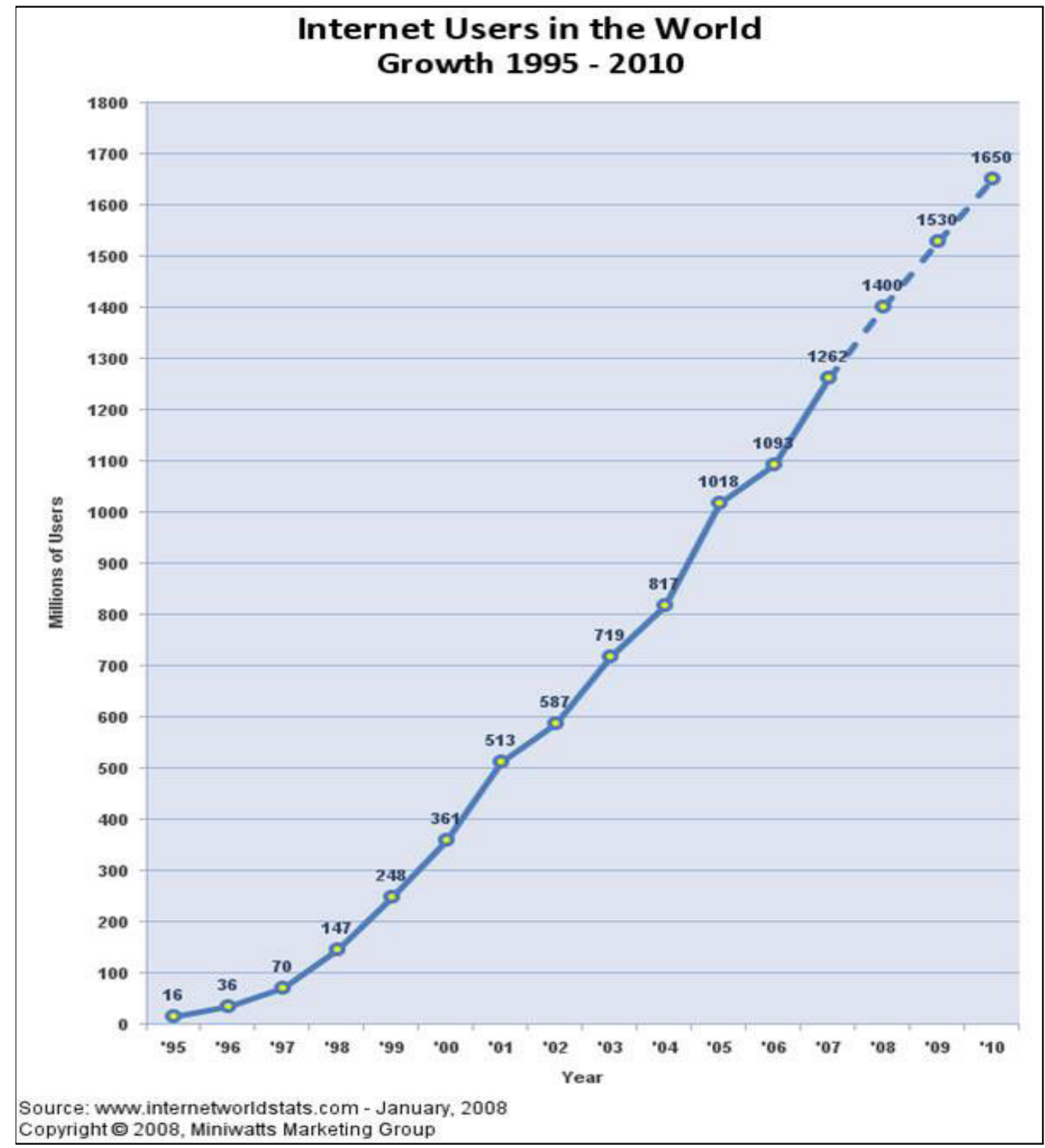

Figura 1.1: Gráfico representando o aumento anual no número de usuários de internet atendidos, segundo pesquisa publicada em 2008, disponível em [8]. 


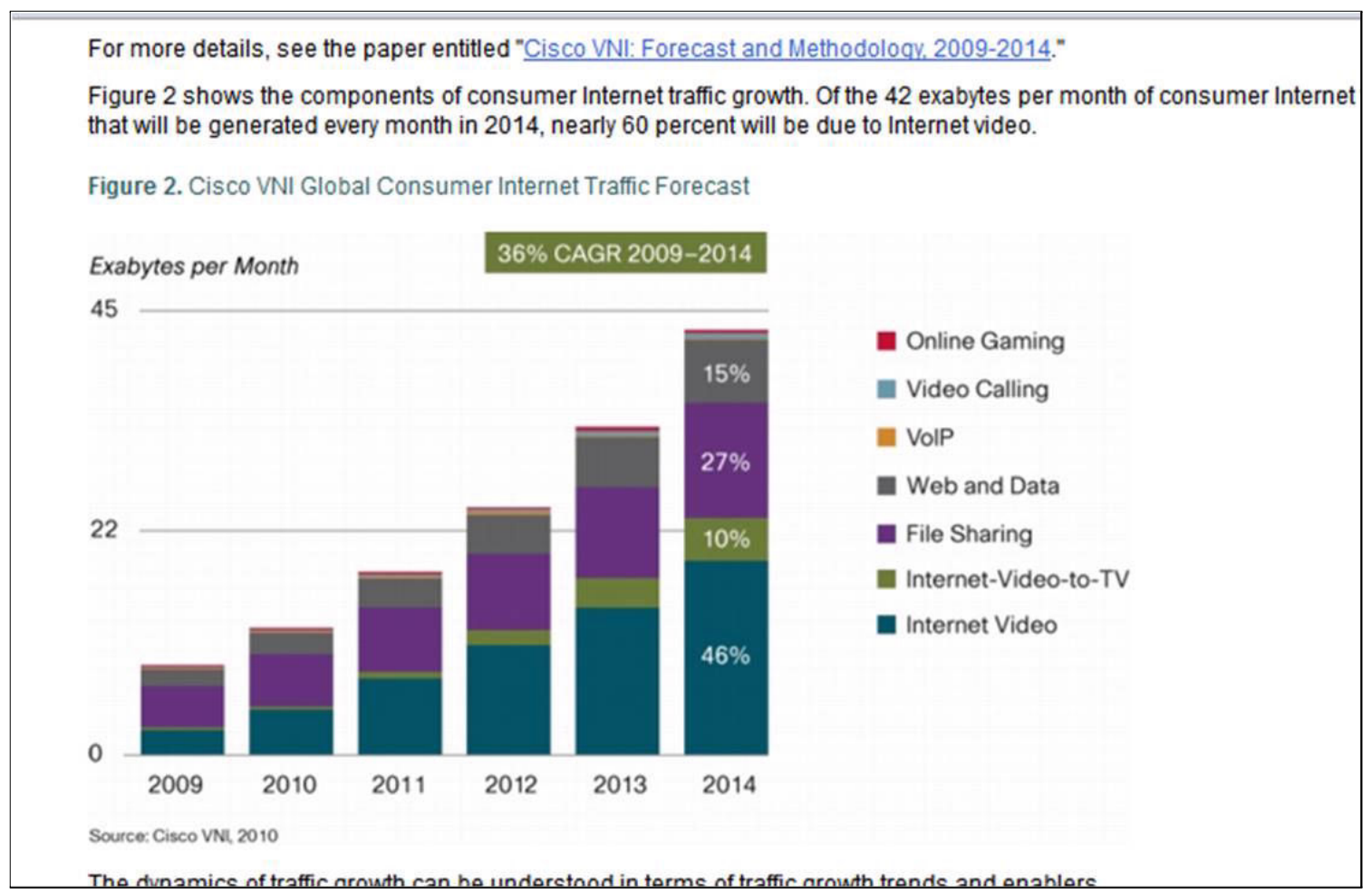

Figura 1.2: Gráfico representando o crescimento no fluxo de dados pela internet. A pesquisa realizada pela Cisco [11] estima que no ano de 2014 serão transmitidos 42 exabytes, sendo que $56 \%$ serão resultantes do tráfego de vídeo e $27 \%$ são referentes ao compartilhamento ponto-aponto de arquivos.

Estes desafios têm motivado os pesquisadores a buscar soluções que atendam a tais demandas (seja no aumento do número de usuários, seja no aumento das taxas de transmissão oferecidas) provendo a qualidade de serviço (Quality of Service - QoS) adequada enquanto mantêm os custos, CAPEX (Capital Expenditure) e OPEX (Operational Expenditure), associados à implantação, operação, administração e manutenção de tais redes, num nível aceitável [12]. Dentre as possíveis maneiras de superar estes desafios estão as redes de acesso baseadas em fibra óptica, que são as redes de acesso ópticas. Elas se dividem em redes ópticas ativas (Active Optical Network - AON), que possuem elementos ativos ao longo do canal de comunicação, e em redes ópticas passivas (Passive Optical Network - PON), cujos elementos constitutivos da rede são todos passivos [13], [14].

A utilização de dispositivos que possibilitem a extensão do orçamento de potência associados às PONs e permite a redução do CAPEX e OPEX pode ser sumarizada na Figura 1.3, que apresenta a redução da complexidade da rede a partir da redução de equipamentos e nós remotos [12], já que a utilização de extensores para as redes ópticas permite a consolidação em 
alguns nós remotos estrategicamente posicionados. Esta redução na quantidade de equipamentos também representa uma redução no consumo de energia requerido pela rede, o que é uma característica cada vez mais importante [15].

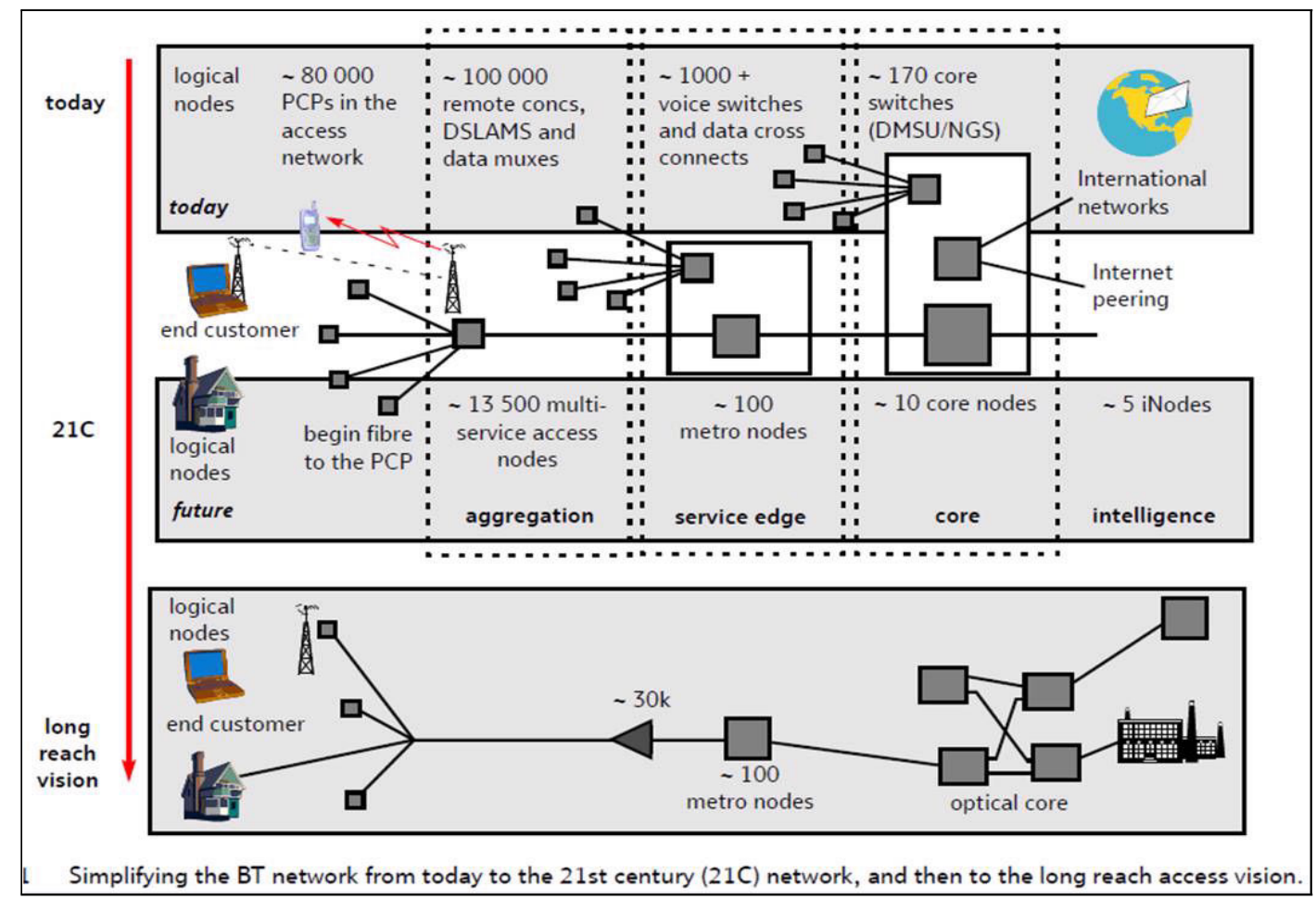

Figura 1.3: Simplificação da rede a partir da unificação de nós remotos [12]. A partir da redução na quantidade de equipamentos necessários, há uma redução no consumo energético requerido.

\section{$1.1 \quad$ Redes Ópticas Passivas}

Como mencionado anteriormente, as redes ópticas passivas são as redes de acesso por fibra óptica que não possuem nenhum elemento ativo ao longo da planta externa, ou seja, os elementos que constituem a rede não necessitam de alimentação elétrica para seu funcionamento. Em razão disto, as PONs possuem uma enorme vantagem sobre as AONs, uma vez que sua gerência e manutenção são mais simples que aquelas associadas às redes ativas.

Em princípio, para que cada usuário seja capaz de utilizar algum serviço de comunicação oferecido, é necessário que ele possua um link "direto", isto é, uma rede ponto-a-ponto com o fornecedor de tal serviço [1], [2]. Entretanto, através de técnicas de multiplexação, não é necessário que cada usuário possua uma fibra óptica desde a central somente para si. Serão 
discutidos a seguir os dois principais tipos de multiplexação utilizados tanto nestas redes.

\subsubsection{Multiplexação por Divisão de Tempo}

Como várias unidades de redes ópticas (Optical Network Units - ONUs) serão atendidas por um mesmo terminal de linha óptica (Optical Line Terminal - OLT), uma técnica bastante disseminada atualmente é a multiplexação por divisão de tempo (Time Division Multiplexing - TDM) para o acesso no upstream (Time Division Multiple Access - TDMA) [16]. Ela consiste na divisão temporal da largura de banda disponível entre os usuários conectados a uma mesma estrutura de rede, alocando janelas de tempo a cada usuário. A Figura 1.4 mostra, esquematicamente, o funcionamento de um sistema TDM.

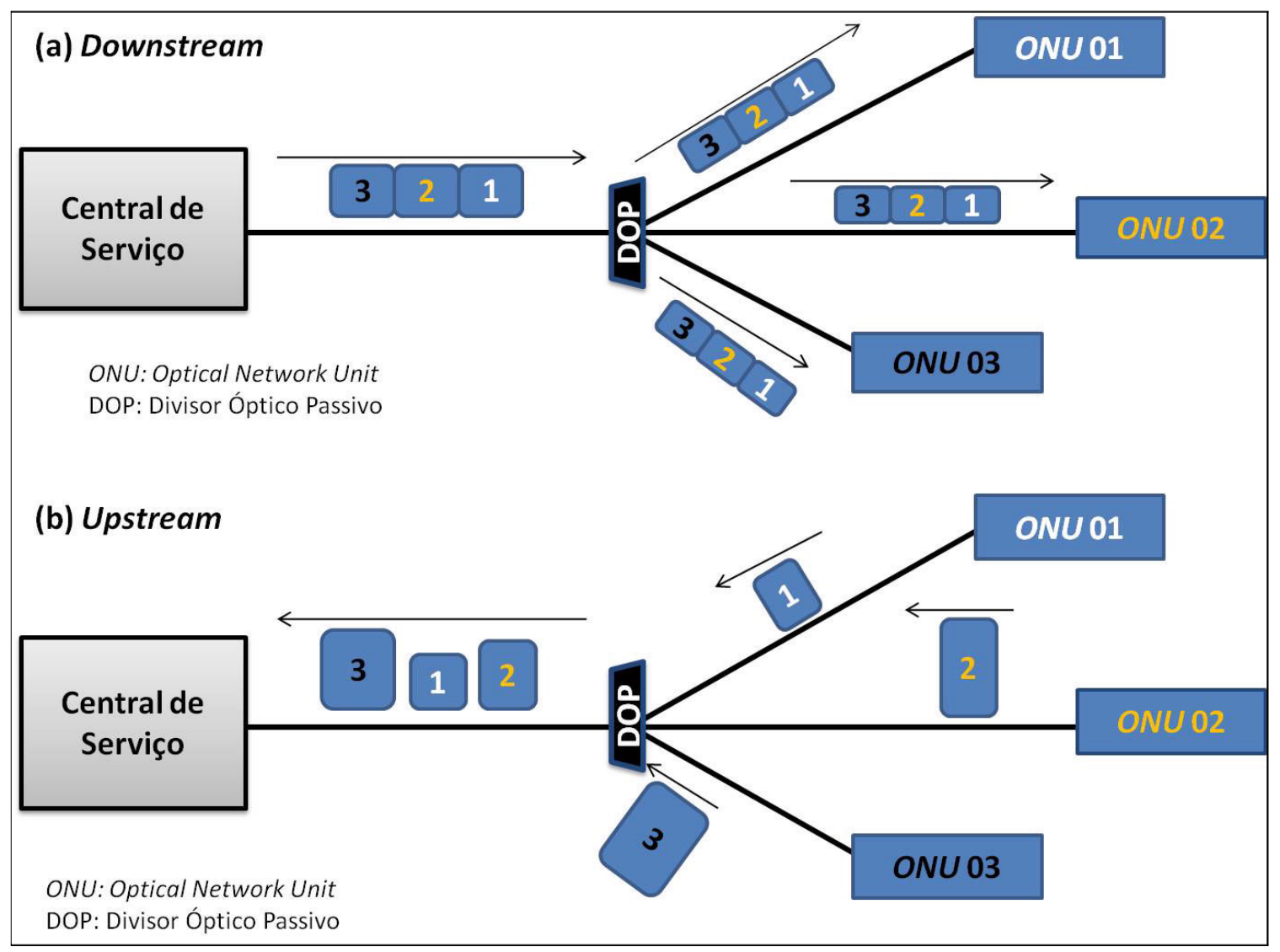

Figura 1.4: Representação esquemática da transmissão com multiplexação por divisão no tempo. A Figura 1.4 (a) representa a transmissão downstream, que é feita em broadcast. A Figura 1.4 (b) mostra o tráfego upstream, que é feito a partir da divisão de tempo, para que cada usuário envie seus dados no instante correto. 


\subsubsection{Multiplexação por Divisão de Comprimento de Onda}

Uma maneira de elevar o número de usuários atendidos, bem como a largura de banda, é prover o acesso através da multiplexação por divisão de comprimento de onda [14] (Wavelength Division Multiplexing Access - WDMA), em que são atribuídos a cada usuário comprimentos de onda específicos, para realização de tráfego downstream (da operadora para o usuário) e para transmissão upstream (do usuário para a operadora). A Figura 1.5 apresenta um esquema de multiplexação por comprimento de onda. É importante observar que as ONUs podem transmitir suas informações a qualquer tempo, uma vez que a multiplexação é realizada na freqüência óptica, diferentemente da multiplexação no domínio do tempo.

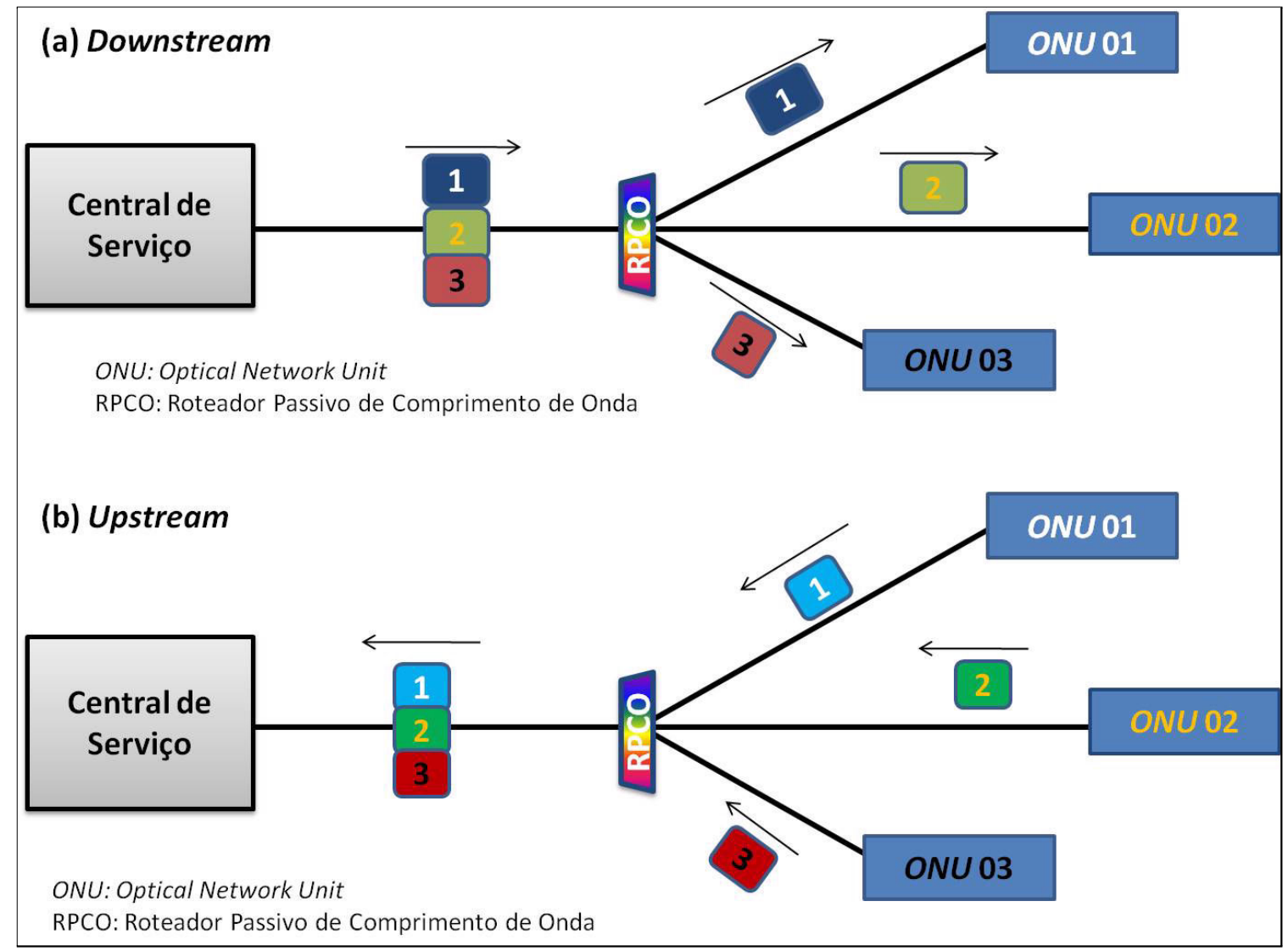

Figura 1.5: Representação esquemática de uma rede WDM-PON (Wavelength Division Multiplexing-Passive Optical Network). Deve-se observar que os tráfegos nos dois sentidos utilizam comprimentos de onda específicos, sendo que cada usuário possui um par dedicado. 
O foco deste trabalho será a investigação de redes ópticas passivas que garantam o aumento no número de usuários bem como o aumento das distâncias entre as centrais de serviço e seus usuários, como forma de reduzir os CAPEX e OPEX associados, sobretudo mantendo o caráter passivo da rede. Na literatura, são encontradas duas vertentes de pesquisa de tais redes que apresentam perdas elevadas devido às altas taxas de divisão de potência e distâncias percorridas. A primeira, denominada Extended PON, consiste na introdução de dispositivos que estendam o orçamento de potência de PONs já instaladas, sem, no entanto, alterar os dispositivos da central e dos usuários, ou seja, sem que haja modificações nas atuais normas regulamentadoras. Já as redes ópticas passivas de longo alcance (Long-Reach PONs - LRPONs) representam a segunda linha de pesquisa e propõem a unificação das redes de acesso com as redes metropolitanas, configurando o metro-acesso. Além disto, como são mantidas as mesmas especificações das redes metropolitanas, é necessário que se troquem os equipamentos dos usuários, isto é, novas normas sejam definidas. As principais propostas de ambas serão abordadas no Capítulo 2.

Este trabalho está dividido da seguinte maneira. No capítulo 2, serão abordados os tipos de extensores que podem ser usados em redes ópticas passivas. Também serão mostradas as principais propostas encontradas na literatura das duas vertentes mencionadas anteriormente. Os resultados obtidos são apresentados no capítulo 3, sendo que o extensor baseado em amplficadores ópticos semicondutores foi utilizado na extensão da rede GIGA, que é uma rede experimental de alta velocidade com tráfego ethernet real. Ainda nestes experimentos na rede GIGA, foi obtida uma topologia do tipo Fiber-to-the-Building, na qual poderiam ser atendidos 128 usuários localizados a uma distância de $80 \mathrm{~km}$ da central de serviço. O capítulo 3 traz ainda simulações de topologias do tipo LR-PONs contendo fibras dopadas com érbio bombeadas remotamtente. Finalmente, as conclusões são apresentadas no capítulo 4. 


\section{Capítulo 2}

\section{Extensores de Redes Ópticas}

Um dos grandes desafios inerentes às redes ópticas passivas de altas perdas é o fato do orçamento de potência ser bastante limitado, posto que as taxas de divisão de potência óptica, bem como as distâncias percorridas pelo sinal propagante, são elevadas. Uma das formas de se transpor estas barreiras se dá por meio da inserção de repetidores optoeletrônicos ao longo do enlace [17], havendo uma regeneração do sinal óptico, já que, ao ser recebido, ele pode ser reformatado e reemitido ou ainda reformatado, re-sincronizado e reemitido. Outra alternativa é a inserção de amplificadores ópticos [18], [19].

\subsection{Regeneradores Optoeletrônicos}

Os regeneradores optoeletrônicos são um dos tipos de extensores possíveis de aplicação em redes ópticas. Entretanto, sua inserção ao longo do caminho óptico transforma a rede óptica passiva em rede óptica ativa, uma vez que seus componentes (fotodetectores, circuitos de recuperação, lasers) necessitam de alimentação elétrica [17].

Como mencionado, estes repetidores podem utilizar a chamada regeneração $3 R$, que consiste na recuperação de sincronismo e formato dos bits (Re-timing + Re-shaping), também conhecida como CDR (Clock and Data Recovery), além da reemissão (Re-amplifying), a partir de uma fonte óptica. Estes são os três Rs desta regeneração [20].

A inserção destes repetidores como extensores de redes ópticas é capaz de produzir resultados extremamente interessantes, como os apresentados em [21] e [22].

Os resultados mostrados em [21] podem ser descritos da seguinte maneira: os transmissores localizados na central de serviço emitem 40 comprimentos de onda distintos e localizados 
na banda $\mathrm{C}$, que possui comprimentos de onda entre 1530nm e 1565nm [23]. Estes comprimentos de onda serão multiplexados e transmitidos por uma fibra padrão, cujo comprimento é de $125 \mathrm{~km}$, havendo em cada uma das extremidades um amplificador óptico. Em seguida, cada canal é selecionado por um filtro óptico e direcionado ao seu respectivo repetidor optoeletrônico, operando conforme o padrão GPON (Gigabit Passive Optical Network), ou seja, possui as mesmas taxas e comprimentos de onda especificados em suas normas [24]. Para cada canal da banda C há um repetidor que encaminhará o respectivo sinal recebido e convertido em comprimento de onda do padrão GPON para a região de acesso, que possui no máximo 10km e uma razão de divisão de 64. Fundamentalmente, os equipamentos dos usuários permanecerão os mesmos. Para o tráfego upstream, os repetidores também realizam a conversão do modo rajada dos sinais em 1310nm para comprimentos de onda da banda C. Durante ambas as conversões, são realizadas regenerações 3R. Duas fibras são utilizadas, uma para downstream e a outra para upstream, uma vez que os comprimentos de onda estão localizados na mesma região espectral. A Figura 2.1 ilustra a arquitetura investigada.

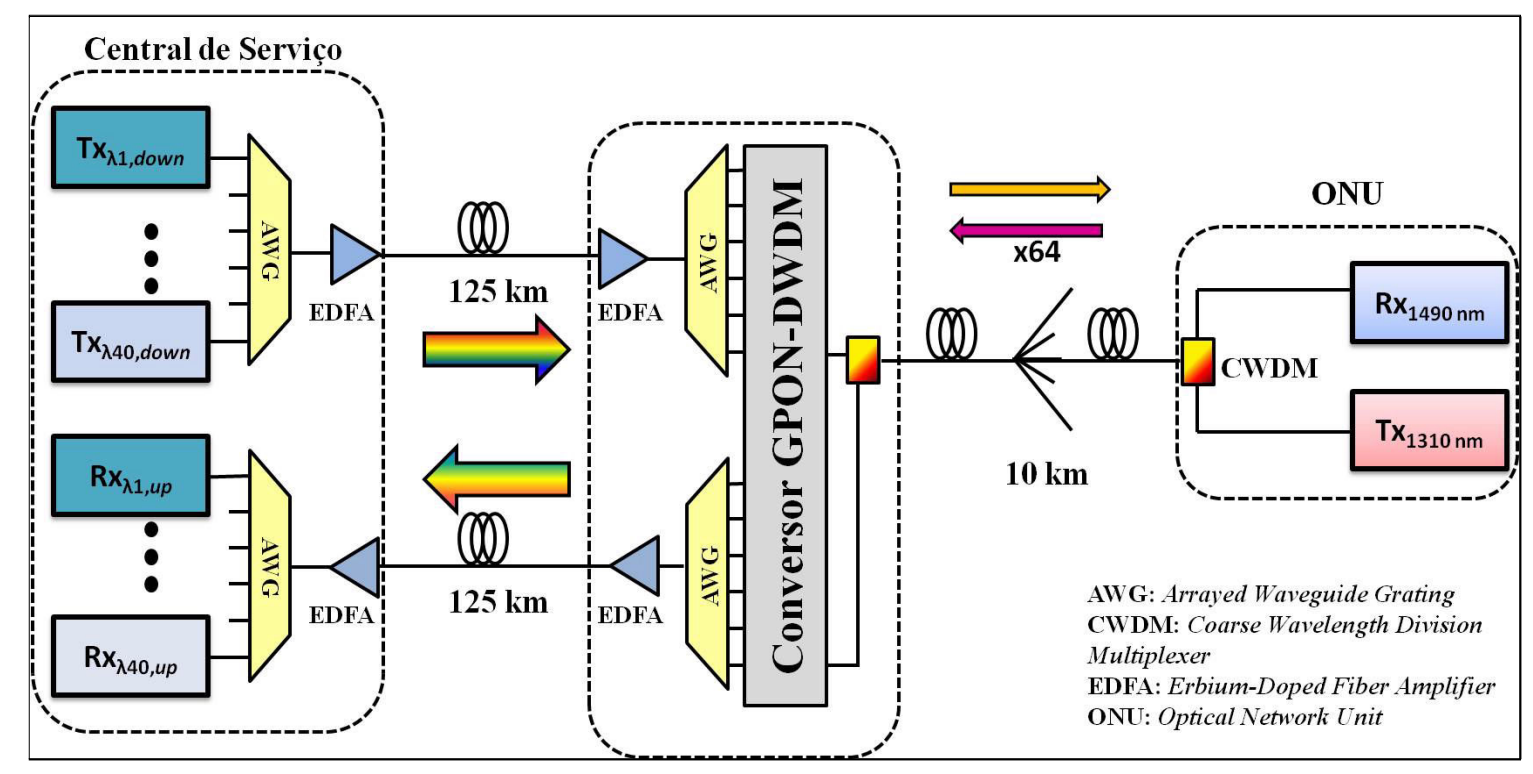

Figura 2.1: Ilustração representando a integração de um esquema DWDM com o padrão GPON, a partir da utilização de regeneradores optoeletrônicos presentes no conversor GPON-DWDM.

Já em [22], é proposta uma topologia em anel, sendo que em determinados pontos, denominados MAPs (Metro Access Point), há a inserção dos repetidores optoeletrônicos, utilizando a regeneração 3R. A distância total entre o usuário e a central de serviço é de $100 \mathrm{~km}$, sendo utilizados $70 \mathrm{~km}$ entre a central e o MAP e 30km deste até o usuário. Os comprimentos de 
onda utilizados estão na banda C, para ambos os tráfegos. E as taxas são de 10Gbps simétricas.

Além dos regeneradores $3 \mathrm{R}$, existem também os repetidores $2 \mathrm{R}$, que realizam a reformatação e reamplificação do sinal recebido, sendo, portanto, mais simples que os regeneradores 3R. Esta maior simplicidade do repetidor $2 \mathrm{R}$ faz com que ele se torne um dispositivo de menor custo que o repetidor 3R, resultando numa redução de custos quando introduzidos na rede. No entanto, os conversores OEO (Óptico-Elétrico-Óptico) apresentam algumas limitações uma vez que são desenvolvidos para operação em taxas de transmissão e formatos de modulação específicos [25].

Alternativamente à inserção dos regeneradores optoeletrônicos, estão os amplificadores ópticos, que serão descritos na próxima secção.

\subsection{Amplificadores Ópticos}

Neste trabalho, serão investigados esquemas de amplificação óptica visando à obtenção de um orçamento de potência adequado, mantendo, sempre que possível, o caráter passivo da rede. Para tal, é necessária a compreensão dos princípios fundamentais que governam os amplificadores ópticos e as diferenças principais entre os tipos existentes. Neste contexto, serão brevemente apresentados os amplificadores ópticos semicondutores (Semiconductor Optical Amplifers - SOAs), os amplificadores de fibra dopada (Doped Fiber Amplifiers - DFAs) e a amplificadores Raman. Além de uma breve abordagem dos amplificadores que podem ser usados na extensão de redes ópticas, algumas LR-PONs e Extended PONs citadas [26] - [31] ilustram o uso de cada tipo de amplificador.

\subsubsection{Princípios Básicos de Amplificação Óptica}

A compreensão do funcionamento dos amplificadores ópticos está fundamentada em dois princípios básicos que são a emissão estimulada e a inversão de população.

\section{Processo de Emissão Estimulada}

O mecanismo responsável pela amplificação óptica nos amplificadores mencionados anteriormente é a denominada emissão estimulada, cuja representação esquemática encontrase explicitada na Figura 2.2.

A principal característica da emissão estimulada é o fato dos fótons estimulados serem 


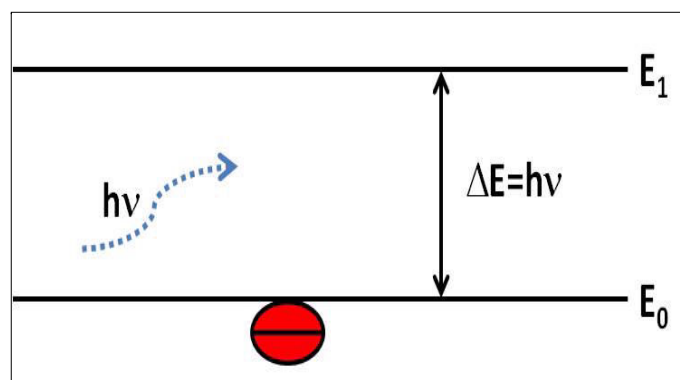

(a)

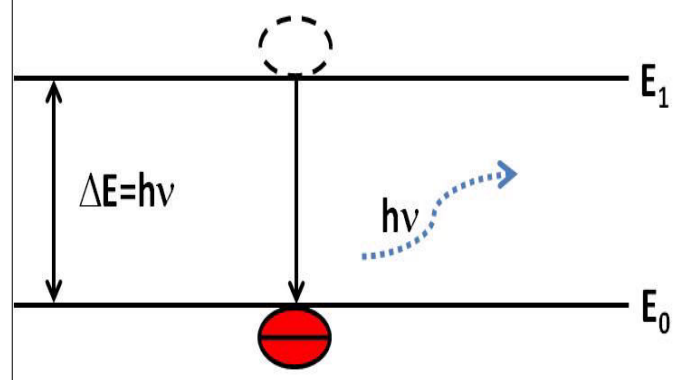

(c)

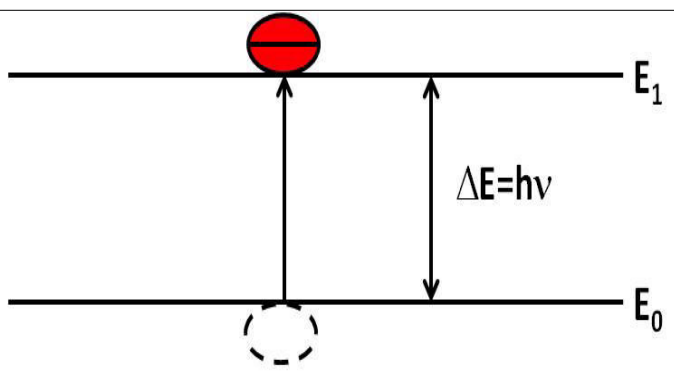

(b)

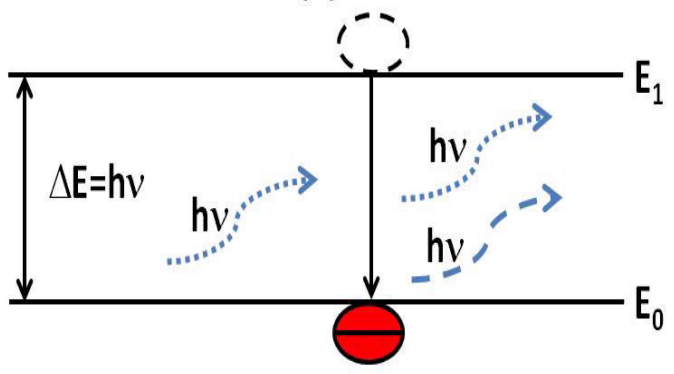

(d)

Figura 2.2: Esquema representando o princípio da emissão estimulada. Na figura (a), um elétron presente no estado fundamental, $\mathrm{E}_{0}$, absorve o fóton, representado em linha pontilhada, e atinge o nível de excitado $E_{1}$, como pode ser visto em (b). A energia do fóton corresponde à diferença de energia entre os dois níveis, $\mathrm{E}_{0}$ e $\mathrm{E}_{1}, h v=E_{1}-E_{0}$. Em (c), o elétron, no nível $\mathrm{E}_{1}$, decai espontaneamente emitindo um fóton idêntico ao absorvido em (a). Finalmente, em (d) ocorre o processo de emissão estimulada, no qual a presença de um fóton estimula o decaimento de um elétron presente no nível mais energético, levando à emissão de outro fóton (linha tracejada). Como conseqüência, os dois fótons, o incidente e o emitido, são coerentes, ou seja, possuem a mesma fase e amplitude.

coerentes com os fótons incidentes, isto é, ambos os fótons apresentam a mesma amplitude e fase. Supondo que o número de fótons idênticos na saída do amplificador é maior que o número de fótons incidentes, pode-se afirmar que houve amplificação.

Para que ocorra a emissão estimulada é necessário que haja a chamada inversão de população, discutida a seguir.

\section{Inversão de População}

A inversão de população é o fenômeno associado à maior ocupação, isto é, maior concentração de elétrons no nível $\mathrm{E}_{1}$, representado na Figura 2.2, e é essencial para que haja a amplificação óptica do sinal propagante no amplificador.

O mecanismo responsável por garantir que o nível de maior energia esteja mais ocupado 
que o nível fundamental é o bombeio, que pode ser elétrico, no caso dos SOAs, ou óptico, como ocorre nos amplificadores de fibra dopada [33].

O bombeio elétrico consiste na injeção de portadores na região ativa do SOA, garantindo que o nível $\mathrm{E}_{1}$ esteja mais ocupado que o nível $\mathrm{E}_{0}$. Assim, para que um determinado ganho seja atingido, uma dada corrente de injeção deve ser injetada na região ativa do dispositivo.

Já o bombeio óptico é responsável pela inversão de população nos amplificadores de fibra dopada, uma vez que o feixe do bombeio propaga-se pelo núcleo da fibra e excita os elétrons dos átomos dopantes do núcleo da fibra ao nível acima do fundamental.

Conhecidos estes dois princípios básicos que regem a amplificação óptica, serão descritas, na próxima secção, as principais características dos amplificadores.

\subsubsection{Características dos Amplificadores Ópticos}

Os principais parâmetros de desempenho dos amplificadores são o ganho óptico, potência de saturação, largura de banda e figura de ruído. Cada um deles será detalhado a seguir.

O ganho $\mathbf{G}$ de um amplificador está relacionado à sua capacidade de aumentar a potência do sinal de entrada. Pode-se calcular o ganho $G$ a partir das equações descritas a seguir [34], onde $P_{O U T}$ é a potência do sinal na saída do amplificador e $P_{I N}$ é a potência do sinal na entrada do amplificador:

$$
\begin{aligned}
G & =\frac{P_{\text {OUT }}}{P_{I N}} \\
G(d B) & =P_{O U T}(d B m)-P_{I N}(d B m)
\end{aligned}
$$

O ganho G, também conhecido como fator de amplificação, está relacionado ao coeficiente de ganho g, que é obtido a partir da consideração de que o meio ativo possa ser descrito como um sistema homogêneo de dois níveis (Figura 2.2). Sua forma matemática é [33]:

$$
g(\omega, P)=\frac{g_{0}}{1+\left(\omega-\omega_{0}\right)^{2} T_{2}^{2}+P / P_{S}}
$$

onde $g_{0}$ é o coeficiente de ganho máximo, $\omega$ é a freqüência do sinal óptico, $\omega_{0}$ é a freqüência de transição do elétron entre os dois níveis de energia $\mathrm{E}_{1}$ e $\mathrm{E}_{0}, \mathrm{~T}_{2}$ é o tempo de relaxação, $P$ é a potência do sinal óptico e $P_{S}$ é a potência de saturação, discutida adiante.

Caso o sinal de entrada possua uma potência muito menor que a potência de saturação, ou seja, se $P \ll P_{S}$, então o coeficiente de ganho fica da seguinte forma:

$$
g(\omega)=\frac{g_{0}}{1+\left(\omega-\omega_{0}\right)^{2} T_{2}^{2}}
$$


Nota-se, de acordo com a equação 2.4, que o coeficiente de ganho é máximo quando $\omega=\omega_{0}$. Isto pode ser compreendido da seguinte forma: à medida que a freqüência do sinal óptico incidente se aproxima da freqüência de transição eletrônica entre os níveis $\mathrm{E}_{1}$ e $\mathrm{E}_{0}$, o número de emissões estimuladas aumenta, atingindo seu valor máximo, quando estas freqüências forem idênticas, resultando no ganho máximo.

A potência do sinal óptico incidente aumenta à medida que ele se propaga através do meio ativo do amplificador, pelo fato de ser amplificado. Como foi assumido um ganho de potência homogêneo ao longo do amplificador, obtém-se a seguinte equação diferencial para descrever a variação da potência ao longo do amplificador:

$$
\frac{d P(z)}{d z}=g \cdot P(z)
$$

onde g é o coeficiente de ganho, mostrado na equação (2.4), e $\mathrm{P}(\mathrm{z})$ é a potência do sinal óptico a partir da entrada do amplificador.

Duas condições de contorno são necessárias para a descrição completa do amplificador. A primeira ocorre em $\mathrm{z}=0$ (entrada do amplificador) e a segunda em $\mathrm{z}=\mathrm{L}$ (saída do amplificador), supondo que o comprimento longitudinal do amplificador seja L:

$$
\begin{gathered}
P(0)=P_{I N} \\
P(L)=P_{O U T}
\end{gathered}
$$

Resolvendo-se a equação (2.5), obtém-se a potência como função da distância z, a partir da entrada do amplificador. Sua expressão é:

$$
P(z)=P_{I N} \cdot e^{g z}
$$

A partir da equação (2.8), é possível obter uma relação entre o coeficiente de ganho, que descreve as propriedades físicas do meio ativo, e o fator de amplificação, que representa o aumento na potência óptica. Utilizando-se a definição do ganho linear da equação (2.1), e as condições de contorno das equações (2.6) e (2.7), resulta:

$$
G=e^{g \cdot L}
$$

As aproximações realizadas até o momento são válidas considerando-se que o amplificador esteja fora do regime de saturação $\left(P \ll P_{S}\right)$. No entanto, se a potência de entrada for 
da ordem da potência de saturação, $P_{S}$, devem ser feitas outras suposições. O coeficiente de ganho tem a forma geral dada pela equação (2.3). Assumindo que a frequiência do sinal óptico de entrada seja igual à freqüência de transição eletrônica, ou seja, $\omega=\omega_{0}$, o coeficiente de ganho toma a forma:

$$
g(P)=\frac{g_{0}}{1+P / P_{S}}
$$

Procedendo de maneira análoga ao desenvolvimento anterior, obtém-se

$$
\frac{d P(z)}{d z}=g(P) \cdot P(z)
$$

cuja solução é:

$$
G=G_{0} \cdot e^{-\left(\frac{G-1}{G}\right) \frac{P_{O U T}}{P_{S}}}
$$

onde $G_{0}=e^{g_{0} L}$.

Como mencionado anteriormente, outro importante parâmetro dos amplificadores é a potência de saturação. A saturação ocorre porque o ganho não é independente do valor da potência de entrada, como pode ser visto na Figura 2.3. Ao passo que aumenta a potência de entrada do sinal, o ganho parte de uma região em que é constante, na qual o amplificador opera em regime linear, para uma região onde o ganho decresce (sendo esta a região de saturação) [33], [34], devido à redução no número de elétrons ocupando o nível de maior energia, o que é causado pelo fato de haver mais fótons provenientes do sinal de entrada. A este fenômeno pode-se associar um parâmetro denominado potência de saturação, que é o valor da potência de saída para a qual o ganho é reduzido à metade de seu valor no regime linear. 


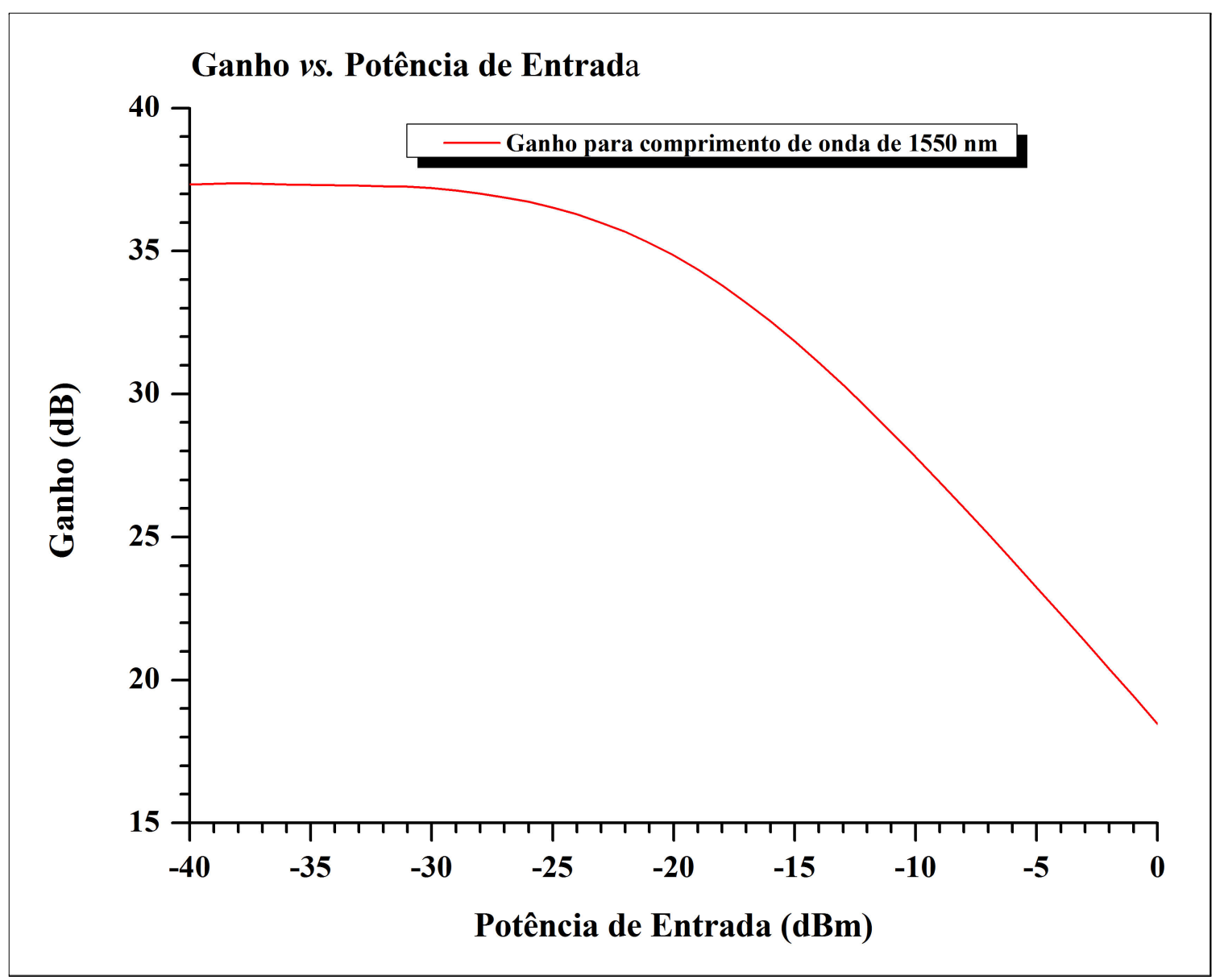

Figura 2.3: Ganho de um amplificador em função da potência de entrada do sinal. À medida que a potência do sinal de entrada aumenta, a amplificação ainda ocorre, porém, em menor intensidade, quando comparada à amplificação de pequenos sinais, que é a amplificação em baixos níveis de potência óptica.

O ganho óptico fornecido por um amplificador também depende do comprimento de onda do sinal de entrada, conforme é mostrado na Figura 2.4. A largura de banda óptica é a banda de freqüências do sinal óptico para a qual o ganho é reduzido em $3 \mathrm{~dB}$ de seu valor máximo. Para sistemas com vários canais, um amplificador com uma grande largura de banda é desejado, ou seja, o ganho deve ser aproximadamente plano para uma dada faixa de comprimentos de onda. Esta característica é desejada para garantir que os diversos canais tenham ganhos aproximadamente iguais [33], [34].

Conforme discutido na secção 2.2.1, os amplificadores realizam a amplificação do sinal através da emissão estimulada. No entanto, também ocorrem as chamadas emissões espontâneas, que têm origem no decaimento espontâneo dos elétrons que ocupavam o nível de maior energia 


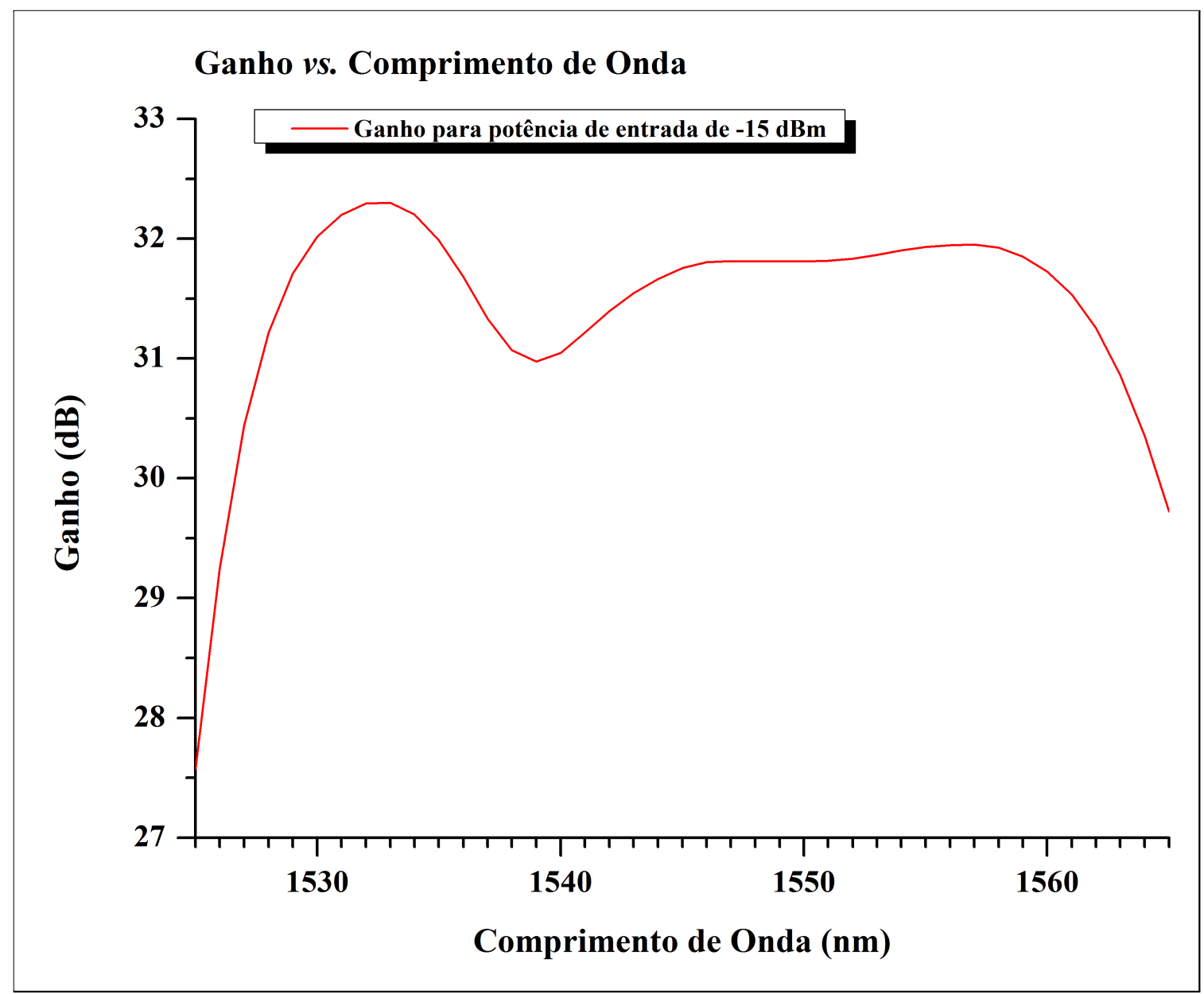

Figura 2.4: Ganho de um amplificador de fibra dopada com érbio em função do comprimento de onda do sinal de entrada. Nota-se que para diferentes valores do comprimento de onda, há diferentes valores do ganho [35].

para o estado fundamental (Figura 2.2c). Como a emissão é espontânea, os fótons emitidos não mantêm a coerência e, ao propagarem-se pelo amplificador, provocarão a emissão de outros fótons incoerentes, num processo em cascata gerando o ruído de emissão espontânea amplificado, ou ASE (Amplified Spontaneous Emission). A Figura 2.5 apresenta um espectro típico de ASE, obtido no software OptiSystem.

Como os fótons emitidos espontaneamente são descorrelacionados com os fótons do sinal óptico, ao serem detectados, ocorrerão batimentos entre as freqüências do sinal e do ruído, introduzindo flutuações na corrente elétrica gerada pelo fotodetector e resultando em uma elevação na taxa de erro de bit (Bit Error Rate - BER) [34]. A conseqüência do ruído da ASE é degradar a relação sinal-ruído (Signal-to-Noise Ratio - SNR) [36]. A figura de ruído do amplifi- 


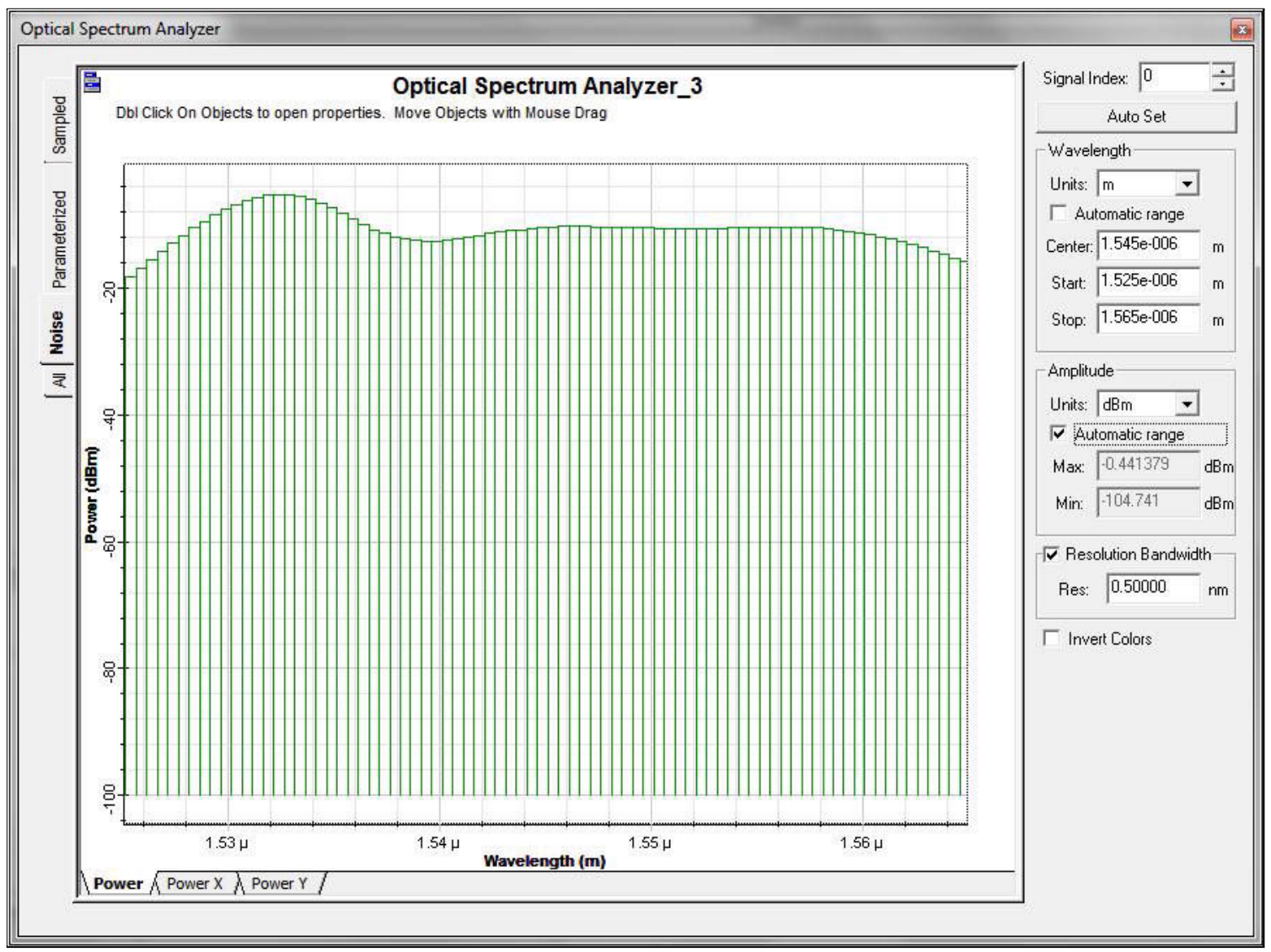

Figura 2.5: Espectro típico da ASE proveniente de um amplificador de fibra dopada a érbio, obtido no software OptiSystem. As emissões espontâneas ocorrem independentemente da passagem de sinal óptico, bastando apenas a presença do bombeio.

cador, que é utilizada para quantificar o ruído introduzido [37], pode ser obtida a partir de sua definição, que é a razão entre a SNR na entrada do amplificador e a SNR na saída. A equação 2.13 mostra a definição da figura de ruído [36]

$$
N F=\frac{S N R_{I N}}{S N R_{O U T}}
$$

\subsubsection{Amplificadores utilizados em Extended PONs}

Nesta seç̧ão serão apresentados os amplificadores mais comumente utilizados na implementação das Extended PONs.

\section{Amplificadores Ópticos Semicondutores}

Os amplificadores ópticos semicondutores (SOAs) são amplificadores ópticos cujo funcionamento é semelhante aos lasers semicondutores, utilizando a mesma tecnologia de fabricação. 
De fato, os SOAs são diodos lasers que possuem faces com refletividades muito inferiores às refletividades convencionais dos lasers, para que o sinal óptico seja apenas amplificado, não oscilando dentro do meio de ganho. Por não permitirem esta oscilação, os amplificadores de semicondutor também são chamados de amplificadores de onda viajante (Traveling-Wave Amplifiers - TWAs), porque o sinal óptico se propaga apenas uma vez através da região ativa do amplificador.

Como mencionado na seç̧ão 2.2.1, o mecanismo responsável pela inversão de população nos SOAs é a injeção de portadores eletrônicos na região ativa. Portanto, é esperado que o ganho, isto é, a potência de saída, varie com diferentes valores de corrente. De fato, a potência de saída de um SOA está relacionada à corrente injetada no amplificador, uma vez que esta corrente determinará a inversão de população, que por sua vez gerará o ganho com a propagação do sinal. Isto pode ser visto na Figura 2.6, que mostra o ganho de um amplificador semicondutor em função da corrente de injeção. Deve-se ressaltar que há uma região em que a potência de saída é menor que a potência de entrada, neste caso, -20dBm. Neste intervalo, as perdas no dispositivo são maiores que o ganho. Porém, ao passo que a corrente aumenta, o ganho supera as perdas e a potência de saída ultrapassa a potência de entrada, havendo a amplificação.

O ganho dos SOAs também é dependente do comprimento de onda do sinal que entra no dispositivo, como pode ser visto na Figura 2.7.

Por apresentarem uma largura de banda óptica tipicamente de 50nm [34], os SOAs podem ser utilizados como amplificadores multicanal, ou seja, são capazes de amplificar mais de um canal simultaneamente. No entanto, é necessário que as potências dos canais amplificados sejam baixas o suficiente para que o dispositivo opere em regime linear [43], pois, em caso contrário, ocorre diafonia entre os canais, isto é, um sinal em um dado comprimento de onda interfere na amplificação do sinal com comprimento adjacente [33]. Este efeito é denominado modulação de ganho cruzado [33], relacionado ao fato de que o ganho de um canal pode ser reduzido instantaneamente pela potência óptica dos demais canais.

O tempo de resposta dos SOAs é da ordem de centenas de picossegundos [38]. Tal característica é extremamente importante para a amplificação do tráfego de informação no sentido upstream em redes PON [18], [19], já que o fluxo de informação ocorre no modo rajada e o amplificador deve ser rápido o suficiente para amplificar os pulsos de informação que chegam à porta de entrada, provenientes de ONUs localizadas a distâncias distintas. 


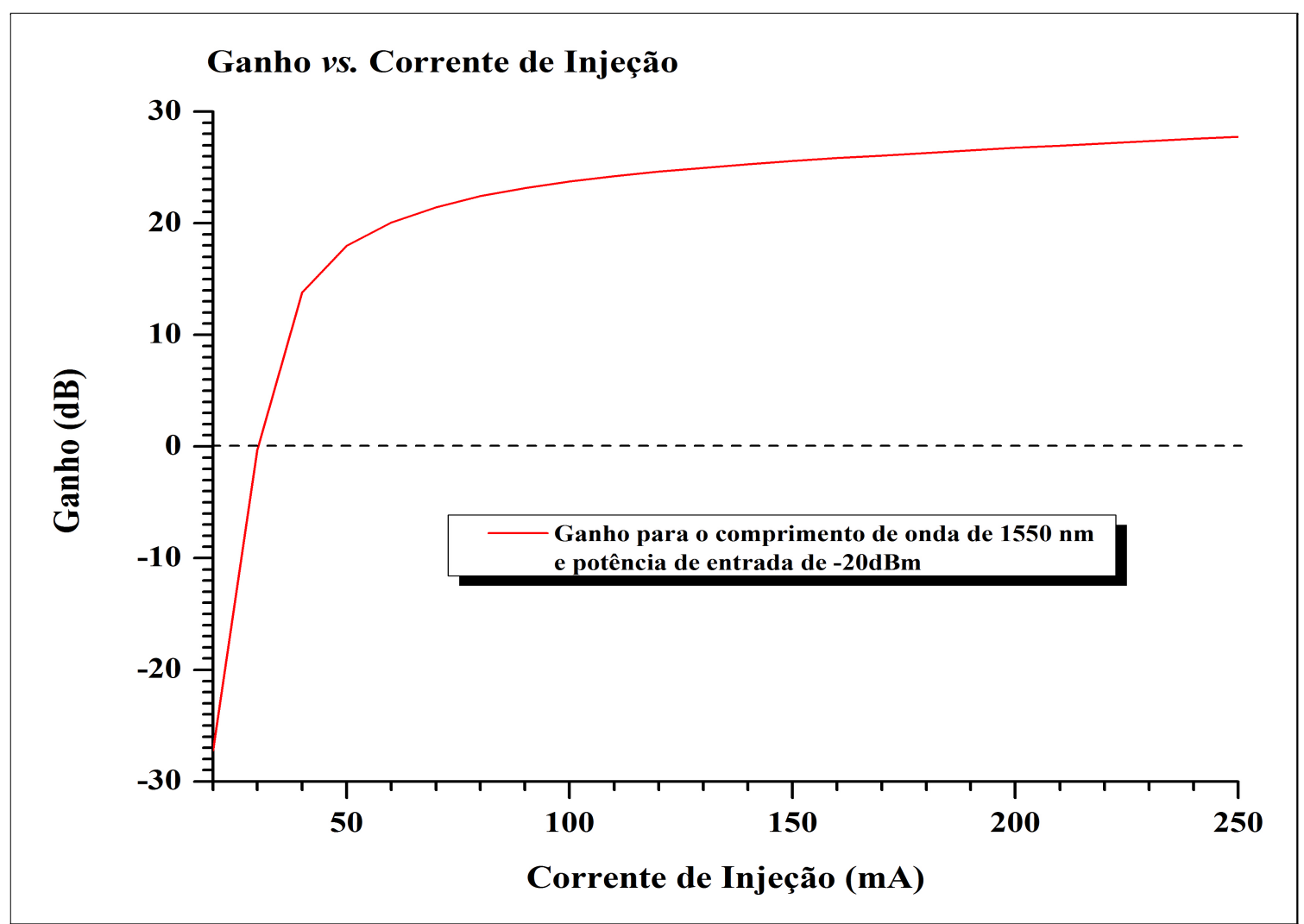

Figura 2.6: Ganho óptico de um SOA em função da corrente de injeção. Observa-se que com a elevação da corrente de injeção a potência de saída do amplificador aumenta, partindo de uma região em que a perda é maior que o ganho até uma região em que o ganho é superior à perda, onde ocorre a amplificação óptica. 


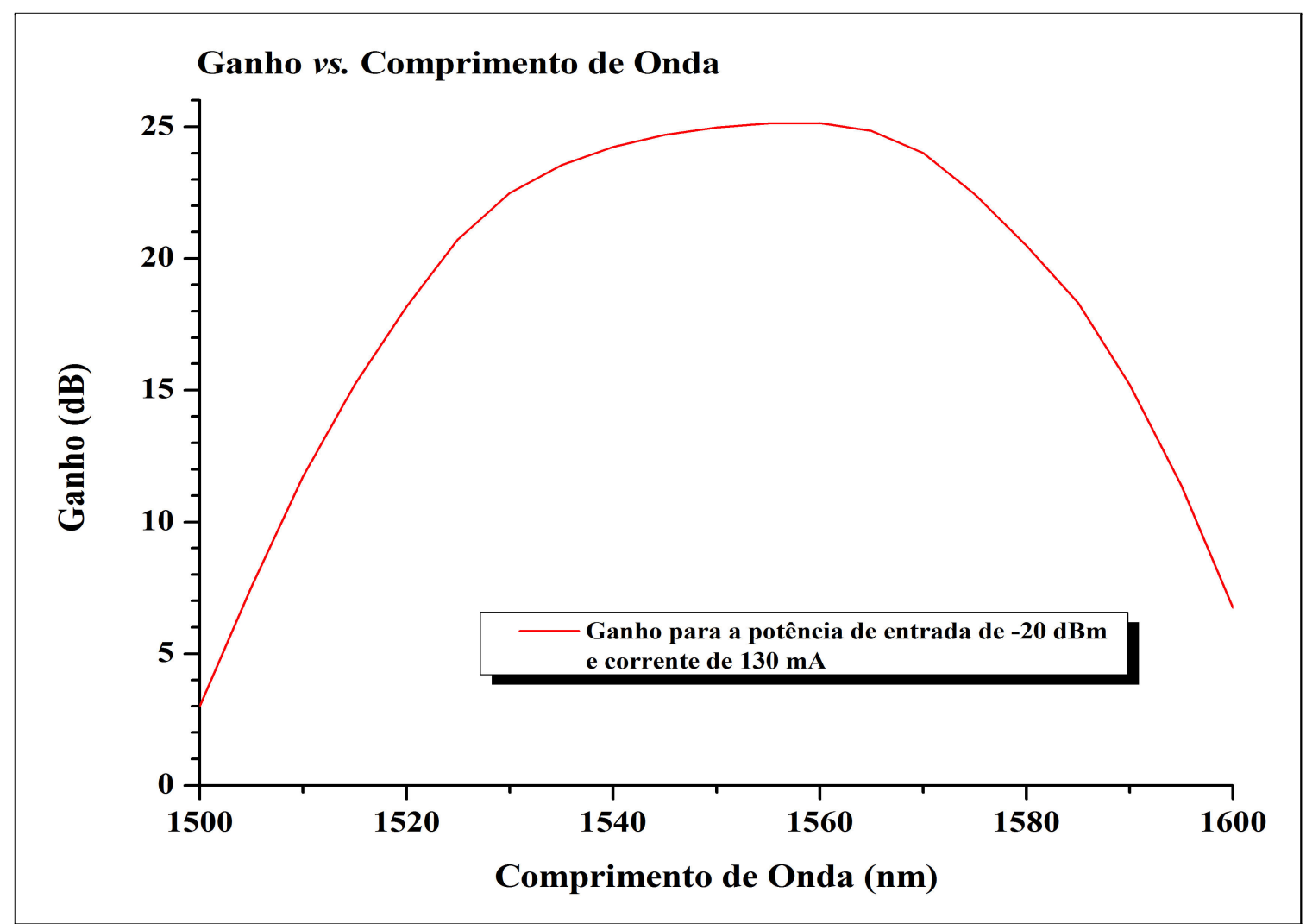

Figura 2.7: Ganho óptico de um SOA em função do comprimento de onda do sinal de entrada. Deve-se notar que esta figura de ganho é diferente daquela mostrada na Figura 2.4, que se referia a um amplificador de fibra dopada com érbio. Estes dispositivos possuem larguras de banda óptica de 30 a $80 \mathrm{~nm}[38]-[42]$.

Uma vantagem inerente aos amplificadores semicondutores é o fato de poderem ser construídos de maneira integrada a outros componentes ópticos, como os filtros ópticos, para serem utilizados na pré-amplificação, por exemplo. A construção integrada dos SOAs com filtros ópticos, para redução do ruído que incidirá sobre o fotodetector, permite a obtenção de dispositivos compactos e que garantem um bom desempenho das redes ópticas [33], [43]. No entanto, eles apresentam uma figura de ruído elevada, da ordem de $7 \mathrm{~dB}$, devido às altas perdas de acoplamento do sinal óptico na entrada do dispositivo e à emissão espontânea na banda do sinal.

Repetidores optoeletrônicos (secção 2.1) são possíveis opções para serem utilizados como extensores de sistemas do tipo GPON. Outra opção são os extensores baseados em amplificadores ópticos semicondutores [44], [45], uma vez que estes são os amplificadores mais comumente utilizados para a região espectral determinada pela norma GPON [24]. De fato, 
embora existam outros tipos de amplificadores para estes comprimentos de onda [46], os SOAs representam uma tecnologia mais madura e desenvolvida para fins comerciais [47].

Como já dito, outra característica que leva ao uso dos SOAs como amplificadores de redes ópticas está no fato de que, no upstream, o tráfego em modo rajada requer que o amplificador possua um tempo de resposta curto o suficiente de modo que seja capaz de amplificar os diferentes trens de pulsos ópticos com diferentes potências que incidem sobre ele [18]. Um exemplo de utilização destes amplificadores no upstream é mostrado na Figura 2.8, que representa a proposta original de uma PON de longo alcance [48].

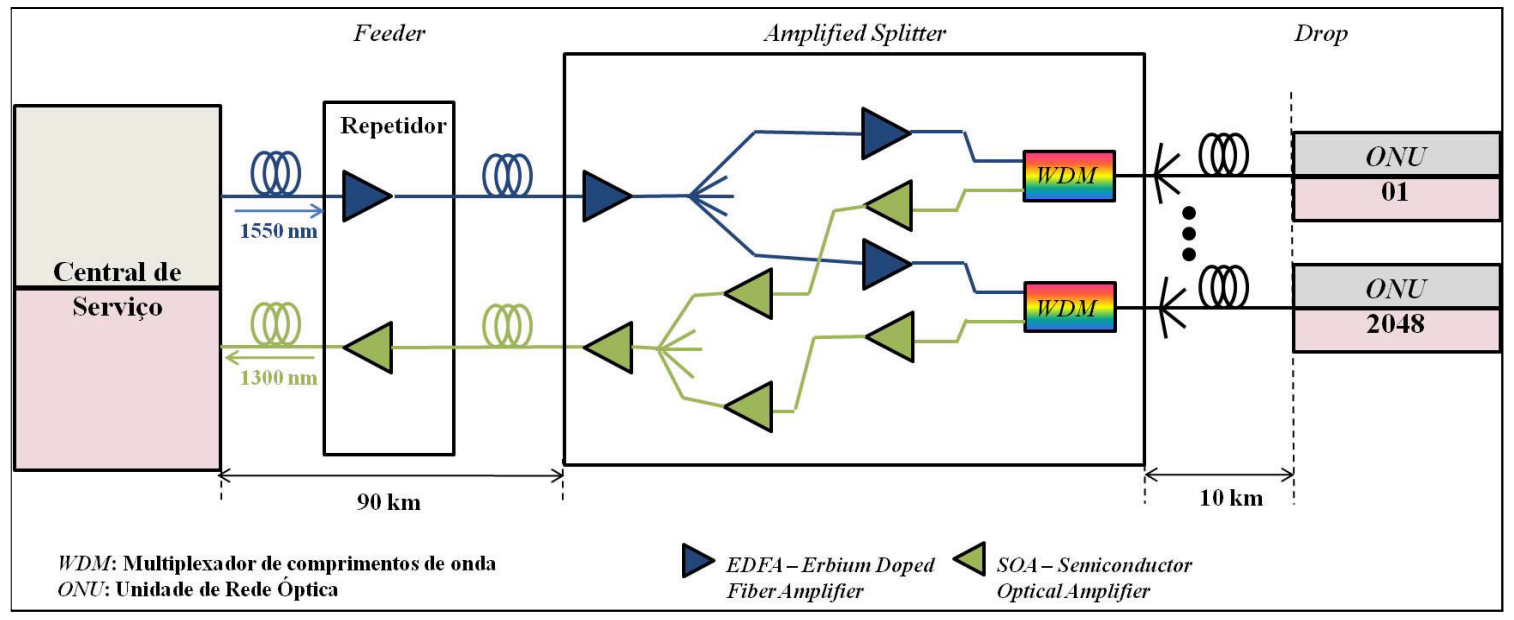

Figura 2.8: Arquitetura proposta pela ACTS-PLANET [48]. A central de serviço é conectada ao Amplified Splitter (AS) por meio das duas fibras da região de alimentação, que contém um repetidor localizado no centro do enlace. No AS, os sinais de downstream e upstream são amplificados. A conexão entre a rede de distribuição e o AS é realizada pelo WDM, que torna possível a utilização de uma única fibra distribuidora para cada uma das 2048 ONUs.

Nesta rede, seriam atendidos 2048 ONUs a uma distância total de $100 \mathrm{~km}$ da central de serviço. As taxas de transmissão sugeridas seriam de $2.5 \mathrm{Gbps}$ para downstream e de $311 \mathrm{Mbps}$ para upstream. Era utilizada a multiplexação por divisão no tempo para downstream em $1550 \mathrm{~nm}$, enquanto o upstream, em 1300nm, era realizado através do acesso múltiplo por divisão no tempo [49].

Esta proposta surgiu de uma iniciativa européia através da ACTS-PLANET (Advanced Communication Technologies and Services-Photonic Local Access NETwork) para investigar possíveis evoluções do APON (ATM(Asynchronous Transfer Mode) Passive Optical Network), padrão então vigente.

A Figura 2.8 mostra, esquematicamente, a arquitetura proposta em [48]. Uma parte 
do enlace, denominada fibra alimentadora, possui comprimento total de $90 \mathrm{~km}$, sendo que um repetidor, consistindo de um EDFA (Erbium-Doped Fiber Amplifier), cujos detalhes de funcionamento serão apresentados na próxima secção, para amplificação do sinal downstream e um SOA para o upstream, é inserido a $45 \mathrm{~km}$ da central de serviço. Percorrendo-se mais $45 \mathrm{~km}$, chega-se ao Amplified Splitter (AS), onde o sinal de downstream é amplificado e dividido nos divisores de potência. Já o upstream, proveniente das ONUs, será amplificado e combinado em divisores de potência diferentes daqueles do sinal de descida. Os dispositivos denominados WDM serão responsáveis pela multiplexação dos canais de 1550nm e 1300nm na mesma fibra da região de distribuição, que possui 10km de extensão. Deve-se notar ainda que, na região de distribuição, existem divisores de potência que, combinados com os divisores presentes no Amplified Splitter, tornarão possível o atendimento às 2048 ONUs.

Os desafios enfrentados podem ser sumarizados na introdução de ruído, principalmente no upstream, devido aos vários amplificadores em paralelo, na complexidade de gerenciamento dos dados de upstream para prevenir a colisão dos pacotes e na necessidade de um receptor no modo burst para o upstream que seja capaz de gerenciar rajadas de informação com maiores diferenças de potência entre si, uma vez que as várias ONUs podem estar a diferentes distâncias da central de serviço, resultando, assim, em diferentes atenuações.

O primeiro desafio pode ser superado a partir de um gerenciamento dos SOAs. Isto pode ser feito deixando todos os amplificadores no estado off e, somente com a chegada do sinal de upstream, o amplificador passará ao estado on [18]. Já o segundo é resolvido com a sincronização das ONUs utilizando um protocolo MAC (Medium Access Control) adequado. Por fim, o terceiro obstáculo é superado com a utilização de um receptor próprio para o modo rajada, garantindo que diferentes potências de sinal sejam interpretadas corretamente [48].

Utilizando outro esquema de amplificação, pesquisadores da British Telecom (BT) foram capazes de atender a 1024 ONUs distantes $100 \mathrm{~km}$ da central de serviço e com taxas simétricas de 10Gbps [50].

Estas são as principais características que diferenciam a proposta realizada pela BT da Super-PON original [48]. A arquitetura pode ser vista no esquema da Figura 2.9. O sinal de downstream é amplificado na central de serviço propagando-se pela fibra de 90km e atingindo o Local Exchange, onde é amplificado duas vezes nos amplificadores $\mathrm{AO}_{2}$ e $\mathrm{AO}_{3}$. O dispositivo denominado multiplexador CWDM (Coarse Wavelength Division Multiplexer) é responsável pela multiplexação dos sinais de up e downstream na seç̧ão de distribuição, que possui um total de 
10km de extensão. Deve-se notar ainda que é na distribuição que estão localizados os divisores de potência, permitindo, assim, que as 1024 ONUs sejam atendidas.

Embora o número de usuários seja metade do número proposto originalmente [49], a quantidade de amplificadores ópticos utilizados é significativamente reduzida (enquanto a SuperPON possuía 36 amplificadores, a proposta pela BT possui apenas 6 no total), acarretando numa redução do custo total e um gerenciamento mais simples da rede, para a central de serviço.

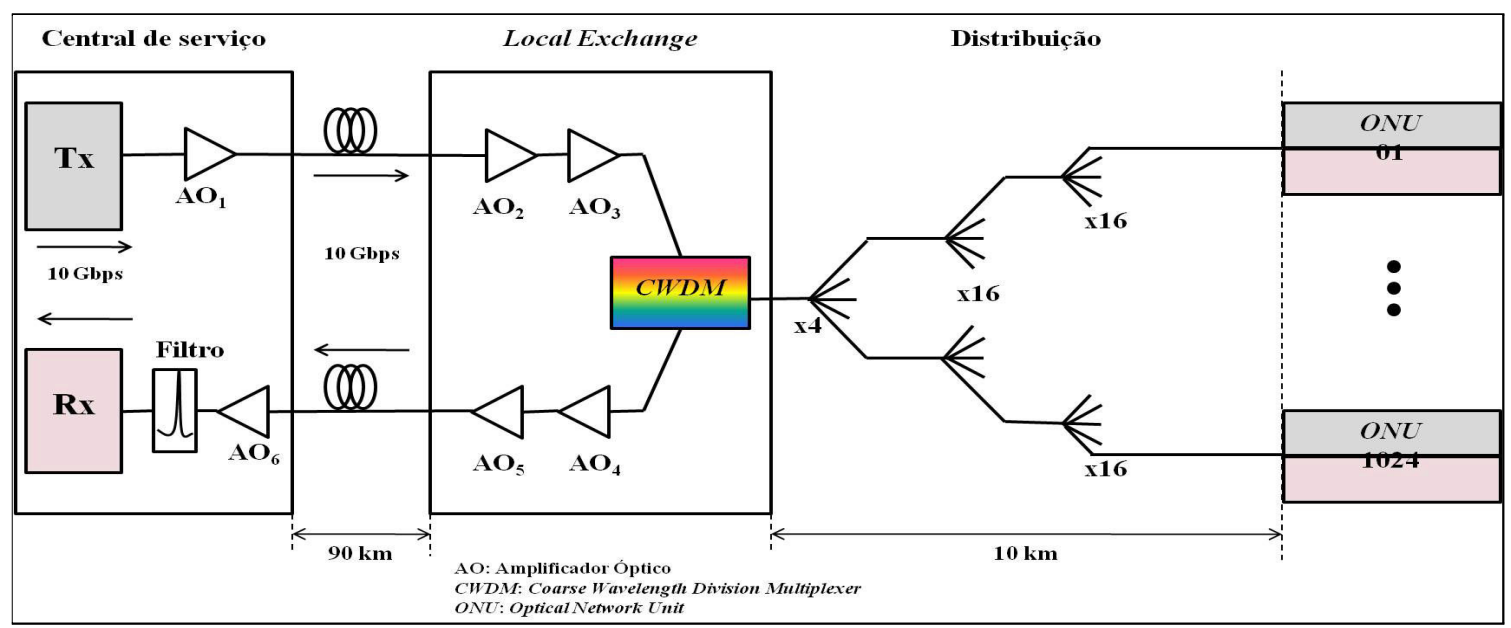

Figura 2.9: Esquema de PON de longo alcance proposto pela British Telecom. As taxas utilizadas são de 10Gbps e são atendidas 1024 ONUs. Novamente, uma seção de alimentação de $90 \mathrm{~km}$ conecta a central de serviço ao chamado Local Exchange (LE), que é onde a amplificação é feita. Os sinais de up e downstream são mutliplexados na fibra de distribuição por meio do dispositivo CDWM conectado à rede de distribuição, que possui um comprimento máximo de $10 \mathrm{~km}$, entre o LE e as ONUs.

Todos os amplificadores estão localizados antes dos splitters, o que faz com que os custos totais da rede sejam divididos por todos os usuários. Além disto, esta divisão dos custos permite a inserção de equipamentos mais sofisticados, nesta secção da rede, reduzindo os custos de cada ONU. Com este esquema de amplificação, foi possível garantir um adequado orçamento de potência, para uma taxa de erro de $10^{-10}$.

\section{Amplificação Raman}

A amplificação Raman é outra modalidade de amplificação que pode ser utilizada nas Extended PONs. Ela utiliza a fibra como meio de ganho e, portanto, necessita de um de bombeio óptico. Contudo, não é estritamente necessário utilizar uma fibra especial para que haja a amplificação, como ocorre nos DFAs. Este é o caso da amplificação Raman distribuída, 
a qual faz uso da própria fibra transmissora para realizar a amplificação óptica. Se for desejada utilização de uma fibra especial alojada em um local específico, o esquema de amplificação passa a ser denominado amplificador Raman concentrado.

Diferentemente do que foi apresentado anteriormente, a amplificação Raman utiliza como mecanismo de amplificação um efeito não-linear conhecido como espalhamento Raman estimulado (Stimulated Raman Scattering - SRS). Este efeito ocorre devido ao fato de que as moléculas do núcleo da fibra absorvem os fótons de bombeio e emitem outros fótons com menor energia (maior comprimento de onda), sendo a diferença entre a energia do bombeio e dos fótons emitidos transformada em fônons [33]. Este processo é distinto da emissão estimulada, em que um fóton incidente estimula a criação de outro fóton idêntico sem perda de energia [34].

A Figura 2.10 mostra o perfil de ganho Raman, para sílica, em função da diferença de freqüências entre o bombeio e o sinal. Deve-se notar que o máximo ganho é obtido para uma diferença de freqüências de aproximadamente $13 \mathrm{THz}$ [33], isto é, a freqüência do bombeio é $13 \mathrm{THz}$ maior, ou, equivalentemente, em torno de $100 \mathrm{~nm}$ menor, se o comprimento de onda do sinal estiver na região de $1550 \mathrm{~nm}$.

Uma vez que o máximo ganho Raman ocorre numa freqüência $13 \mathrm{THz}$ menor que a do bombeio, escolhendo-se bombeios com freqüências adequadas [52], é possível realizar a amplificação de vários canais simultaneamente [34]. De fato, a utilização de um conjunto de lasers de bombeio é capaz de criar uma largura de ganho elevada, característica essencial para a amplificação multicanal [53], pois cada bombeio produzirá um ganho máximo em uma dada freqüência $13 \mathrm{THz}$ menor, como mostrado na Figura 2.10, resultando numa combinação de vários perfis de ganho, associados aos vários bombeios.

A Figura 2.11 mostra o funcionamento da amplificação multicanal. Os quatro canais propagam-se pela mesma fibra e sofrem atenuações diferentes e, portanto, terão diferentes potências depois do enlace (Figura 2.11a). Se for utilizado um bombeio para um canal específico, como o mostrado em (b), este canal será amplificado. Os demais também poderão ser amplificados, entretanto apresentarão ganhos diferentes, uma vez que o ganho Raman máximo está localizado no canal "vermelho", como se vê na parte (b) da Figura 2.11. Assim, caso sejam utilizados bombeios com freqüências diferentes, sendo produzidos perfis de ganho com seus respectivos máximos em frequiências diferentes, é possível obter ganhos aproximadamente iguais para os quatro canais, gerando uma largura de ganho plana para a amplificação multicanal [33]. A parte (c) da Figura 2.11 ilustra a situação. 


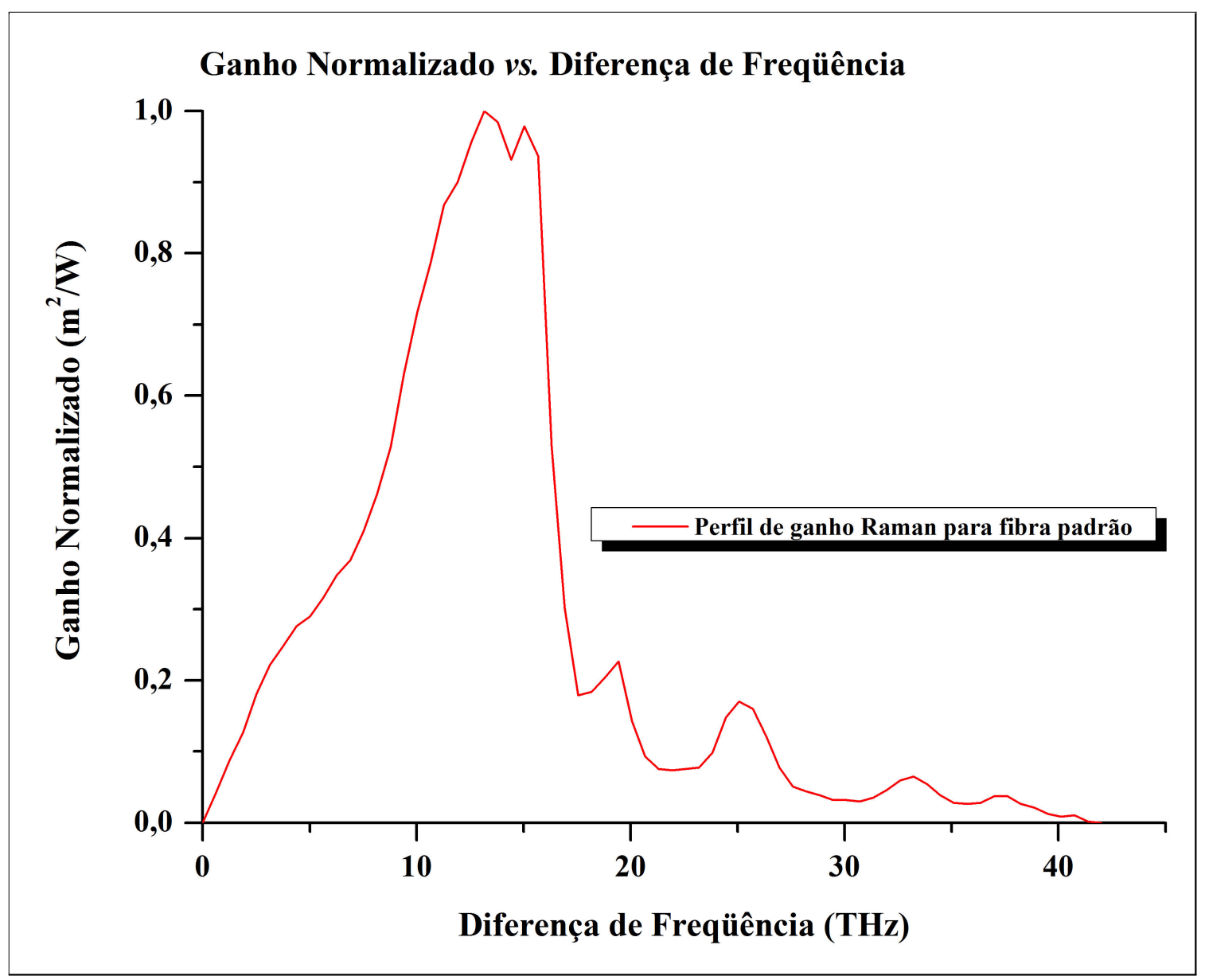

Figura 2.10: Perfil de ganho Raman em função da diferença de freqüências entre o bombeio e o sinal, para a silica. O ganho máximo ocorre em torno de $13 \mathrm{THz}$. Os demais picos ocorrem devido aos modos de vibração das moléculas de silica [51]. 


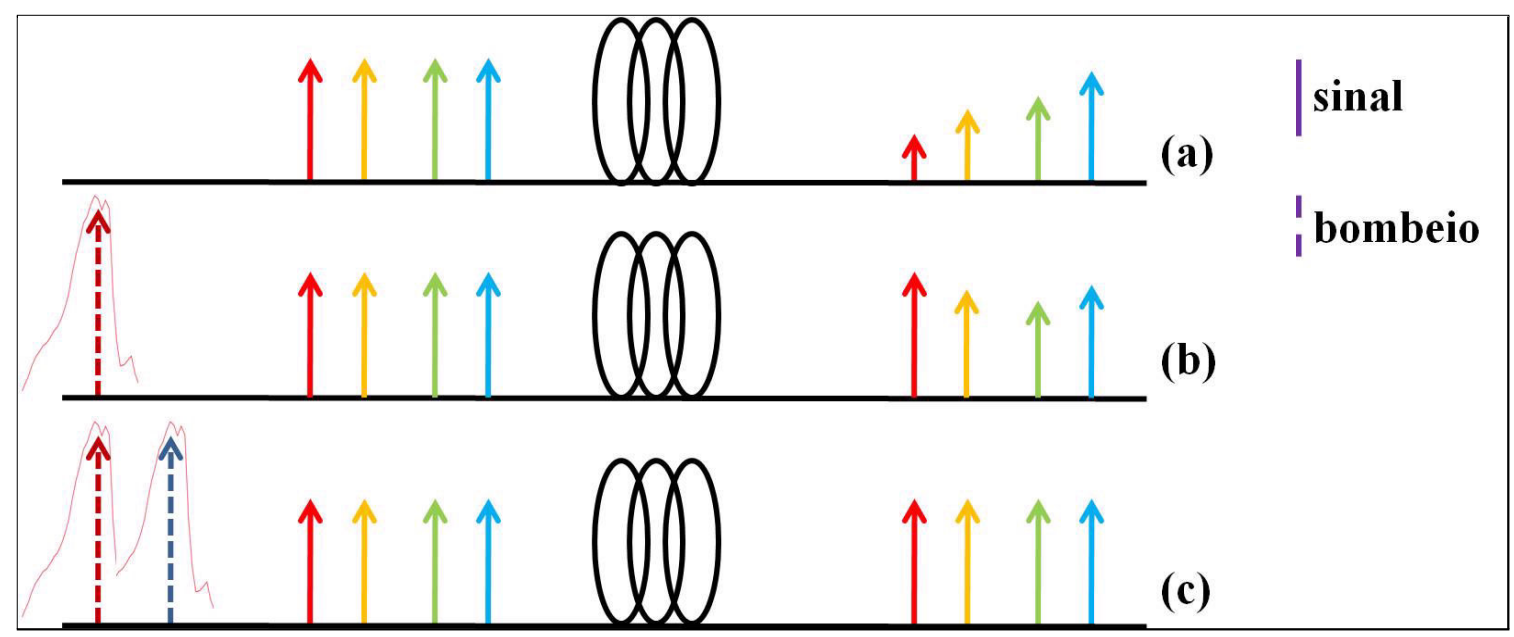

Figura 2.11: Amplificação multicanal utilizando a amplificação Raman distribuída. Em (a), os quatro canais, representados em vermelho, laranja, verde e azul, propagam-se pela fibra sem serem amplificados, sofrendo atenuações diferentes. Em (b), é utilizado um bombeio para a amplificação do canal vermelho. Este canal é amplificado com o ganho máximo proveniente do bombeio, ao passo que os demais podem ser amplificados, porém em diferentes intensidades. Por fim, a parte (c) mostra que utilizando um conjunto de bombeios é possível ter um ganho homogêneo para todos os canais.

Como mencionado anteriormente, o pico de amplificação Raman ocorre numa diferença de freqüência $13 \mathrm{THz}$. Devido a este fato, a amplificação Raman pode ocorrer em qualquer região espectral, desde que escolhidos os bombeios corretamente. Assim, podem ser desenvolvidos amplificadores Raman para os mais variados sistemas de comunicações ópticas. Por exemplo, a utilização de lasers semicondutores em 1240nm para amplificação do tráfego upstream e em 1400nm para a transmissão downstream [30]. A Figura 2.12 mostra a arquitetura investigada. Deve-se notar que a amplificação Raman é realizada somente sobre o upstream, uma vez que é este quem limita a extensão da rede.

Observando-se a Figura 2.12, notam-se duas fontes de bombeio de 1240nm conectadas a um acoplador de polarização. Sua utilização se deve em função de o sinal de upstream apresentar ganho dependente de polarização (Polarization Dependent Gain - PDG), que é a diferença entre os ganhos para estados ortogonais de polarização do campo eletromagnético, para apenas um bombeio, de 2,4dB [30]. Com o uso destas duas fontes de bombeio ortogonais, uma potência de bombeio igual a $650 \mathrm{~mW}$ é injetada na fibra transmissora e possibilita a redução da PDG para 0,8dB. Um ganho de 14,3dB é obtido nesta configuração.

Outra arquitetura que utiliza amplificadores Raman, discretos e distribuídos, para aumentar o orçamento de potência é mostrada em [31]. Nesta proposta, é utilizado um amplificador 


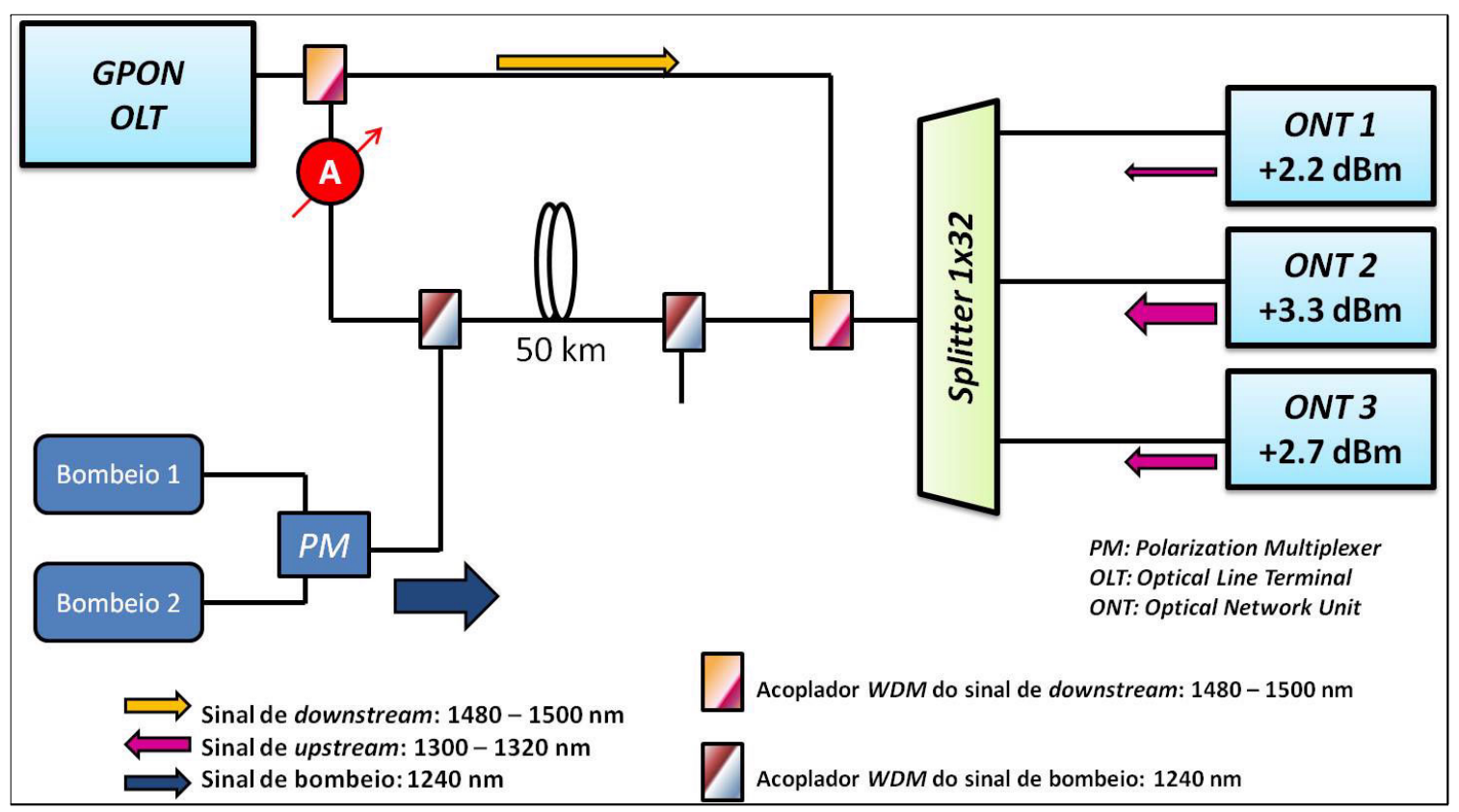

Figura 2.12: Representação esquemática de um sistema GPON utilizando amplificação Raman para aumentar o orçamento de potência. A análise desta extensão é realizada para o tráfego upstream, já que é ele o responsável pela limitação da extensão da rede.

Raman discreto para amplificação do sinal de 1490nm e um amplificador Raman distribuído contra-propagante para amplificação do sinal upstream. A distância total atingida foi de $60 \mathrm{~km}$ de fibra AllWave ${ }^{\circledR}$ [32] e a taxa de divisão de potência suportada foi de 128 [31]. Os orçamentos de potência obtidos para os sinais downstream e upstream foram, respectivamente, de $38,3 \mathrm{~dB}$ e $44,9 \mathrm{~dB}$.

\subsubsection{Amplificadores Ópticos utilizados nas LR-PONs}

Como as LR-PONs visam à unificação das redes de acesso com as redes metropolitanas, mantendo as especificações destas últimas, o principal tipo de amplificador que pode ser utilizado são os amplificadores de fibra dopada com érbio, os EDFAs, descritos na próxima secção.

\section{Amplificadores Ópticos de Fibra Dopada}

Além dos amplificadores descritos, existem os amplificadores ópticos de fibra dopada. Estes amplificadores são constituídos pela introdução de átomos dopantes no núcleo da fibra, durante seu processo de fabricação. Os átomos dopantes são escolhidos de acordo com a janela óptica a ser amplificada, sendo elementos de terras raras, como érbio, praseodímio, túlio e 
outros [54]. Nesta seç̧ão, serão considerados apenas os amplificadores de fibra dopada a érbio, responsáveis pela amplificação na janela de 1550nm.

Diferentemente dos SOAs, os amplificadores de fibra dopada utilizam o bombeio óptico para obter a inversão de população. Os lasers mais comumente utilizados no bombeio dos EDFAs emitem nos comprimentos de onda de $980 \mathrm{~nm}$ e 1480nm [34]. Os comprimentos de onda do feixe de bombeio devem ser menores que os comprimentos de onda do sinal propagante, uma vez que eles devem possuir mais energia [35], [55]. A razão pela qual o feixe de bombeio deve possuir mais energia que o sinal propagante reside no fato de que os níveis de energia permitidos nos átomos de érbio, presentes no núcleo da fibra, estão localizados acima dos níveis do sinal [55], de forma a garantir a inversão de população necessára para a ocorrência de emissão estimulada. Portanto, para atingir um nível mais energético, é necessária a utilização de freqüências maiores [34].

Como os DFAs necessitam de bombeio óptico para garantir a inversão de população, é possível que o feixe de bombeio se propague na mesma direção que o sinal óptico, configurando um bombeio copropagante, como pode ser visto na Figura 2.13. No entanto, se o feixe de bombeio se propagar na direção contrária à do sinal, tem-se o bombeio contra-propagante (Figura 2.14). É também possível ter os dois esquemas juntos num bombeio bi-direcional [36].

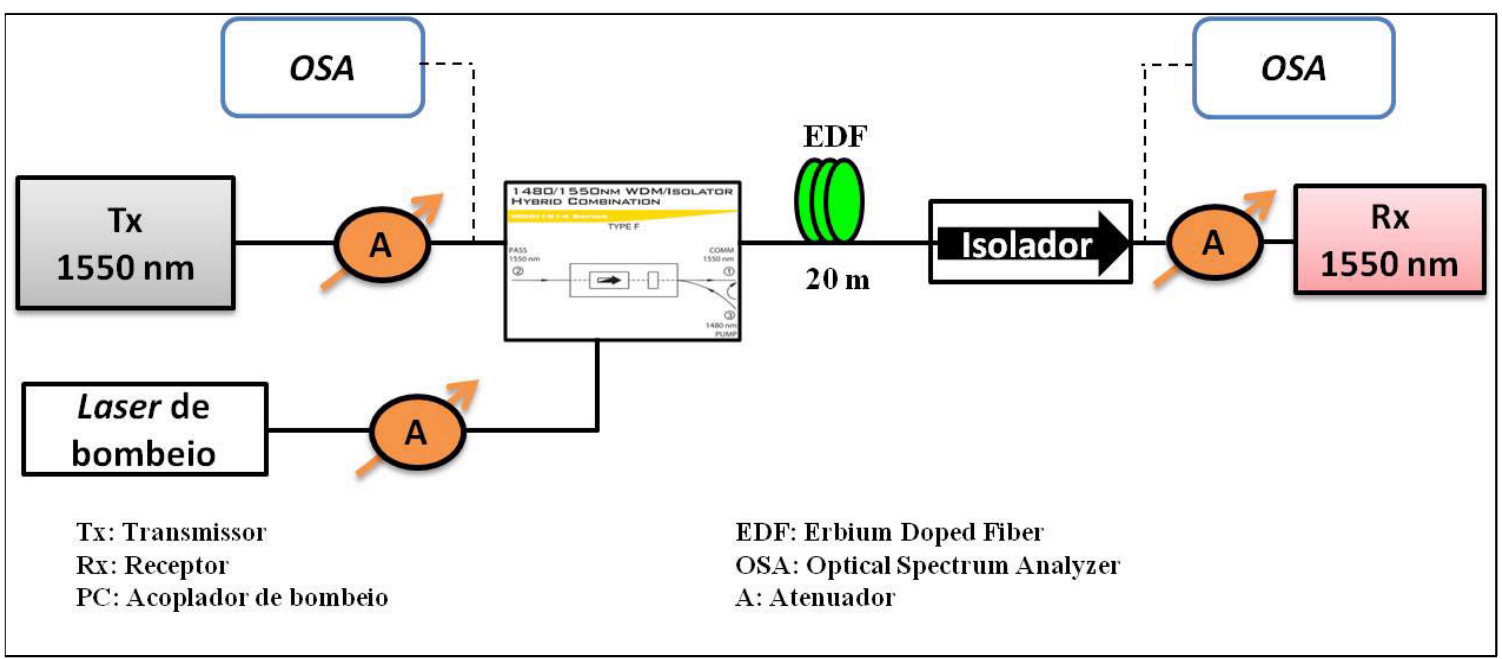

Figura 2.13: Enlace óptico ponto-a-ponto utilizando bombeio remoto, garantindo que a rede permaneça passiva. O EDFA está localizado ao longo do enlace e o laser de bombeio está posicionado junto do transmissor óptico. Como o sinal óptico e o de bombeio se propagam na mesma direção, o esquema é bombeio co-propagante. A inserção dos dois sinais na fibra dopada é feita pelo acoplador de bombeio. 


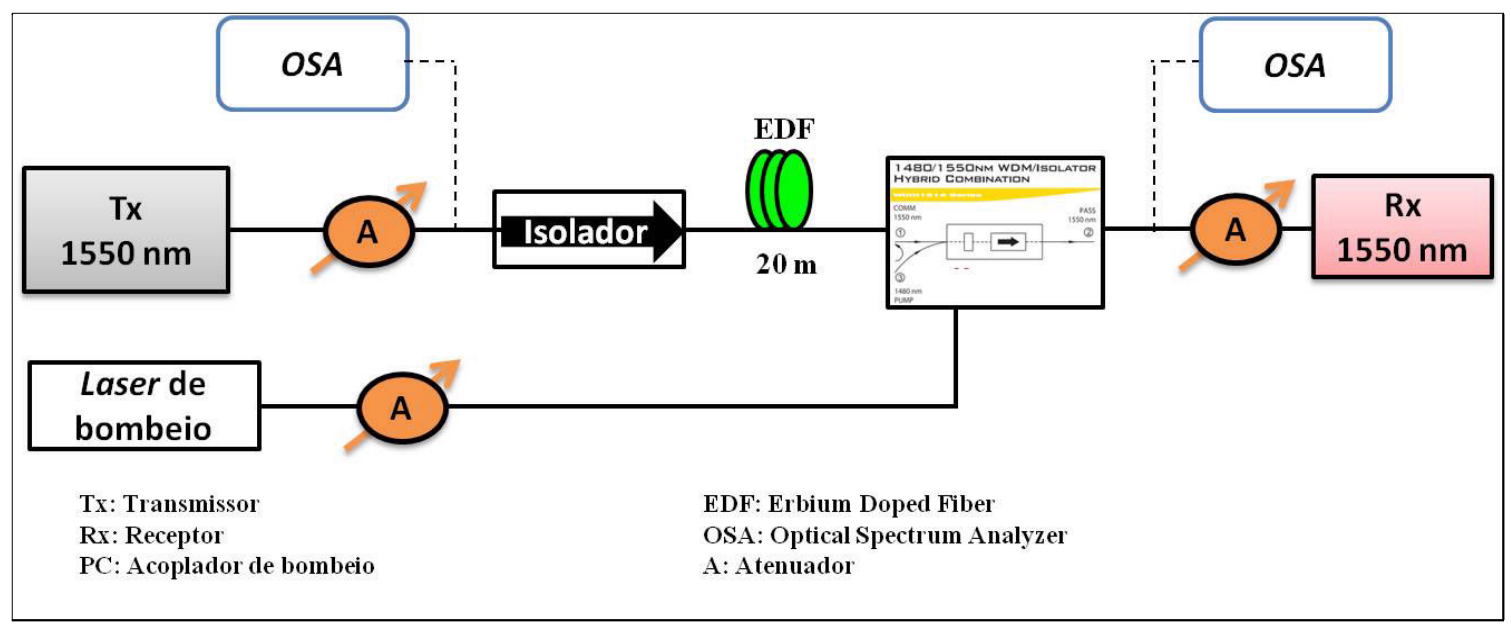

Figura 2.14: Enlace óptico ponto-a-ponto utilizando bombeio remoto, garantindo que a rede permaneça passiva. O EDFA está localizado ao longo do enlace e o laser de bombeio está posicionado junto do transmissor. Como o sinal óptico e o de bombeio se propagam em direções opostas, o esquema é bombeio contra-propagante. A inserção do sinal de bombeio na fibra óptica é feita pelo acoplador de bombeio.

A partir destas informações, podem-se comparar os dois tipos de bombeio utilizando os dois diferentes comprimentos de onda, ou seja, é possível comparar os bombeios co e contrapropagantes para o laser de 980nm e para o 1480nm. Além disto, comparações para cada esquema de bombeio considerando os dois lasers também pode ser feitas.

Deve-se notar que em ambos os esquemas de bombeio, o bombeio pode ser realizado remotamente. Isto mantém o caráter passivo da rede, uma vez que o componente ativo (laser de bombeio) está localizado em uma das extremidades do enlace. Entretanto, na utilização do bombeio remoto, lasers de bombeio com comprimento de onda entre 1450nm e 1490nm devem ser usados já que o comprimento de onda de corte da fibra padrão ser 1260nm [56], [57].

Como mencionado no início da secção, a utilização de diferentes dopantes produz amplificadores próprios para diferentes regiões do espectro [54]. Alguns exemplos de arquiteturas que utilizam EDFAs são apresentados a seguir.

Com o objetivo de utilizar a estrutura já instalada, pesquisadores da University College Cork, Irlanda, propuseram, em 2006, uma arquitetura híbrida DWDM-TDM (Dense Wavelength Division Multiplexing-Time Division Multiplexing) [19], com 10Gbps simétricos, por canal.

A Figura 2.15 mostra o esquema utilizado na obtenção da LR-PON híbrida. São utilizados 17 canais entre $1529 \mathrm{~nm}$ e $1541,6 \mathrm{~nm}$, espaçados de $100 \mathrm{GHz}$, para downstream e outros 17 canais entre $1547,2 \mathrm{~nm}$ e $1560,1 \mathrm{~nm}$, com a mesma separação, no upstream. Os canais de 
downstream são multiplexados por um AWG (Arrayed Waveguide Grating) e encaminhados à porta 1 do circulador. $\mathrm{O}$ sinal de downstream sai pela porta 2 do circulador, passa por uma DCF (Dispersion Compensating Fiber), sendo conduzido à fibra de 88km, responsável pela conexão do Core Exchange (CE) com o Local Exchange (LE). No LE, um dispositivo chamado RBF (Red Blue Filter) é responsável pela combinação/separação dos canais de up e downstream, direcionando o sinal "azul" (que é o sinal de downstream com comprimentos de onda mais curtos) para o amplificador e injetando o sinal "vermelho"(que é o sinal de upstream, que possui comprimentos de onda mais longos) na fibra de $88 \mathrm{~km}$.

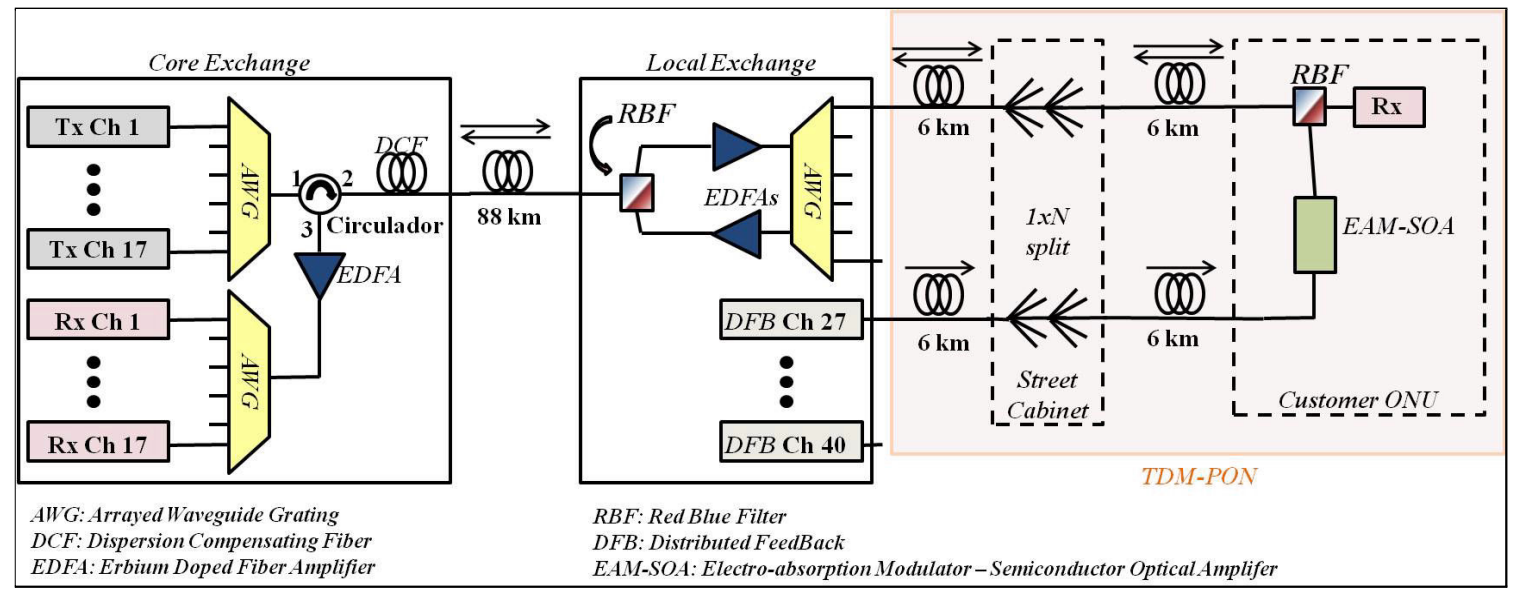

Figura 2.15: Esquema da topologia híbrida DWDM-TDM proposta em [19]. A secção alimentadora possui $88 \mathrm{~km}$ e é DWDM-PON. Já a região de distribuição possui comprimento máximo de $12 \mathrm{~km}$, sendo TDM-PON. Cada TDM-PON, com suas 256 ONUs, está conectada a um dos canais DWDM.

Observando-se o LE, pode-se notar que além dos amplificadores, do AWG, que é o responsável pela multiplexação/demultiplexação nas TDM-PONs, e do RBF, existem também 17 lasers DFB (Distributed FeedBack). Estes DFBs fornecerão os comprimentos de onda que serão utilizados no upstream, utilizando o conceito de fonte óptica centralizada.

Prosseguindo para a parte sombreada em laranja da Figura 2.15, tem-se uma rede de distribuição de $12 \mathrm{~km}$, com divisão de potência nos splitters cascateados, sendo que em cada um dos canais há 256 ONUs conectadas. Nas ONUs, há um RBF desempenhando a mesma função do RBF presente no LE. Os dados de upstream são inseridos no sinal provido por um dos DFBs localizados no LE através de um modulador de eletro-absorção integrado a dois SOAs, dispositivo chamado EAM-SOA (Electroabsorption Modulator-Semiconductor Optical Amplifier). O sinal proveniente dele é dirigido ao CE, propagando-se pelo mesmo caminho que o downstream. 
Outras duas propostas de esquemas de amplificação por fibra dopada foram implementadas a partir de um consórcio de países integrantes da União Européia. Ambas utilizam a multiplexação por comprimento de onda no enlace de maior comprimento, enquanto que na região de distribuição é realizada multiplexação no domínio do tempo. Os parágrafos seguintes descrevem estas duas propostas.

A primeira é denominada PIEMAN, que é um acrônimo para Photonic Integrated Extended Metro and Access Network [58]. É um projeto subsidiado pela União Européia e possui como objetivo investigar maneiras de integrar a rede metropolitana com a rede de acesso, visando à redução do CAPEX, devido à grande quantidade de elementos/equipamentos de rede [59], e OPEX, devido à necessária e complexa manutenção que deve ser realizada [59].

A topologia investigada é semelhante à mostrada na Figura 2.15. Suas principais características são as taxas de transmissão de 10Gbps simétricas, 32 pares de comprimentos de onda, localizados dentro da banda $\mathrm{C}$, com espaçamento de $50 \mathrm{GHz}$, por ONU, sendo um para downstream e o outro para upstream. Além disto, são utilizadas split ratios de até 512 . A Figura 2.16 mostra a topologia [59], [60].

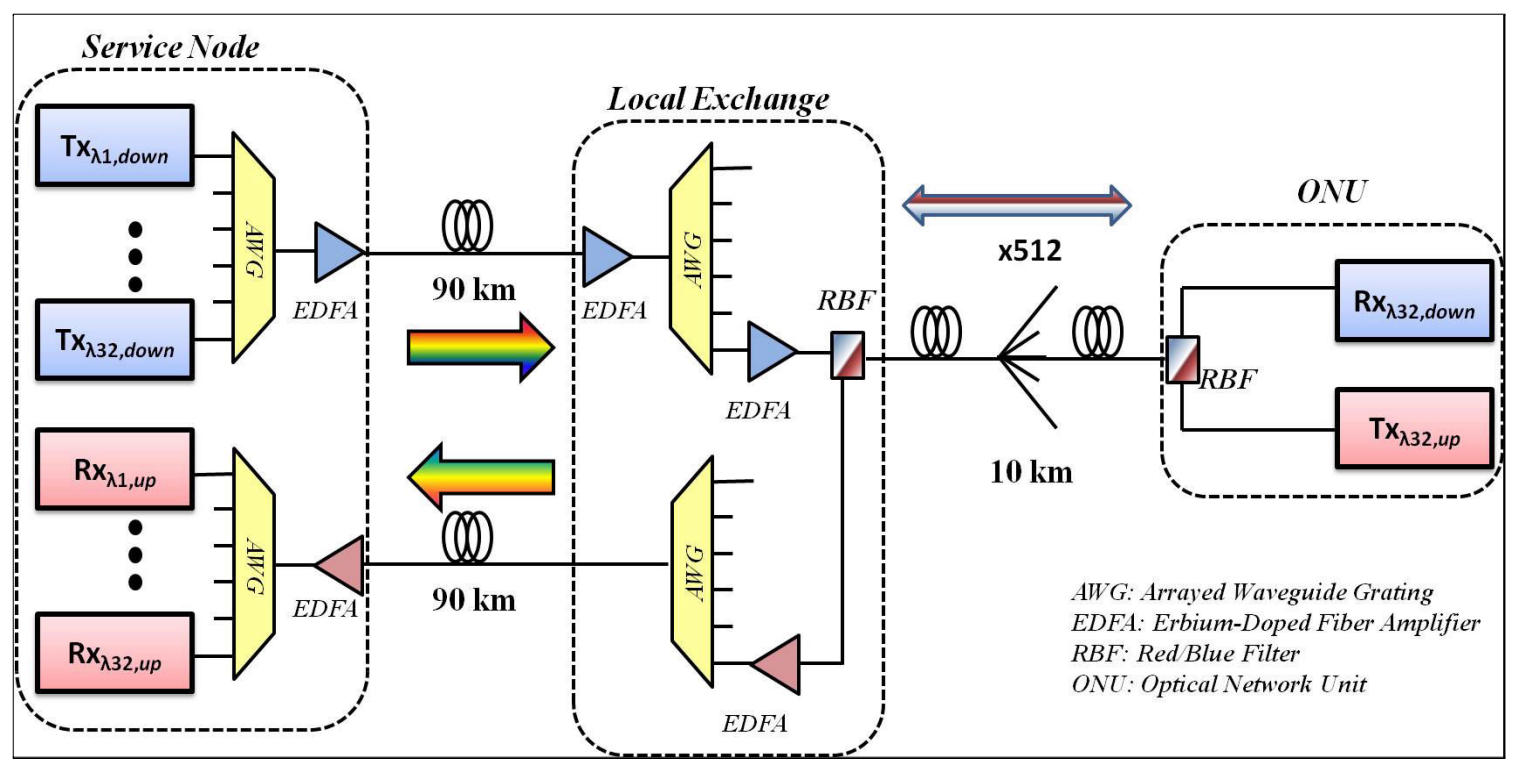

Figura 2.16: Representação esquemática da topologia PIEMAN [58]. Ela é semelhante à proposta híbrida DWDM-TDM feita por Talli em [19]. Deve-se notar que na secção metropolitana, os tráfegos up e downstream são separados em duas fibras, enquanto na região de acesso, há apenas uma fibra transmitindo os dois fluxos de informação.

O Service Node (SN) contém os transmissores e receptores da provedora de serviço, sendo equivalente à Central de Serviço. Os 32 comprimentos de onda de downstream são multi- 
plexados em um AWG, pós-amplificados e enviados do SN ao Local Exchange (LE) por meio de uma fibra de 90km exclusiva para este tráfego. No LE, os canais são amplificados e, em seguida, demultiplexados por um AWG idêntico ao primeiro. Cada um dos comprimentos de onda, após a demultiplexação, é encaminhado a uma fibra de, no máximo, 10km até as ONUs. É ao longo desta fibra que está localizado o divisor de potência que produzirá a split ratio de até 512 . O comprimento de onda de upstream de cada usuário é encaminhado ao LE por meio da mesma fibra de 10km e mesmo divisor de potência. Ao atingirem o LE, os canais de upstream são amplificados e multiplexados por um AWG diferente do primeiro, uma vez que eles serão transmitidos até o SN por meio de uma fibra diferente daquela usada para o sinal de downstream. No SN, eles são demultiplexados e detectados em seus respectivos receptores. Note-se que as regiões de acesso $(10 \mathrm{~km})$ operam com uma fibra apenas e as regiões metropolitanas $(90 \mathrm{~km})$ operam com duas.

De forma similar à rede PIEMAN, SARDANA é um acrônimo para $\boldsymbol{S}$ calable $\boldsymbol{A}$ dvanced $\boldsymbol{R}$ ing-based Passive Dense Access Network Architecture [61]. Consiste de um consórcio realizado entre universidades e institutos de pesquisa de países europeus, que tem por objetivo a investigação de uma topologia em anel (Figura 2.17) que atenda a um elevado número de usuários, da ordem de milhares, distribuídos ao longo de uma distância em torno de 100km e que suporte grande capacidade (32 canais transportando 10Gbps cada) [17], [62].

As arquiteturas apresentadas até o momento utilizam EDFAs como os extensores das redes ópticas. Entretanto, utilizando-se outros tipos de DFAs, torna-se possível realizar a amplificação em regiões espectrais diferentes da banda C. Um exemplo é a utilização de fibras dopadas com praseodímio e com túlio, a fim de se realizar amplificação nos comprimentos de onda de sistemas GPON [46]. 


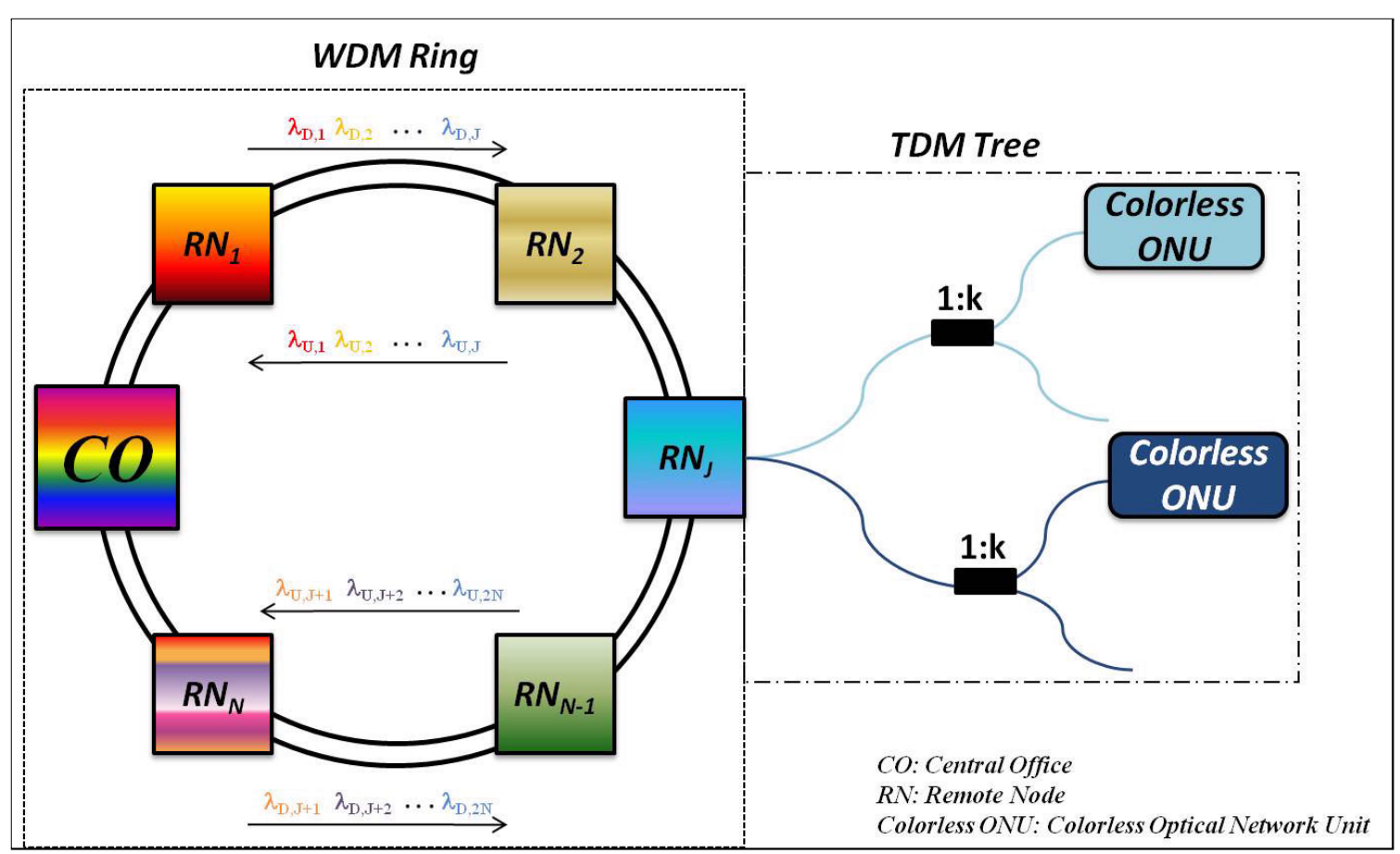

Figura 2.17: Representação esquemática da topologia em anel SARDANA. A arquitetura de um anel com tráfego WDM bidirecional com taxas de 10Gbps downstream e 1,25/2,5Gbps upstream, conforme a tecnologia utilizada na Colorless ONU [63].

\subsubsection{Posicionamento dos Amplificadores Ópticos}

Compreendidos os princípios de funcionamento dos amplificadores, pode-se entender suas possíveis aplicações, as quais variam de acordo com a posição em que são colocados nas redes ópticas, uma vez que o aumento da distância entre o transmissor e o receptor pode levar a uma degradação dos bits transmitidos, como é mostrado na Figura 2.18.

O primeiro posicionamento abordado é a localização do amplificador logo após a saída do transmissor, configurado como amplificador de potência. Nesta posição, como representado na Figura 2.19, o amplificador, denominado booster, opera em regime de saturação, por receber potências elevadas provenientes do transmissor [34] e sua função é injetar um sinal de alta potência na fibra. 


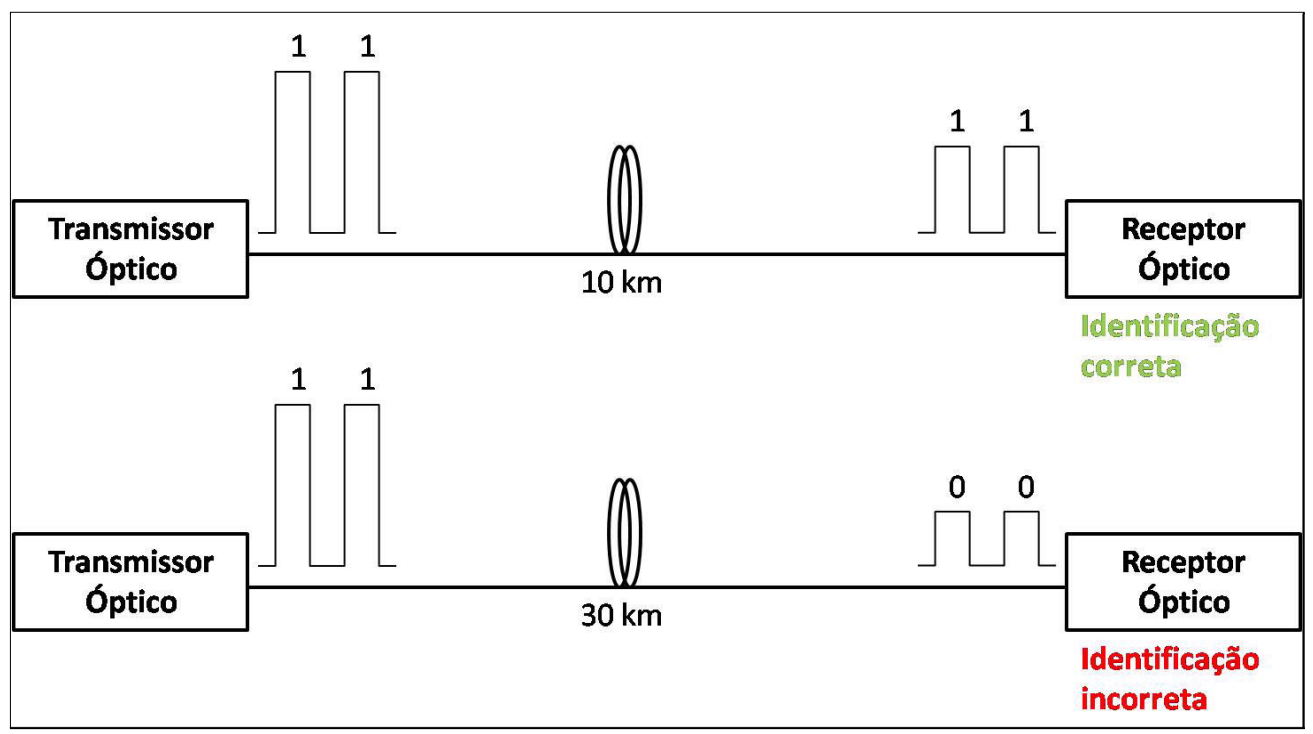

Figura 2.18: Esquema representando o efeito do aumento da distância de propagação sobre a informação transmitida. São utilizados transmissores e receptores idênticos nos dois casos. Na parte superior da figura, o receptor é capaz de identificar corretamente a informação transmitida. Já na parte inferior, a elevação no comprimento do enlace faz com que a potência incidente sobre o receptor esteja abaixo do limite que o fotodetector é capaz de identificar corretamente, levando, portanto, à perda da informação transmitida.

Enquanto a amplificação de potência requer o posicionamento do amplificador após a saída do transmissor, na pré-amplificação o amplificador localiza-se antes do receptor, como apresentado na Figura 2.20, com o objetivo principal elevar a potência recebida para o fotodetector. O pré-amplificador deve possuir como características baixo ruído e, por receber sinais de baixas potências, seu ganho ocorre em regime linear. 


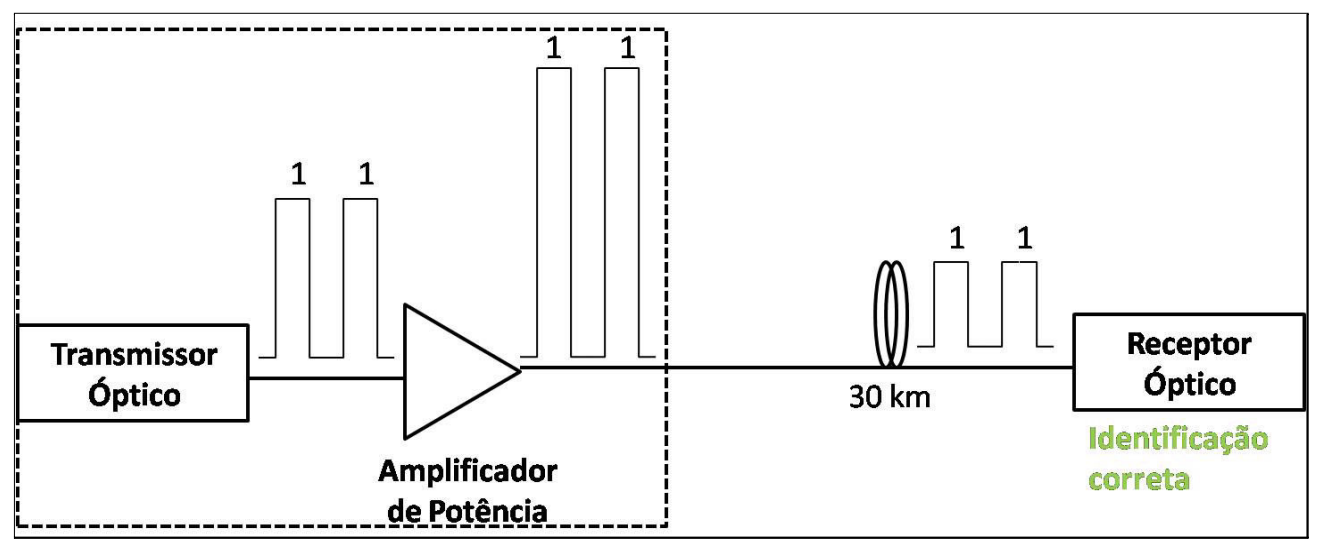

Figura 2.19: Representação esquemática da amplificação de potência. Posicionando o amplificador após a saída do laser: configura-se a amplificação de potência, cujo objetivo é aumentar o comprimento do enlace a partir da injeção de um sinal de alta potência na fibra. Por receber um sinal de alta potência, o amplificador utilizado na amplificação de potência deve operar em regime de saturação.

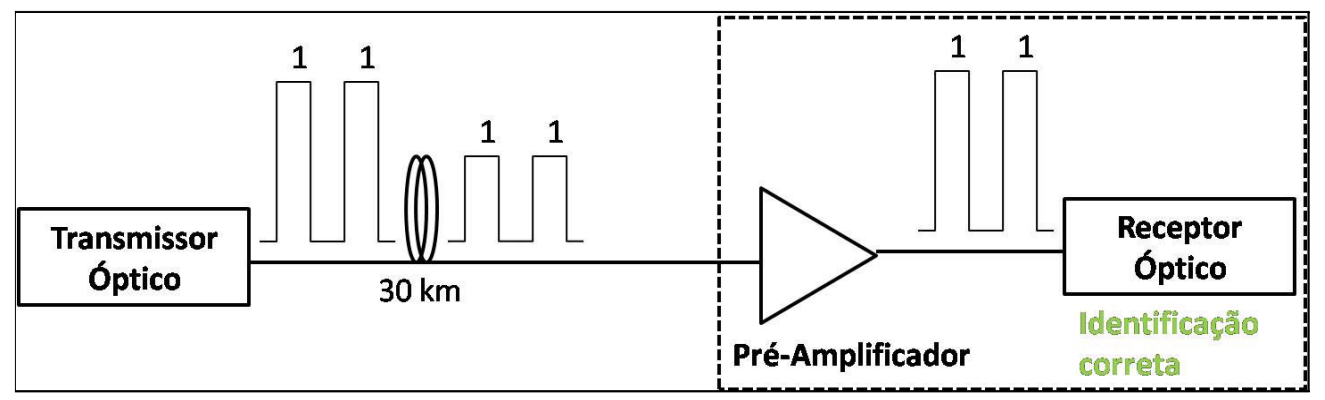

Figura 2.20: Esquema da pré-amplificação. Ao posicionar o amplificador exatamente antes do receptor óptico, tem-se a pré-amplificação, cujo objetivo principal é elevar a potência recebida no fotodetector. Como o sinal sairá do pré-amplificador para o receptor, o amplificador utilizado determinará o ruído que incidirá sobre o fotodetector, podendo levar a elevações nas taxas de erro de bit. Assim, deve possuir uma pequena figura de ruído ou filtros ópticos bastante finos devem ser utilizados, reduzindo o ruído detectado.

Além disto, é possível ainda utilizar os amplificadores ópticos ao longo da fibra do enlace, caracterizando-os como amplificadores de linha. O resultado é o aumento no comprimento do enlace, conforme a Figura 2.21. Todavia, nesta aplicação, algum cuidado deve ser tomado quanto à introdução de um número elevado de amplificadores, pois a dispersão e o ruído acumulados ao longo do enlace podem degradar completamente a informação transmitida.

Não obstante, também é possível posicionar os amplificadores ópticos nas redes locais para compensar as taxas de divisão de potência dos divisores ópticos passivos, ou splitters, conforme mostrado na Figura 2.22. Pode-se considerar esta aplicação uma variação da amplificação 
de linha.

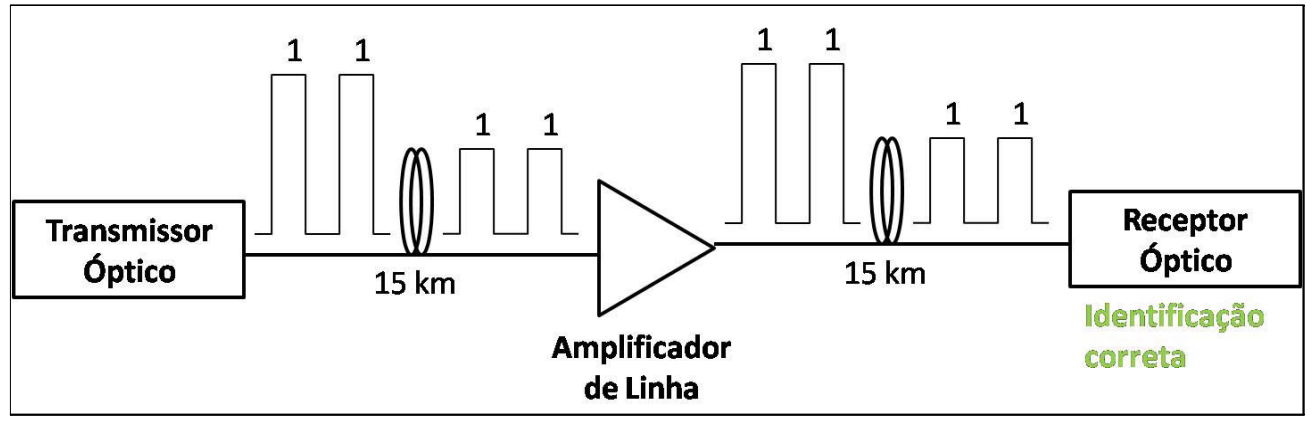

Figura 2.21: Representação esquemática da amplificação de linha, cuja principal função é aumentar o comprimento do enlace.

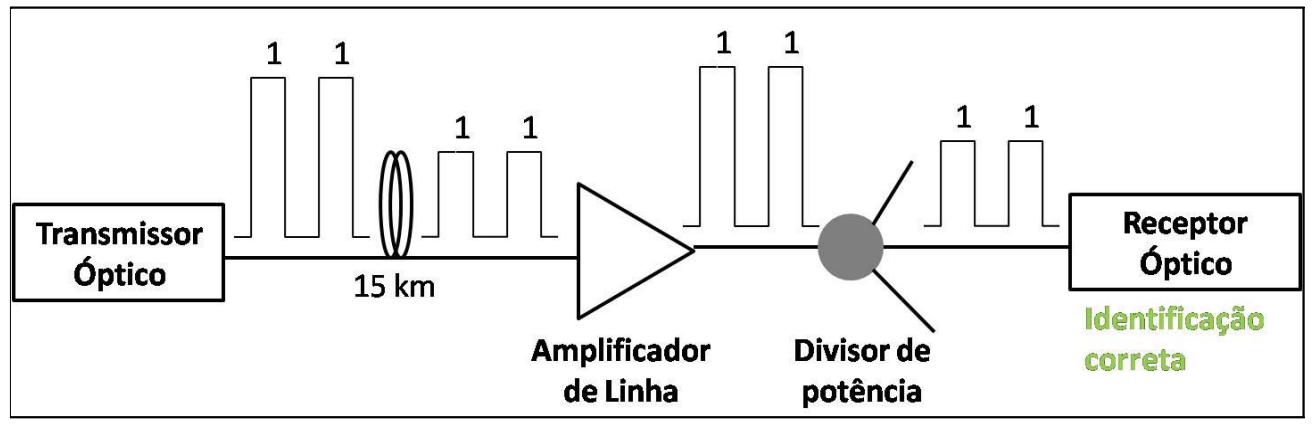

Figura 2.22: Esquema representando a divisão de potência óptica ao longo da rede. O aumento no número de usuários conectados a uma mesma estrutura de rede requer que a potência do sinal óptico seja dividida entre eles. Para garantir que todos os usuários recebam uma potência óptica adequada, insere-se um amplificador antes de realizar a divisão.

Uma vez conhecidos os principais tipos de amplificadores ópticos e suas principais características bem como os possíveis posicionamentos deles nas redes ópticas, além de algumas topologias apresentadas, podem-se explorar outros esquemas de amplificação óptica visando à extensão do alcance das redes ópticas passivas. 


\section{Capítulo 3}

\section{Resultados e discussão}

Com o intuito de estender o orçamento de potência das redes ópticas passivas, foram realizadas investigações experimentais e teóricas. No âmbito de sistemas do tipo Extended PON, foram realizadas abordagens experimentais com o objetivo de determinar possíveis maneiras de utilizar os amplificadores ópticos semicondutores para extensão de sistemas GPON. Foram realizadas também simulações computacionais com SOAs configurados da mesma maneira visando ao estudo de possíveis impactos de SOAs com diferentes características. Em relação às LR-PONs, cenários contendo 1 canal em topologias do tipo árvore foram simulados a partir da utilização de fibras dopadas com érbio bombeadas remotamente. As próximas seções apresentaram os principais resultados obtidos.

\subsection{Extensores para sistemas do padrão GPON}

Como visto no capítulo anterior, os amplificadores ópticos representam possíveis alternativas na extensão das redes ópticas, isto é, são uma das formas de se garantir um orçamento de potência adequado à medida em que o número de usuários e/ou a distância aumentam. Deste modo, foram realizadas investigações experimentais utilizando SOAs visando à extensão do alcance de redes do tipo GPON. A abordagem experimental foi realizada no Centro de Pesquisas e Desenvolvimento em Telecomunicações, CPqD, sob a Meta 3, intitulada Amplificadores Ópticos de Banda Larga e Baixo Consumo, do Projeto Giga Fase 2. O objetivo é o desenvolvimento de um extensor para o padrão GPON. São utilizados um SOA para amplificação em 1310nm, fornecido pela empresa InPhenix [41], e outro para realizar a amplificação em 1490nm, fornecido pela empresa Kamelian [40]. As Figuras 3.1 e 3.2 mostram o aparato experimental utilizado e o 
extensor montado, respectivamente.

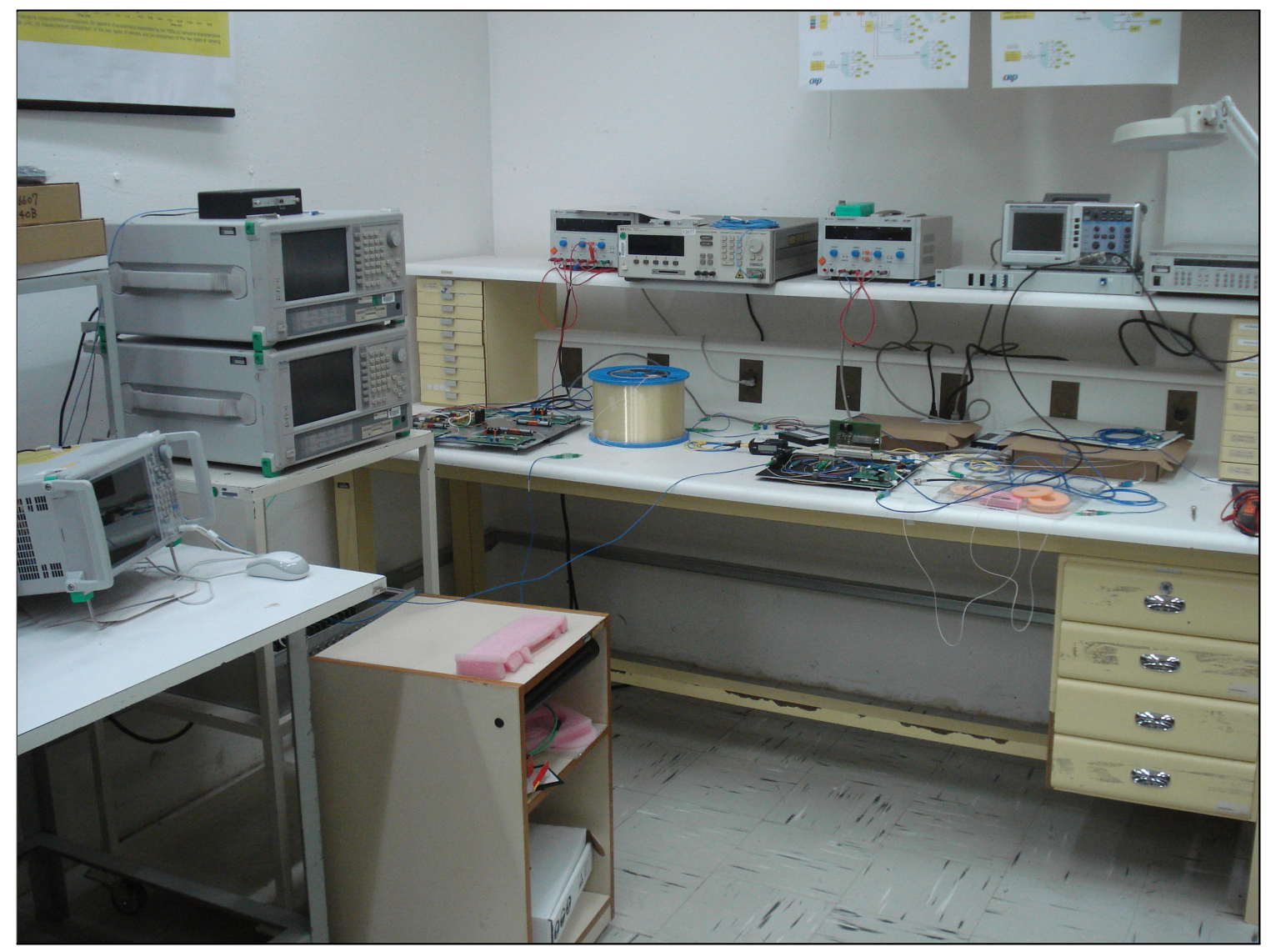

Figura 3.1: Foto do aparato experimental, em laboratório do $\mathrm{CPqD}$, utilizado no estudo de um extensor baseado em SOAs. 


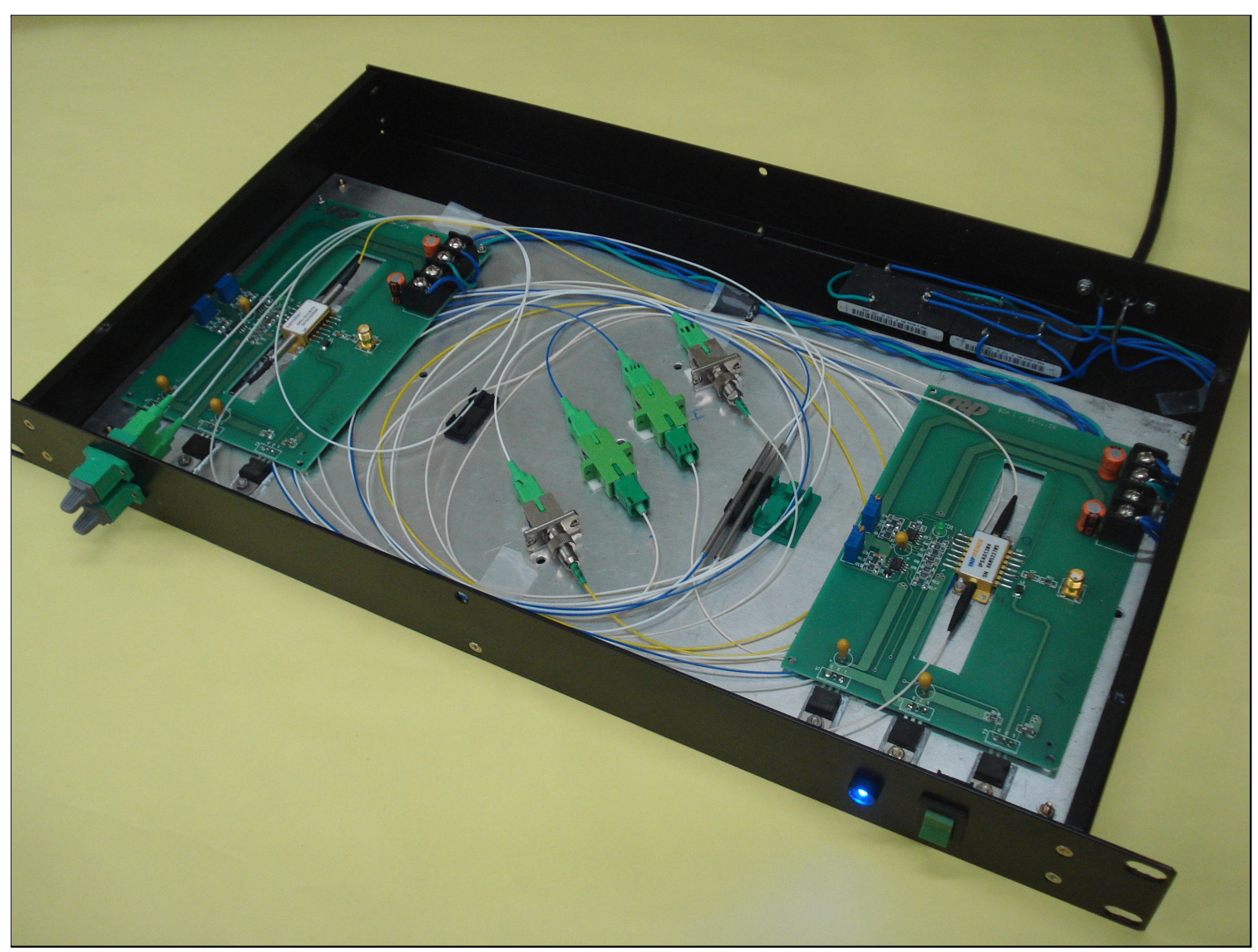

Figura 3.2: Foto do extensor baseado em SOAs desenvolvido no $\mathrm{CPqD}$, contendo os amplificadores de $1490 \mathrm{~nm}$ e $1310 \mathrm{~nm}$ e os acopladores $1310 \mathrm{~nm} / 1490 \mathrm{~nm}$.

Inicialmente, foram feitas caracterizações de ganho e figura de ruído dos dispositivos em função do comprimento de onda para diferentes potências de entrada, cujos resultados são mostrados nas Figuras 3.3, para o SOA em 1310nm, cujo valor máximo de ganho ocorre em torno de 1295nm, e Figura 3.4, para o amplificador em 1490nm e que tem o ganho máximo em 1495nm. As Figuras 3.5 e 3.6 mostram o espectro de ASE dos amplificadores com corrente de $200 \mathrm{~mA}$ cada. 


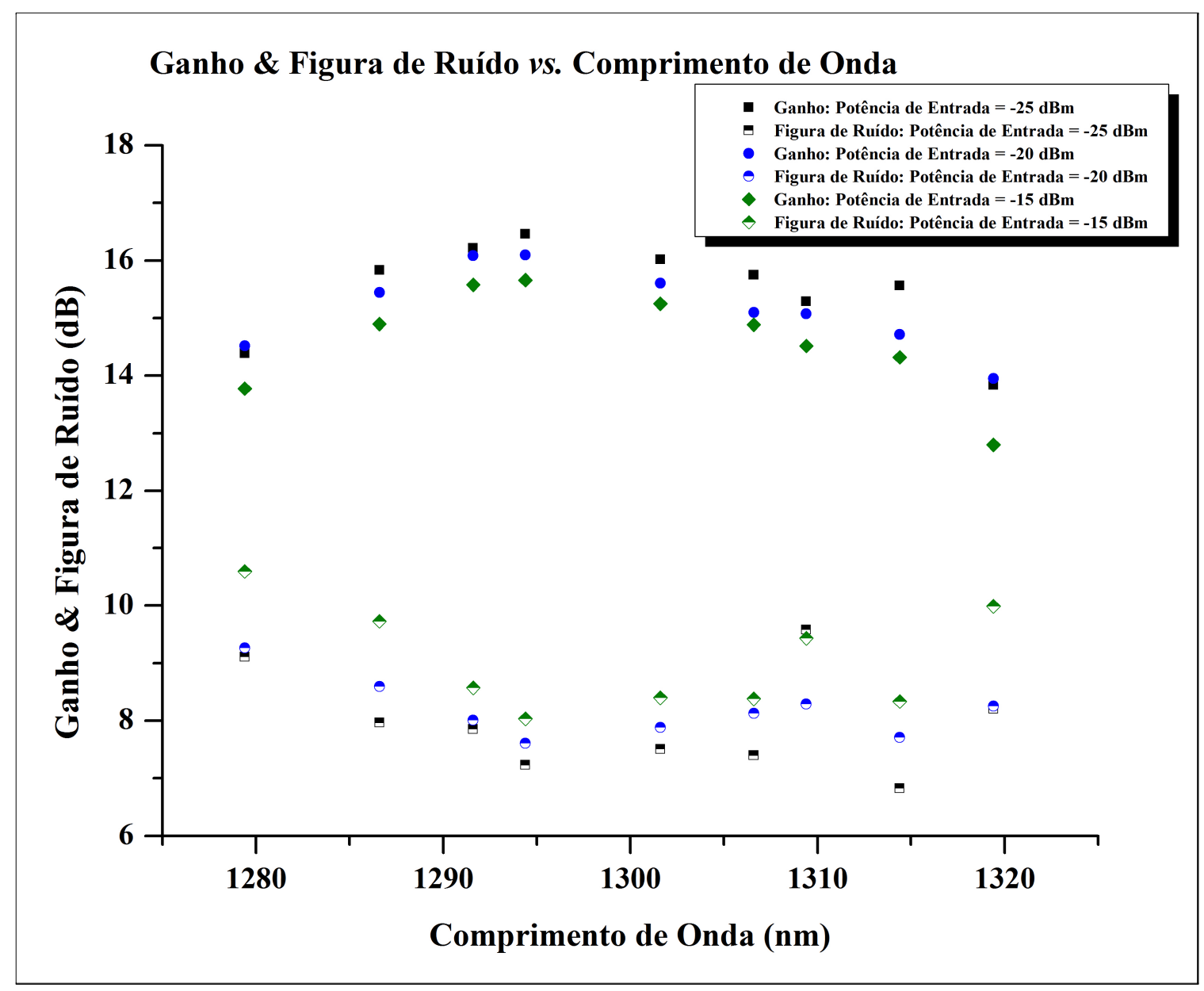

Figura 3.3: Ganho e figura de ruído, do SOA de 1300nm, em função do comprimento de onda do sinal para potências de entrada de $-25 \mathrm{dBm},-20 \mathrm{dBm}$ e $-15 \mathrm{dBm}$. A corrente de injeção do dispositivo é de $180 \mathrm{~mA}$. 


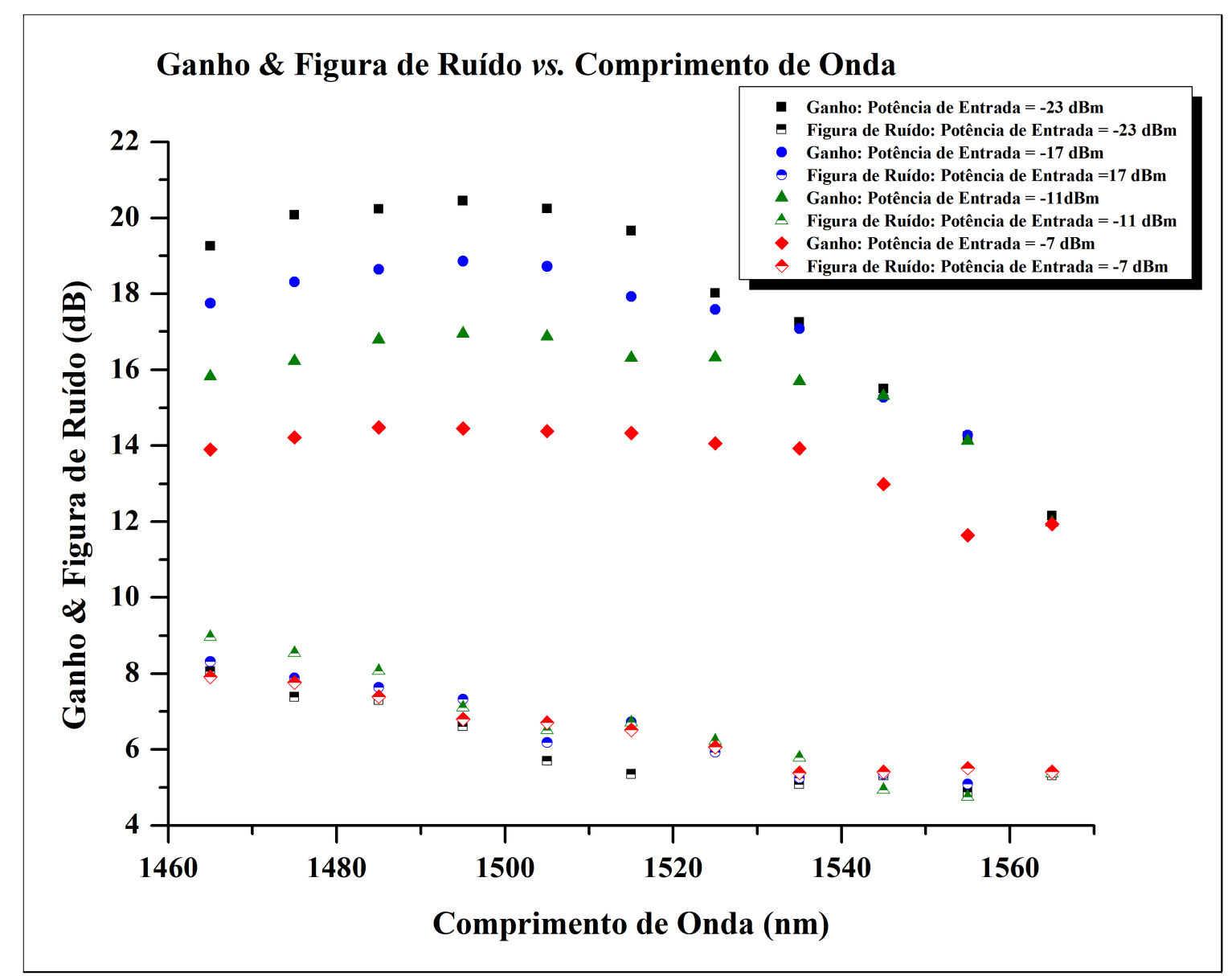

Figura 3.4: Ganho e figura de ruído, do SOA 1500nm, em função do comprimento de onda para potências de entrada de $-23 \mathrm{dBm},-17 \mathrm{dBm},-11 \mathrm{dBm}$ e $-7 \mathrm{dBm}$. A corrente de injeção é de $130 \mathrm{~mA}$. 


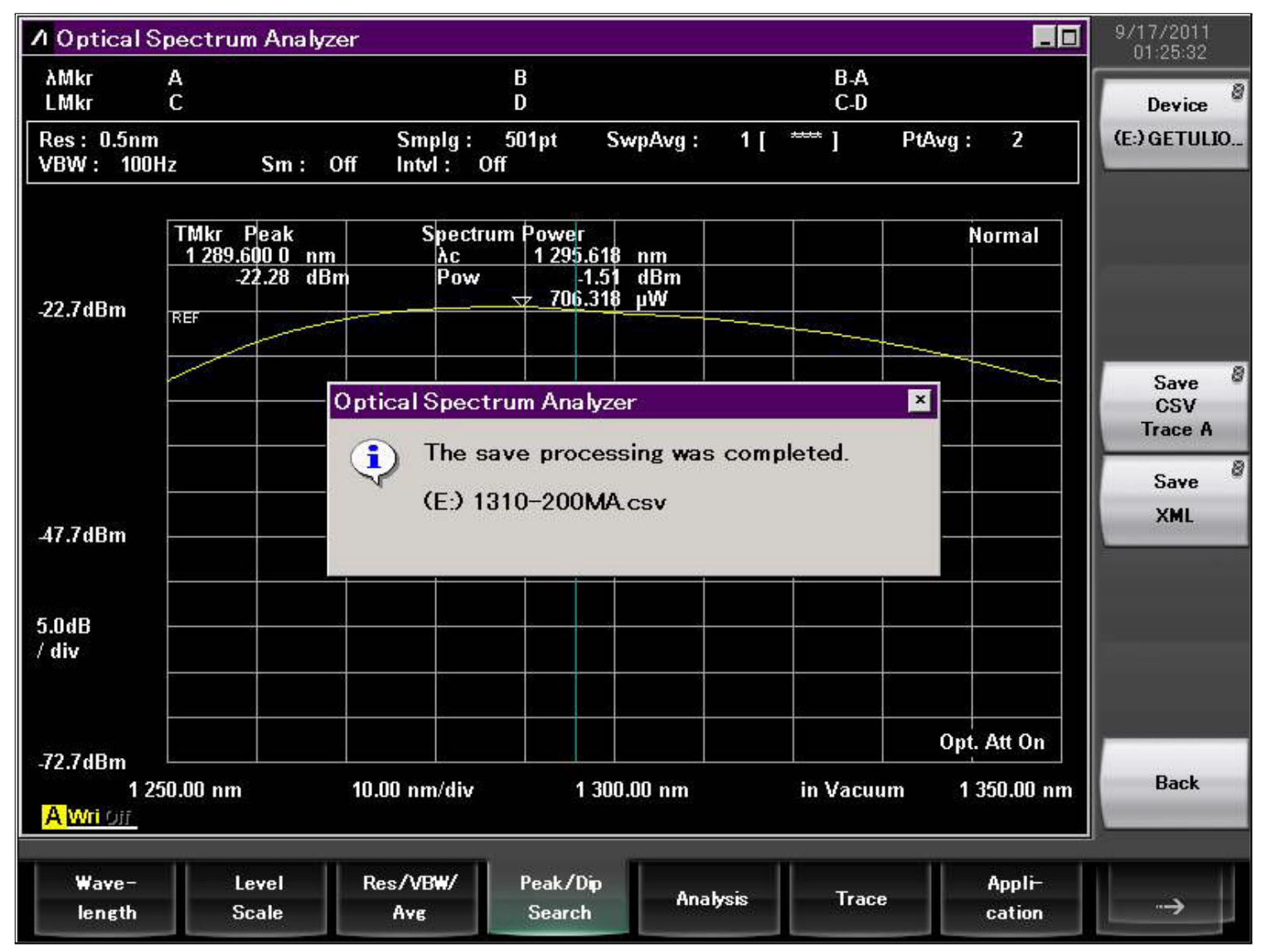

Figura 3.5: Espectro de ASE proveniente do SOA de 1310nm polarizado com 200mA de corrente de injeção. Observa-se que o pico de ASE ocorre aproximadamente em 1295nm. 


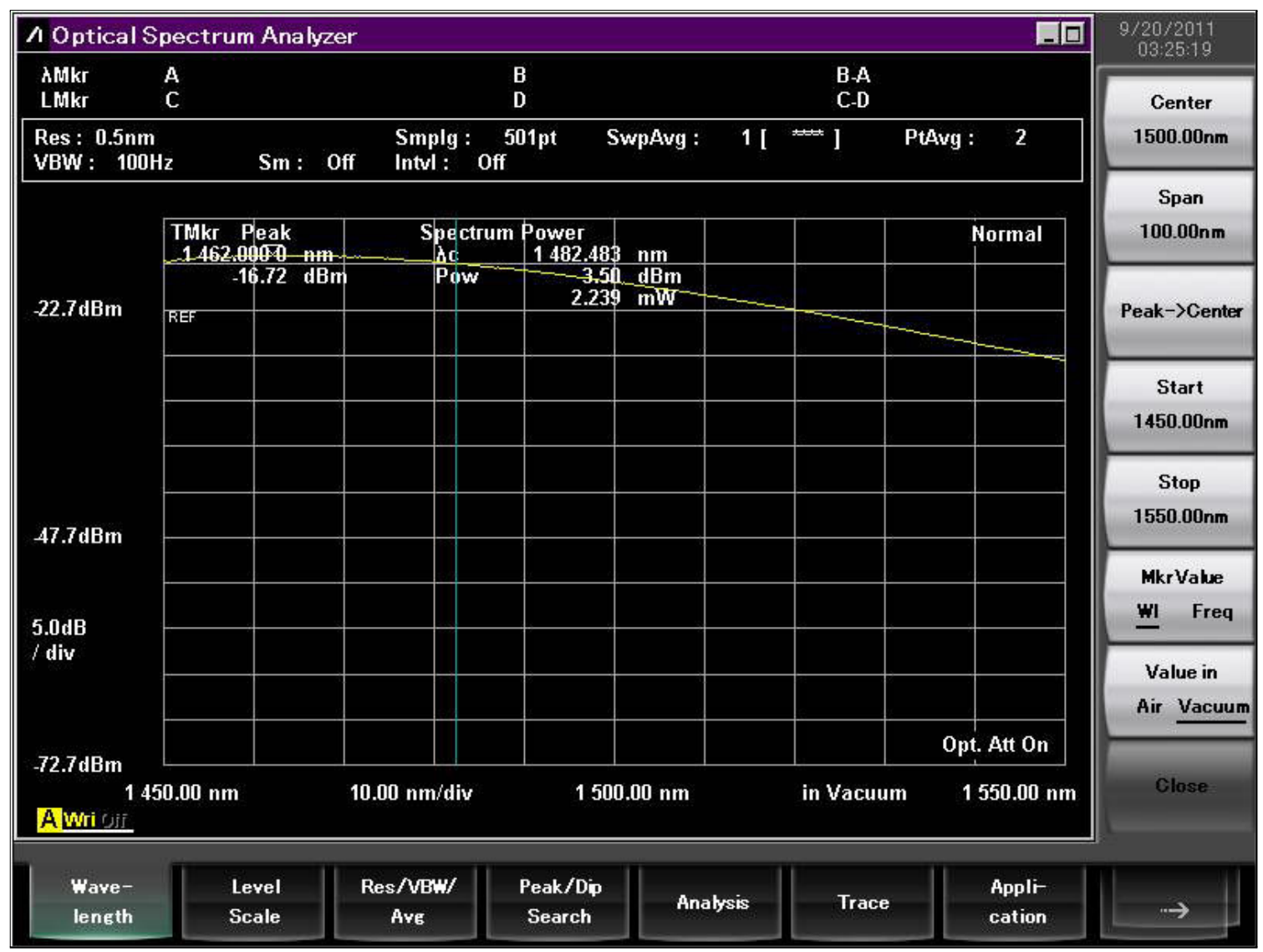

Figura 3.6: Espectro de ASE gerada pelo SOA de 1490nm alimentado com corrente de 200mA. Nota-se que o pico do perfil de ASE ocorre em torno de 1462nm.

Outra caracterização realizada consistiu na obtenção da potência de saída em função da corrente de injeção. Foram tomadas duas potências de entrada, -20dBm e -30dBm, para os comprimentos de onda de 1310nm e 1490nm. A Figura 3.7 mostra os resultados obtidos para o SOA de 1310nm e a Figura 3.8 para o de 1490nm. As linhas tracejadas representam o limite a partir do qual o amplificador produz ganho óptico para a potência de entrada de $-20 \mathrm{dBm}$. As linhas pontilhadas apresentam o limite para a potência de -30dBm. A partir destas linhas, pode-se concluir que o limiar de corrente para a produção de ganho é de $70 \mathrm{~mA}$ para o SOA de $1310 \mathrm{~nm}$ e $40 \mathrm{~mA}$ para o de $1490 \mathrm{~nm}$. 


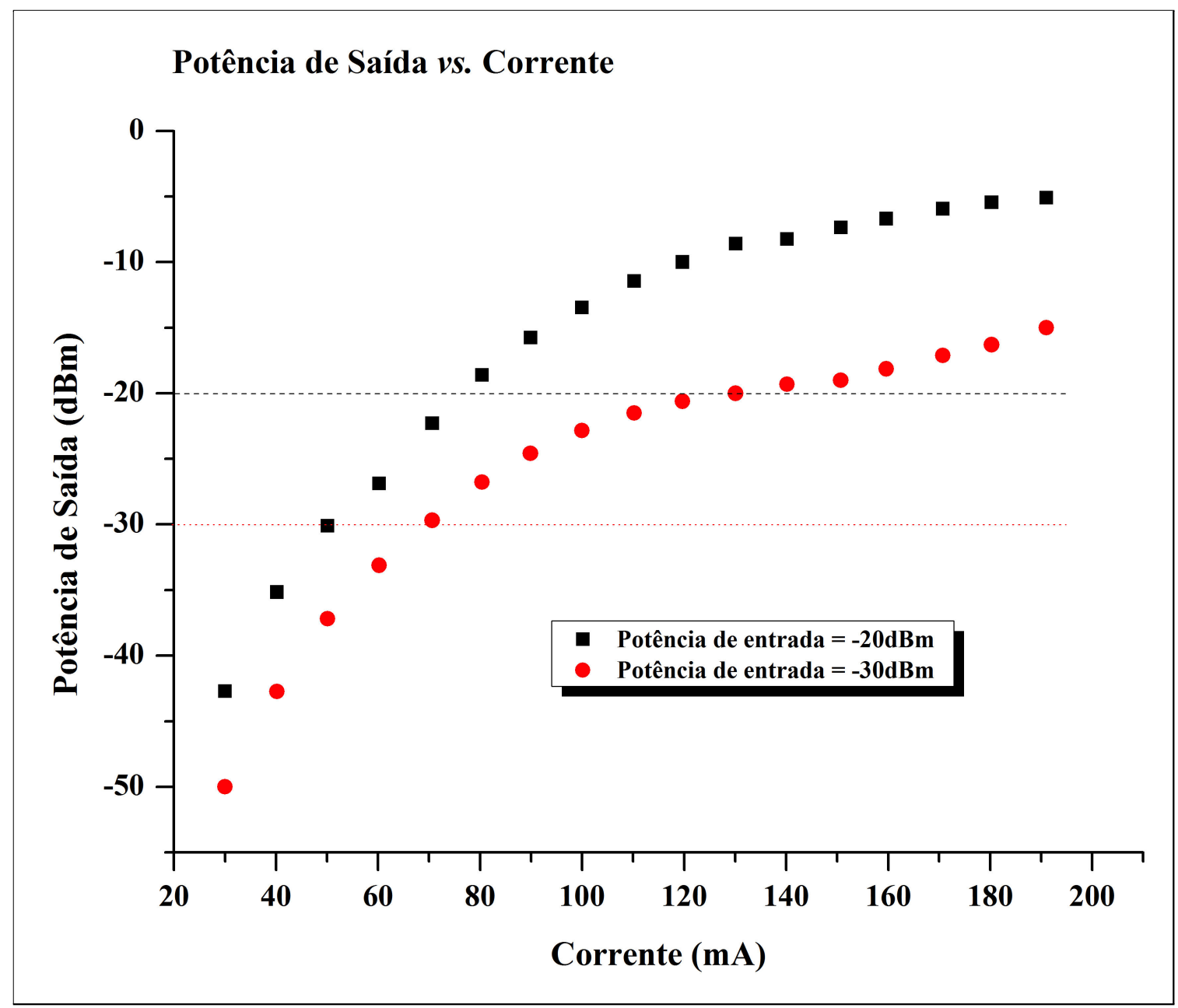

Figura 3.7: Potência de saída do SOA de 1310nm em função da corrente de injeção, para as potências de entrada de $-20 \mathrm{dBm}$ e $-30 \mathrm{dBm}$. As linhas tracejadas mostram o limite para o qual o ganho é positivo, para as duas potências de entrada. 


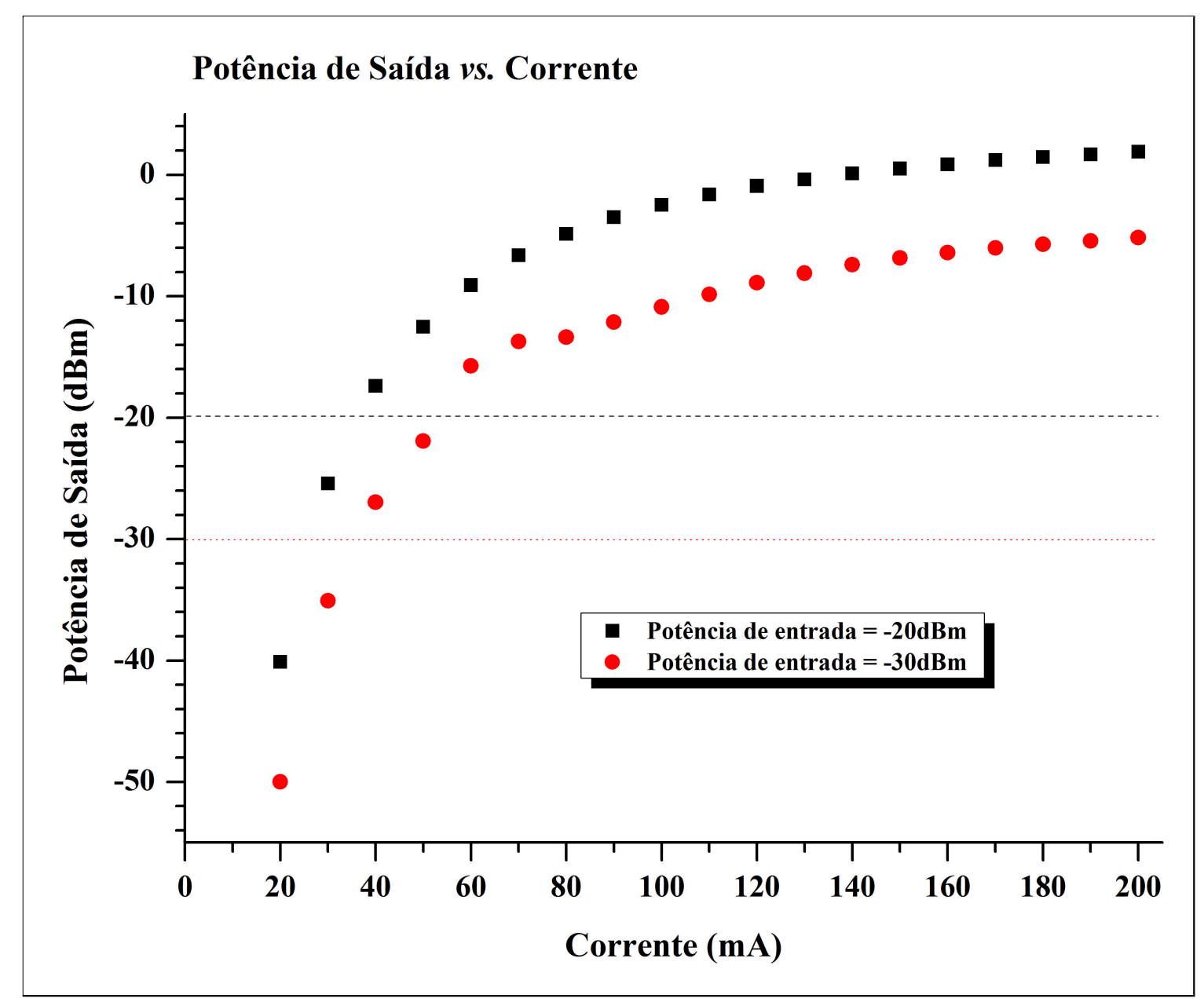

Figura 3.8: Potência de saída do SOA de 1490nm em função da corrente de injeção, para as potências de entrada de $-20 \mathrm{dBm}$ e $-30 \mathrm{dBm}$. As linhas tracejadas mostram o limite para o qual o ganho é positivo, para as duas potências de entrada.

O amplificador de 1310nm é utilizado nas configurações de amplificador de linha e pré-amplificador. Já o amplificador de 1490nm é utilizado para amplificação de linha e de potência. As razões para a utilização destas configurações específicas são econômicas. Em tais configurações, os custos de operação dos amplificadores serão divididos pelos usuários conectados a estes dispositivos, o que reduz o custo final a cada usuário. Esta é a motivação para a escolha dos cenários investigados. Entretanto, se os usuários possuírem amplificadores destinados apenas ao seu equipamento (pré-amplificação para downstream e amplificação de potência para upstream), cada um deles arcará totalmente com os gastos envolvidos na operação. As Figuras 3.9 e 3.10 mostram as arquiteturas investigadas. 


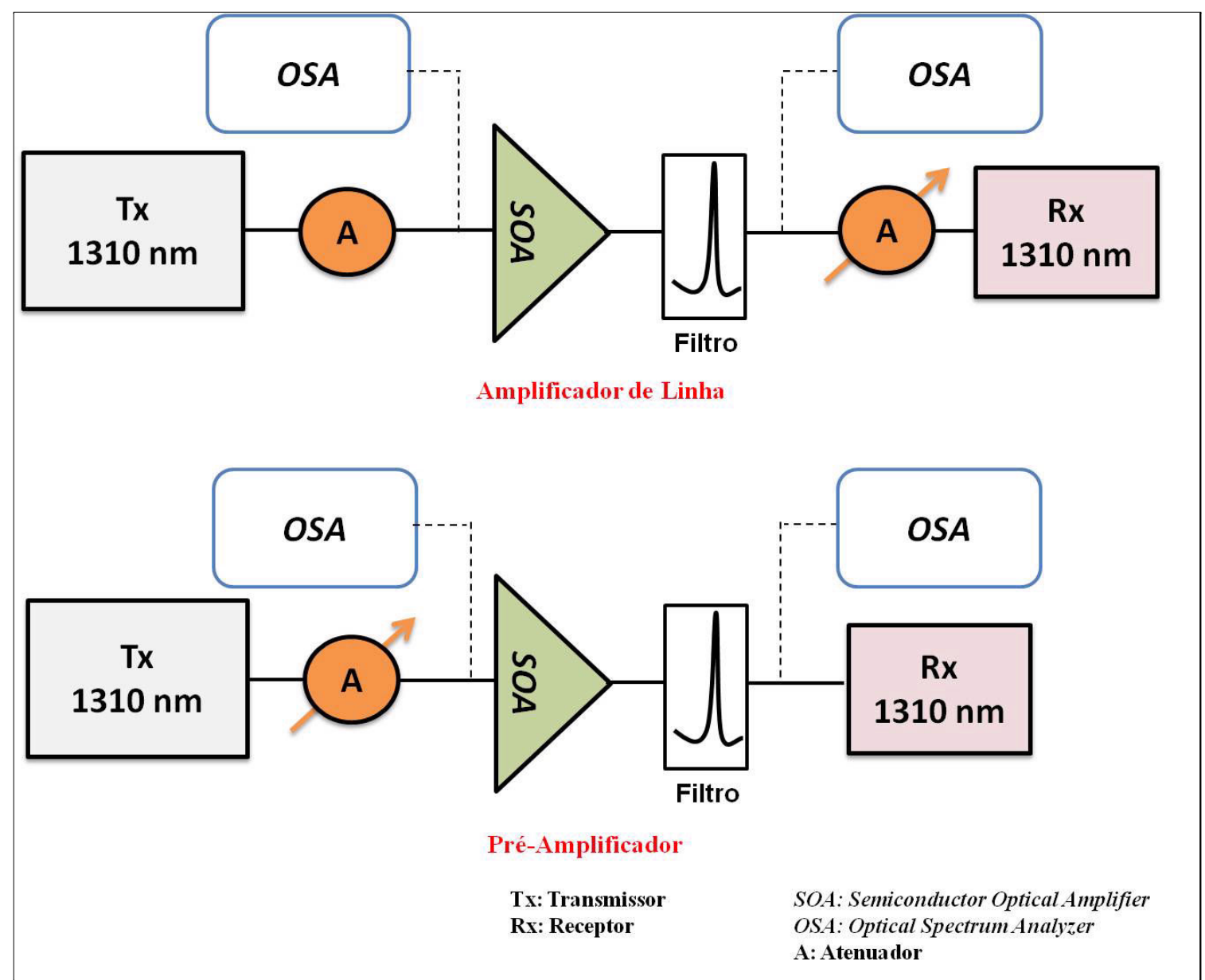

Figura 3.9: Representação esquemática das formas de amplificação investigadas para o SOA de $1310 \mathrm{~nm}$, utilizado no upstream. As duas formas investigadas são a pré-amplificação e amplificação de linha. 


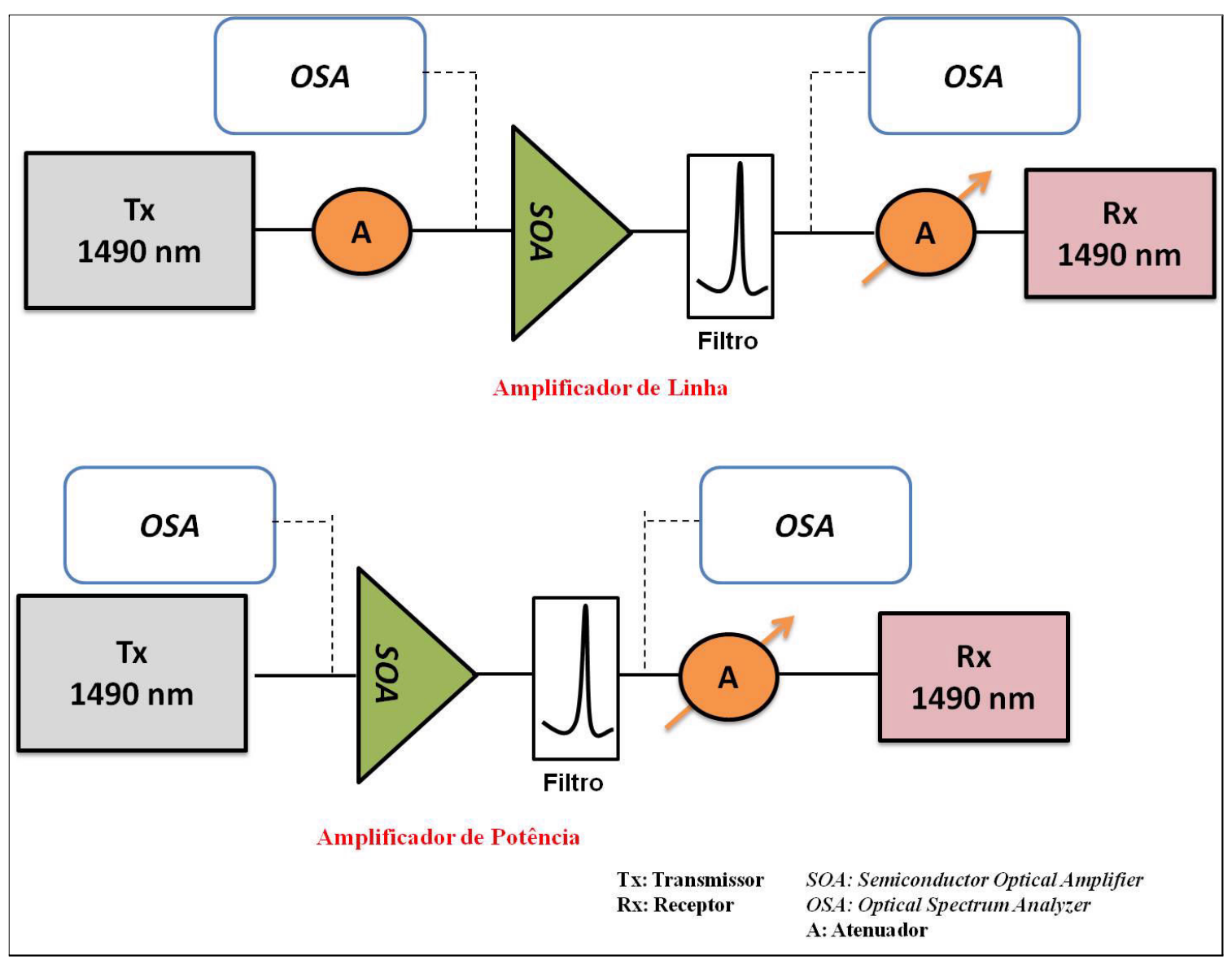

Figura 3.10: Representação esquemática das formas de amplificação para o SOA de 1490nm, utilizado no downstream. As duas formas de amplificação investigadas são a amplificação de linha e de potência.

Em cada uma destas arquiteturas foram realizados experimentos, com o objetivo de avaliar a taxa de erro de bit (Bit Error Rate - BER) utilizando fotodetectores do tipo PIN (P-Intrinsec- $N)$ e do tipo APD (Avalanche Photo Diode), na taxa de transmissão de 2,5Gbps, com uma seqüência aleatória de bits (Pseudo-Random Bit Sequence - PRBS) de $2^{23}-1$.

A Figura 3.11 mostra os dados experimentais obtidos para o SOA de 1310nm utilizando o fotodetector do tipo PIN, enquanto a Figura 3.12 apresenta os resultados obtidos para um receptor com fotodetector do tipo APD. Os dados representados com um quadrado preto são obtidos na condição Back-to-Back (BtB), isto é, existe apenas um atenuador variável entre o transmissor e o receptor. É possível notar que para a potência de entrada de $-20 \mathrm{dBm}$, o desempenho do sistema é bastante próximo à condição BtB, isto é, o que apresenta a menor penalidade de potência. Observa-se também que a utilização do SOA como pré-amplificador para um fotodetector do tipo PIN produz uma sensibilidade aproximadamente igual à do receptor 
com APD. Entretanto, a combinação do pré-amplificador com fotodetector APD não produz os mesmos resultados. Isto pode ser explicado devido à intensidade do nível de ruído de avalanche do APD, que amplifica o ruído de ASE detectado, levando à identificação incorreta dos bits transmitidos.

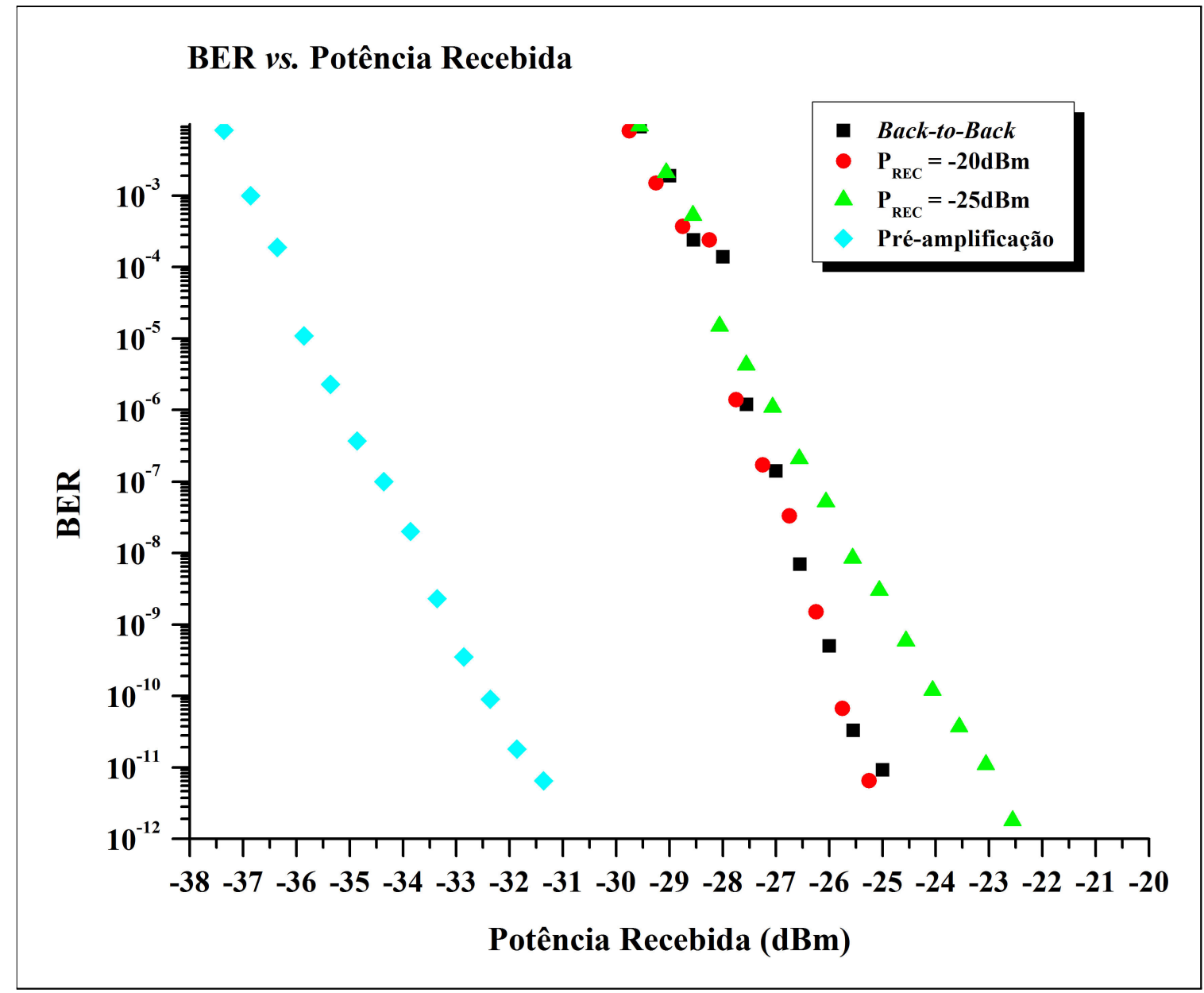

Figura 3.11: Taxa de erro de bit em função da potência incidente em um receptor do tipo PIN, para o SOA de 1310nm. São considerados dois regimes de amplificação de linha com potência de entrada de -20dBm e -25dBm, além da pré-amplificação. 


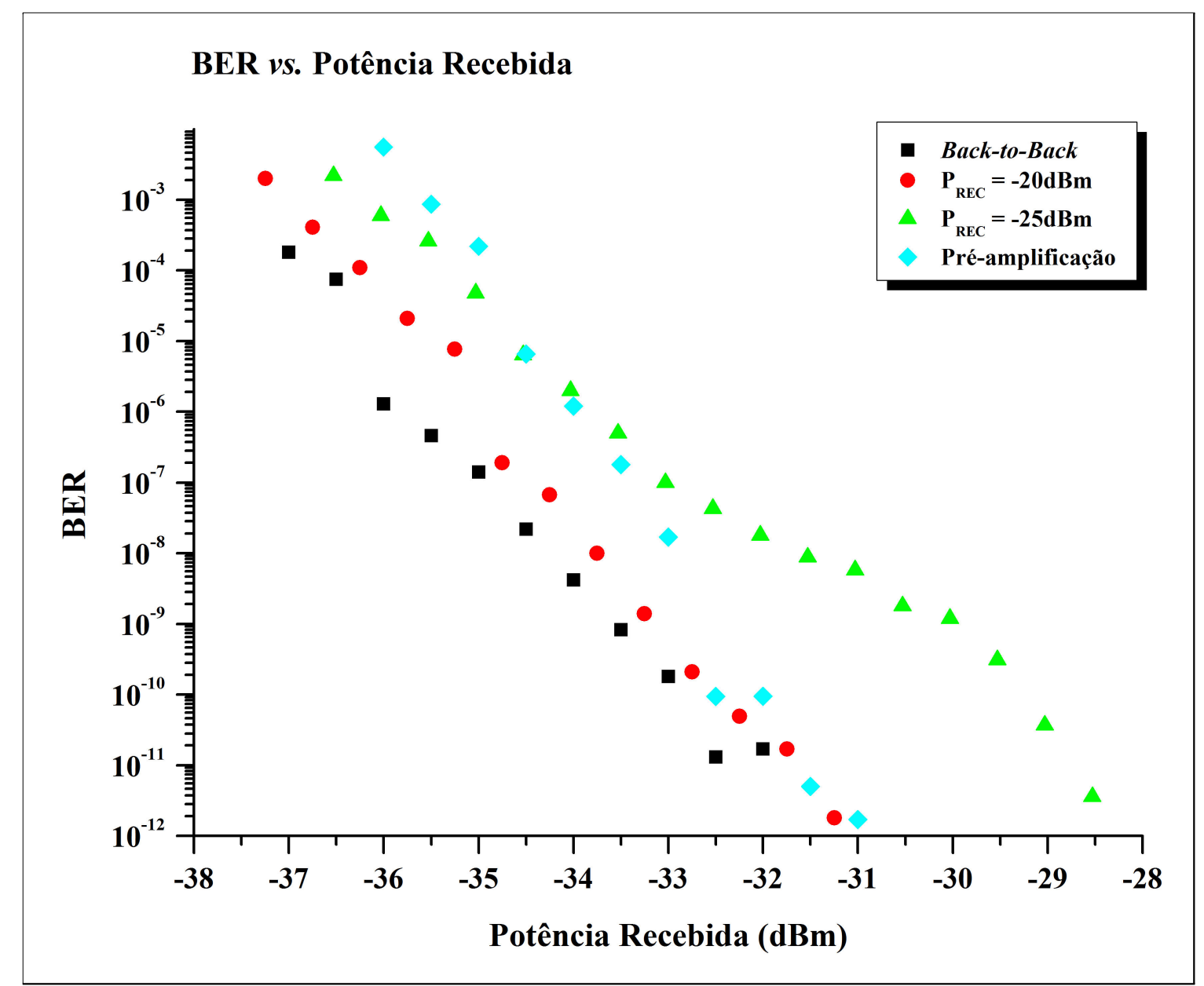

Figura 3.12: Taxa de erro de bit em função da potência incidente em um receptor do tipo APD, para o SOA de 1310nm. São considerados dois regimes de amplificação de linha com potência de entrada de $-20 \mathrm{dBm}$ e $-25 \mathrm{dBm}$, além da pré-amplificação.

Aplicando uma metodologia análoga, obtiveram-se resultados semelhantes para o SOA de 1490nm. Novamente, o sistema com a menor penalidade de potência foi aquele que possui potência de entrada de -20dBm, como mostrado nas Figuras 3.13 e 3.14. Já a amplificação de potência é o que apresenta a maior penalidade devido ao comportamento não-linear do SOA, uma vez que a potência de entrada no dispositivo é elevada. 


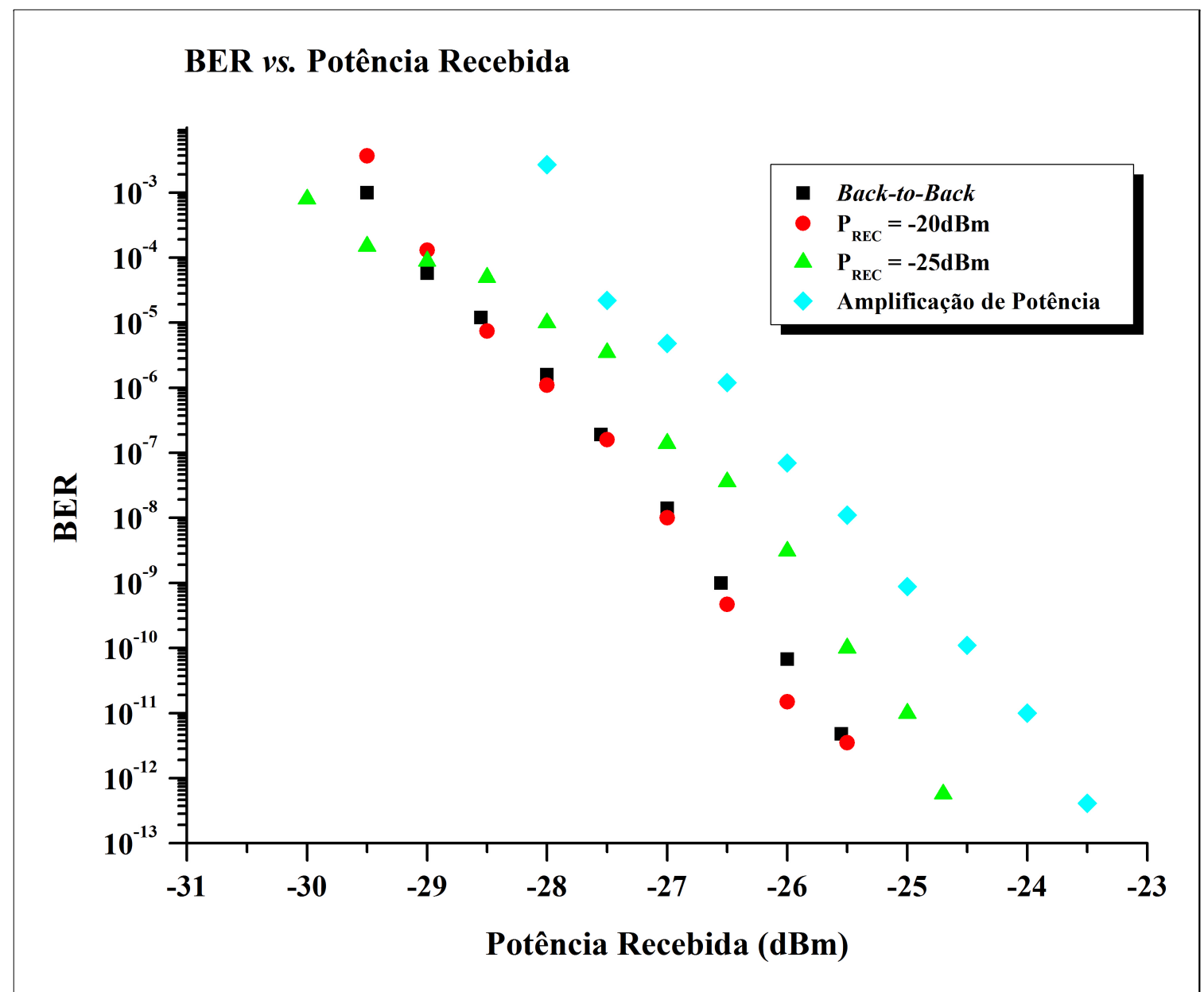

Figura 3.13: Taxa de erro de bit em função da potência recebida na entrada do SOA de 1490nm para um fotodetector do tipo PIN. Além da amplificação de potência, foram consideradas duas potências de entrada, $-20 \mathrm{dBm}$ e -25dBm, para a amplificação de linha. 


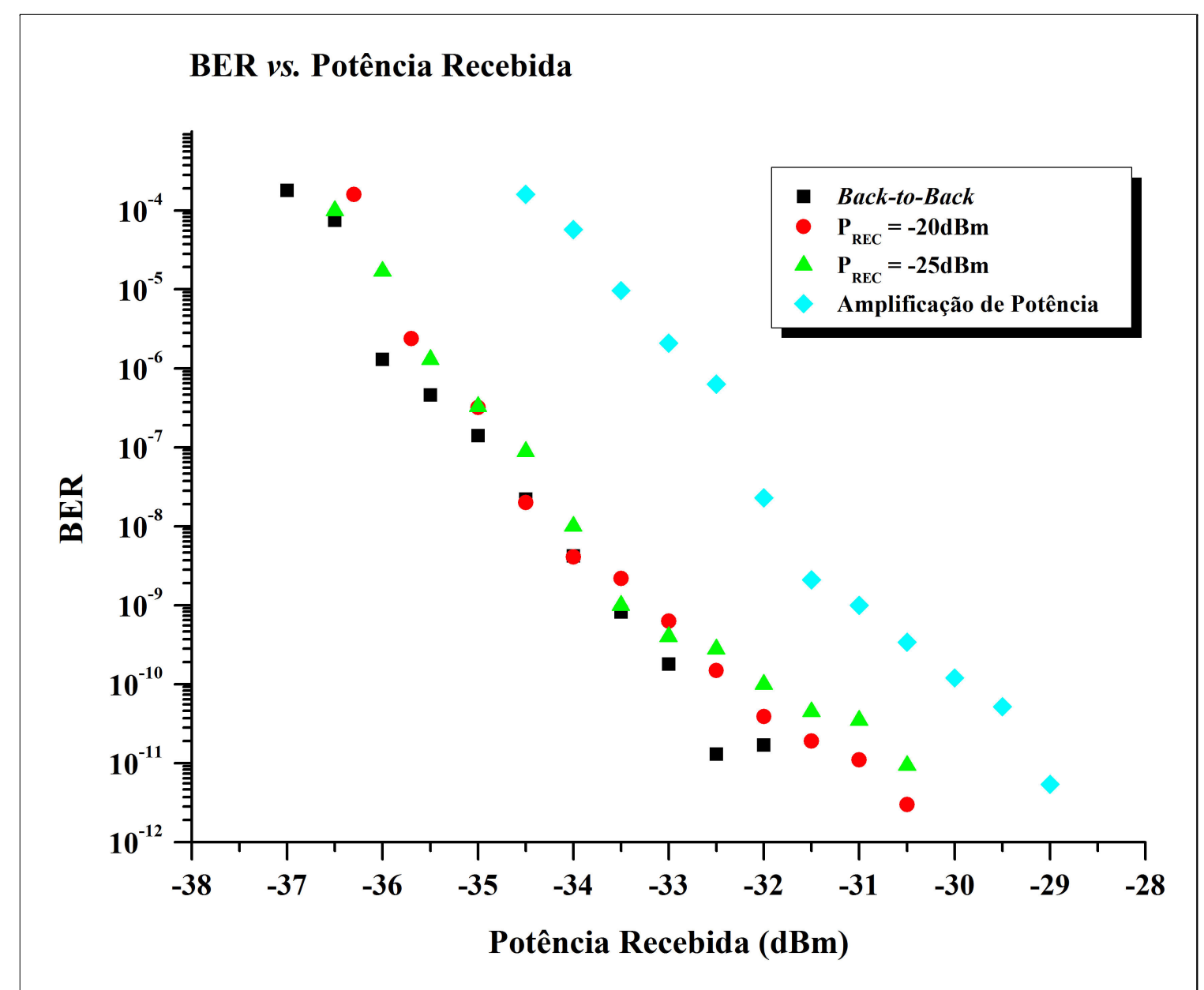

Figura 3.14: Taxa de erro de bit em função da potência recebida na entrada do SOA de 1490nm para um fotodetector do tipo APD. Além da amplificação de potência, foram consideradas duas potências de entrada, $-20 \mathrm{dBm}$ e $-25 \mathrm{dBm}$, para a amplificação de linha.

Até o momento, na avaliação de desempenho do sistema foi utilizado o tráfego em apenas um sentido. No entanto, é interessante avaliar também o desempenho do sistema considerando um tráfego bidirecional, ou seja, upstream e downstream simultaneamente. Para tal, realizaram-se alguns testes nos quais foi considerado um tráfego bidirecional e simétrico em 2,5Gbps, previsto em [24], porém somente em modo contínuo.

O primeiro teste consiste em avaliar o desempenho do sistema considerando a máxima distância, entre a central de serviço e o usuário, prevista em [24]. A Figura 3.15 ilustra genericamente o cenário investigado. Nota-se na Figura 3.15 a existência de um trecho de fibra de comprimento L1km, representando a Optical Trunk Line (OTL), em seguida o extensor contendo os dois SOAs, que por sua vez está conectado ao splitter $1 \mathrm{xN}$, o que determinará quantas ONUs 
poderão ser atendidas pela central de serviço. Por fim, entre o splitter e os usuários há um trecho de L2km de fibra, representando a Optical Distribution Network (ODN). Vale ressaltar que o comprimento L2 define também a máxima distância diferencial que é a máxima distância entre o usuário localizado mais próximo do OLT e o mais distante deste. As normas ITU-T G.984 definem a distância máxima de 60km entre OLT e ONUs, sendo divididos em $20 \mathrm{~km}$ de distribuição (L2) e 40km na região de tronco (L1) [24]. O divisor de potência foi de 1x32. Estes valores foram utilizados na avaliação experimental do extensor em um tráfego bidirecional em $1310 \mathrm{~nm}$ e $1490 \mathrm{~nm}$ e simétrico em 2,5Gbps. Os resultados de desempenho são mostrados na Figura 3.16.

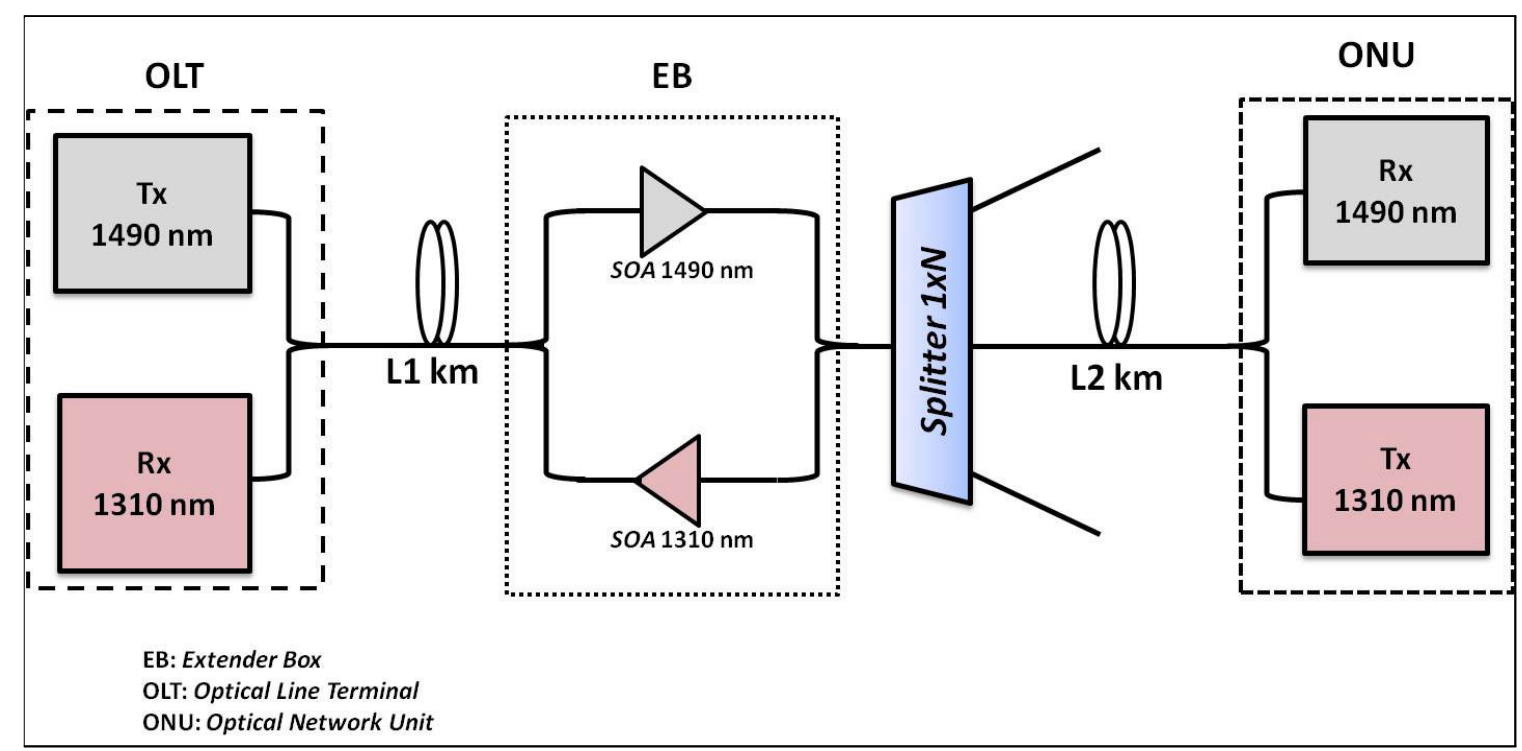

Figura 3.15: Ilustração do esquema utilizando a Extender Box para a extensão de um enlace do sistema GPON. 


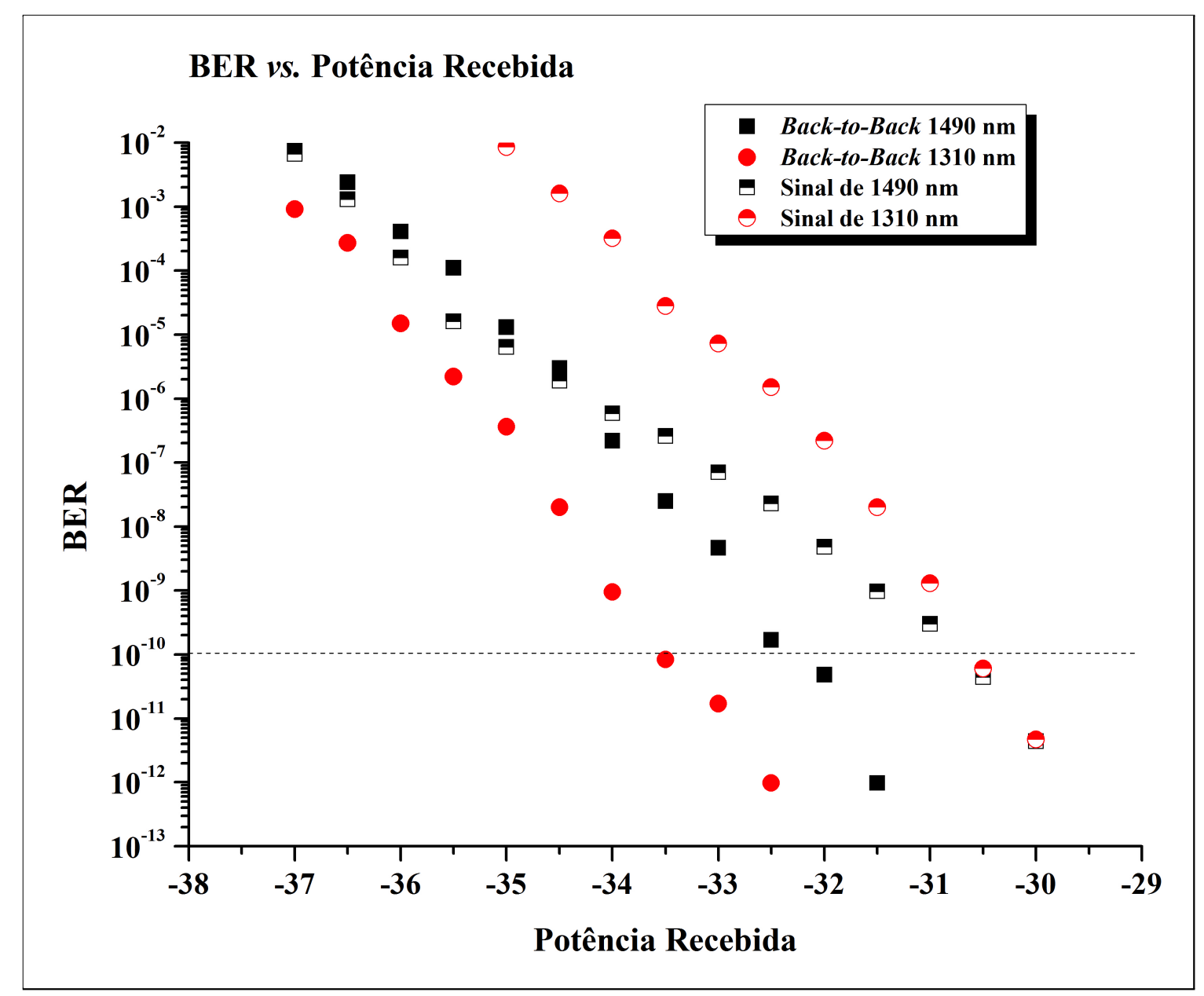

Figura 3.16: Taxa de erro de bit em função da potência recebida no fotodetector para um sistema de 2,5Gbps simétricos. No cenário descrito na Figura 3.15, o comprimento L1 possui $40 \mathrm{~km}$ de extensão enquanto o comprimento L2 tem $20 \mathrm{~km}$. O splitter utilizado foi de $1 \times 32$.

Posto que as normas regulamentadoras do padrão GPON prevêm uma banda óptica, para a transmissão do tráfego upstream, que vai desde 1260nm até 1360nm [24], também é interessante realizar um estudo investigando tais características, isto é, outros possíveis comprimentos de onda para a transmissão do usuário até a central. Para tal, o mesmo cenário anterior foi tomado como referência, sendo que os transmissores localizados nas ONUs foram trocados por lasers de 1290nm, 1310nm e 1330nm. Da mesma forma, o tráfego bidirecional e simétrico em 2,5Gbps foi mantido. A Figura 3.17 resume os resultados de desempenho atingido. 


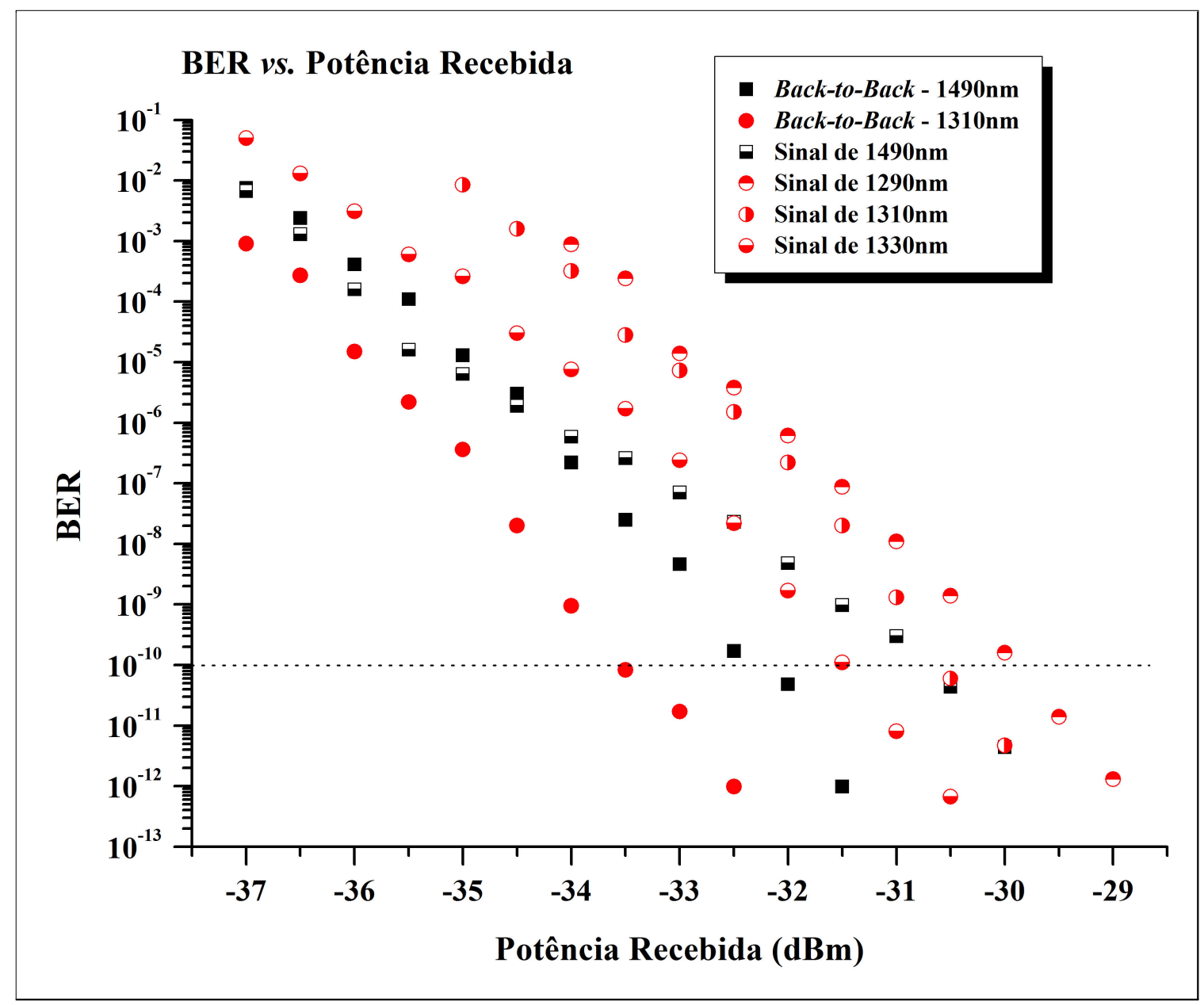

Figura 3.17: Taxa de erro de bit em função da potência recebida no fotodetector para um sistema de 2,5Gbps simétricos. No cenário descrito na Figura 3.15, o comprimento L1 possui 40km de extensão enquanto o comprimento L2 tem $20 \mathrm{~km}$. O splitter utilizado foi de 1x32. Para o tráfego upstream, foi transmitido apenas um comprimento de onda de cada vez.

Uma vez realizadas as caracterizações dos amplificadores e avaliados os possíveis impactos de sua introdução em sistemas ópticos, realizaram-se testes em um equipamento GPON convencional do $\mathrm{CPqD}$, onde o tráfego downstream é realizado em 2,5Gbps no comprimento de onda de 1490nm e a transmissão upstream ocorre no comprimento de onda de $1310 \mathrm{~nm}$ transportando 1,25Gbps, em modo rajada. A Figura 3.18 mostra o aparato experimental desta rede GPON utilizado em um laboratório do $\mathrm{CPqD}$.

Tendo-se em mente que a norma prevê uma distância de até $60 \mathrm{~km}$, sendo até $20 \mathrm{~km}$ de distância diferencial [24], e uma taxa de divisão de potência óptica de até 64, buscou-se atingir este cenário a partir da inserção do extensor baseado em SOAs em algum ponto ao longo do enlace. Os testes realizados tiveram como base a topologia descrita na Figura 3.15. 


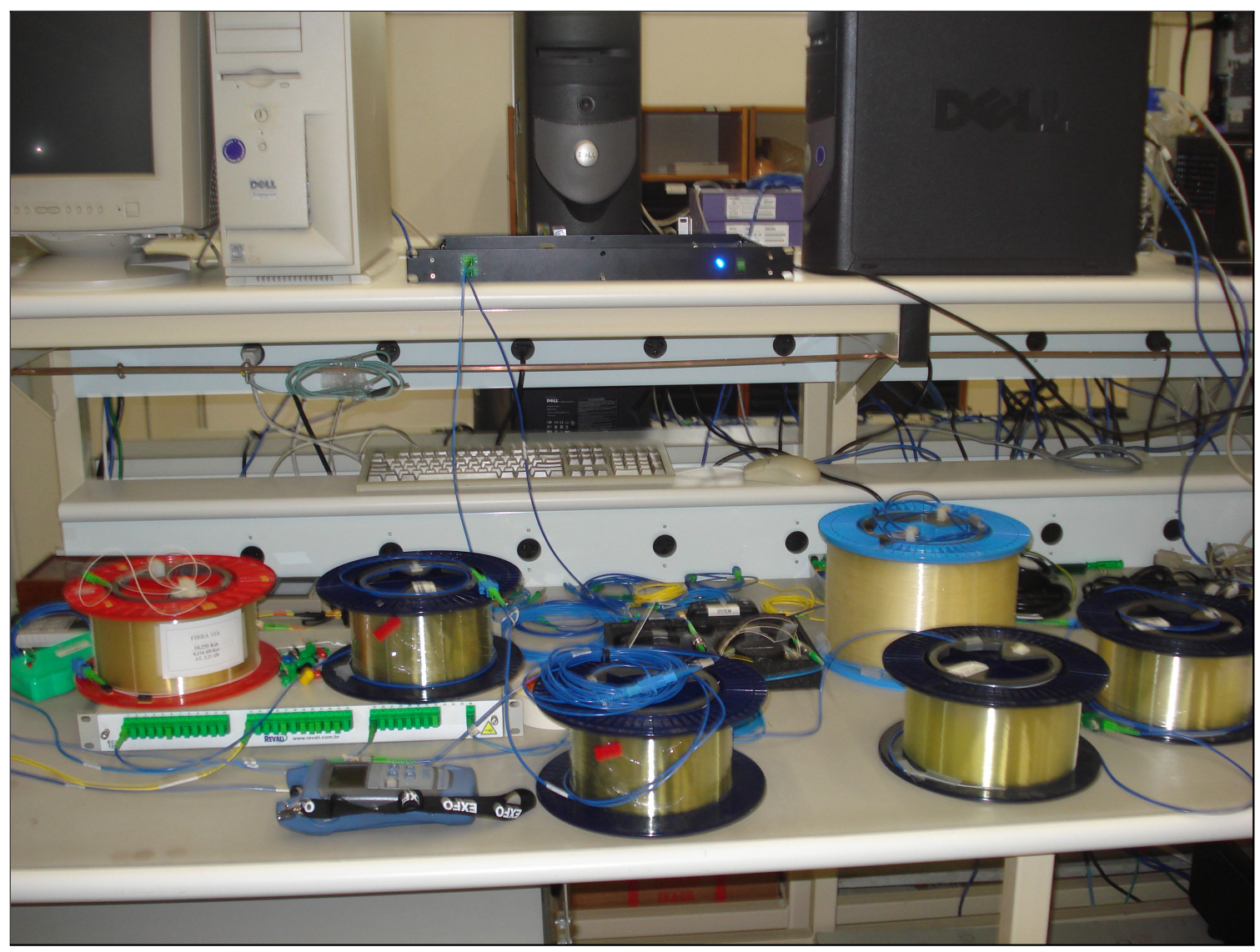

Figura 3.18: Foto do equipamento GPON do CPqD e aparato experimental utilizados na avaliação do extensor baseado em SOAs.

Com os SOAs configurados para a corrente de $200 \mathrm{~mA}$, primeiro teste realizado está representado na Figura 3.19. Foi inserido um carretel de $50 \mathrm{~km}$ de fibra na região de tronco, cujo objetivo era garantir que a potência de entrada no SOA de 1490nm estivesse baixa o suficiente garantindo que os efeitos não-lineares que ocorrem no regime de saturação não interferissem no desempenho do sistema. Em seguida, conectou-se um splitter de 1x64. Foram inseridos 10km na ODN, porém o sistema apresentou perdas sucessivas de pacotes. O comprimento da fibra de distribuição foi reduzido até o limite em que o sistema não apresentava perdas de pacotes, tendo sido obtido o comprimento de $2 \mathrm{~km}$ de ODN. Ainda na Figura 3.19, é possível observar os valores de potência total em cada um dos pontos numerados de 1 a 5 para ambos os sinais. É importante ressaltar que nenhuma alteração foi realizadas nos programas de gerenciamento e controle presentes no OLT do sistema. 


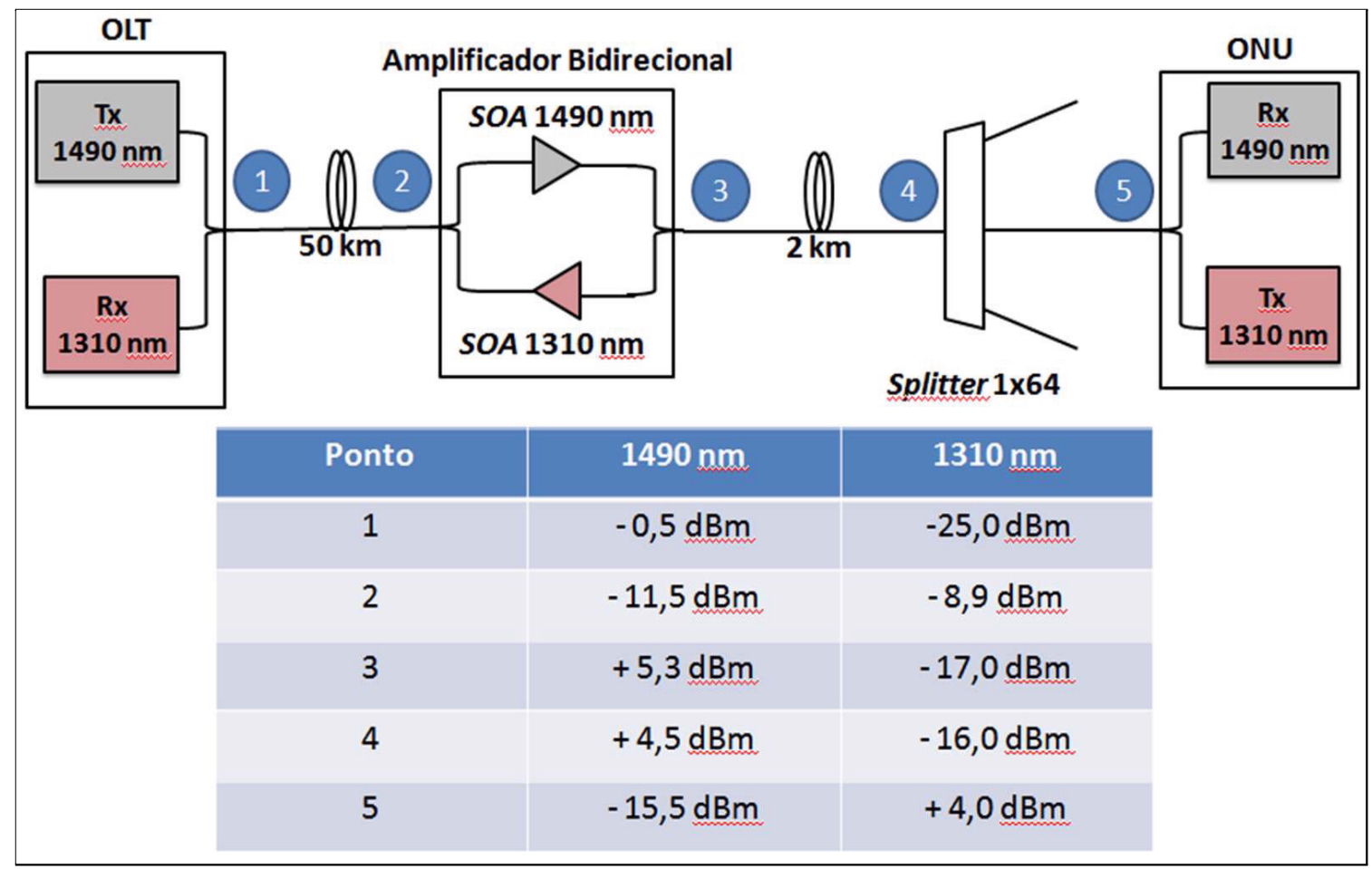

Figura 3.19: Representação esquemática do sistema GPON com os SOAs localizados ao longo do enlace (amplificação de linha). Os pontos numerados de 1 a 5 representam posições em que foram medidas as potências nos dois sentidos e que são mostradas na tabela abaixo da do esquema.

A partir da Figura 3.19 e considerando a atenuação do sinal de 1310nm como sendo 0,5 dB/km [56], pode-se concluir que o orçamento do enlace, para o tráfego upstream, é de 44dB (soma da atenuação total do sinal de 1310nm na fibra mais as perdas no divisor de potência) valor próximo ao reportado em [27] e idêntico ao valor reportado em [28], embora nesta última, os autores mantiveram a diferença de $15 \mathrm{~dB}$ entre orçamento de potência da ONU mais próxima e a mais distante. Portanto, caso seja do interesse da operadora da rede, é possível aumentar o número de usuários, desde que sejam respeitadas as especificações disponibilizadas em [24], bastando reduzir o comprimento do enlace.

Embora tenha sido possível aumentar o orçamento de potência em 16dB, de $28 \mathrm{~dB}$ para $44 \mathrm{~dB}$, buscou-se explorar os limites desta extensão. Para tanto, foi necessária uma reconfiguração no software de gerenciamento das ONUs presente no equipamento GPON do CPqD, tendo sido configurado um tempo máximo de reposta de $50 \mu$ s e um tempo máximo de propagação, denominado Round Trip Delay (RTD) que é o tempo medido no OLT entre o envio da mensagem de interrogação para cada ONU e suas respectivas mensagens de resposta, de $800 \mu$ s. Além disto, 
foram introduzidas mais duas ONUs, porém, por simplicidade, apenas aquela que apresenta o orçamento de potência mais crítico será mostrada. Com tais janelas temporais, o OLT é capaz de gerenciar as ONUs que estiverem conectadas a ele dentro da distância máxima de 84km.

A cada ONU foi atribuído o tráfego de 1000 ethernet frames por segundo, sendo que cada frame possui 128 bytes. Os testes tiveram duração de 3 horas de modo que fosse garantida uma estatística confiável, isto é, que a BER máxima seja menor que $1,0_{X} 10^{-10}$, conforme [24]. Para realizar a conversão da perda de pacotes do tráfego ethernet em termos da BER, utilizaramse os procedimentos descritos em [65] e em [66]. Estes procedimentos se baseiam na equação abaixo:

$$
F L R=1-(1-B E R)^{L}
$$

onde $F L R$ é a porcentagem de pacotes perdidos, $B E R$ é a taxa de erro de bit e $L$ é o comprimento em bits do quadro ethernet.

A primeira configuração testada sob esta nova condição consistiu em elevar o comprimento da fibra de OTL para $60 \mathrm{~km}$, reduzindo ainda mais a potência de entrada no SOA de 1490nm, o que garante que os efeitos não-lineares não interfiram no desempenho do sistema. Além disto, o comprimento da fibra na ODN foi alterado para $20 \mathrm{~km}$, que é o limite previsto pela norma G.984.2 [24]. Em contrapartida, o número de usuários atendidos, isto é, a razão de divisão de potência óptica foi reduzida para 1x32. A Figura 3.20 ilustra a arquitetura obtida. Neste cenário, todos os pacotes enviados foram recebidos corretamente.

Como a região de distribuição atingiu o comprimento máximo previsto e a taxa de divisão de 1x32 representa um valor típico, buscou-se elevar a taxa de divisão de potência óptica para 1x64. Porém, nesta condição, 60km +1 x64 $+20 \mathrm{~km}$, o sistema apresentou perda de pacotes de $0,09 \%$ ou, de maneira equivalente [65] a partir da equação 3.1 , com uma BER de $8,8_{X} 10^{-7}$, inviabilizando o sistema.

Mantendo-se a mesma taxa de divisão de potência e aumentando-se a região de tronco para $70 \mathrm{~km}$, reduziu-se a ODN até se obter um sistema sem perdas de pacotes. O comprimento obtido foi de $14 \mathrm{~km}$, resultando numa configuração de $70 \mathrm{~km}+1 \mathrm{x} 64+14 \mathrm{~km}$ sem que o sistema apresentasse perda de pacotes. A Figura 3.21 mostra a topologia obtida. 


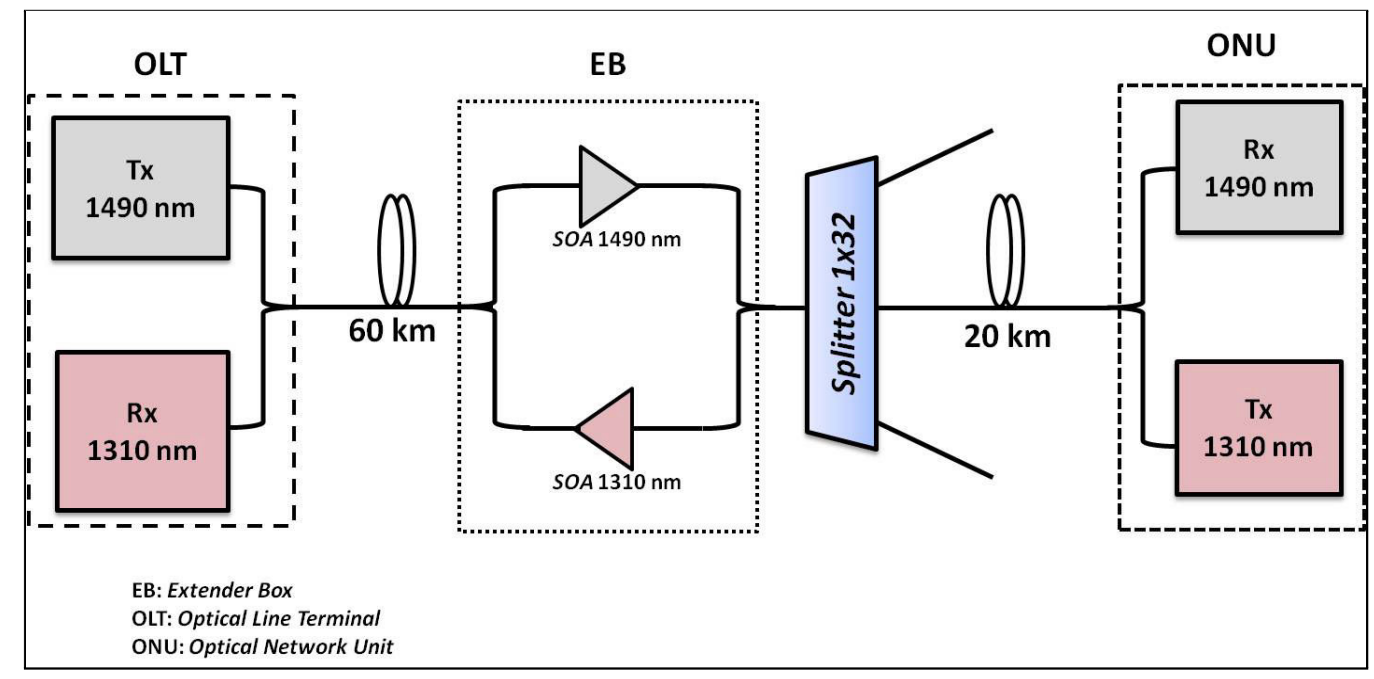

Figura 3.20: Representação esquemática mantendo a distância diferencial de $20 \mathrm{~km}$ e a taxa de divisão de potência óptica de 1x32. A fibra de tronco foi fixada em $60 \mathrm{~km}$.

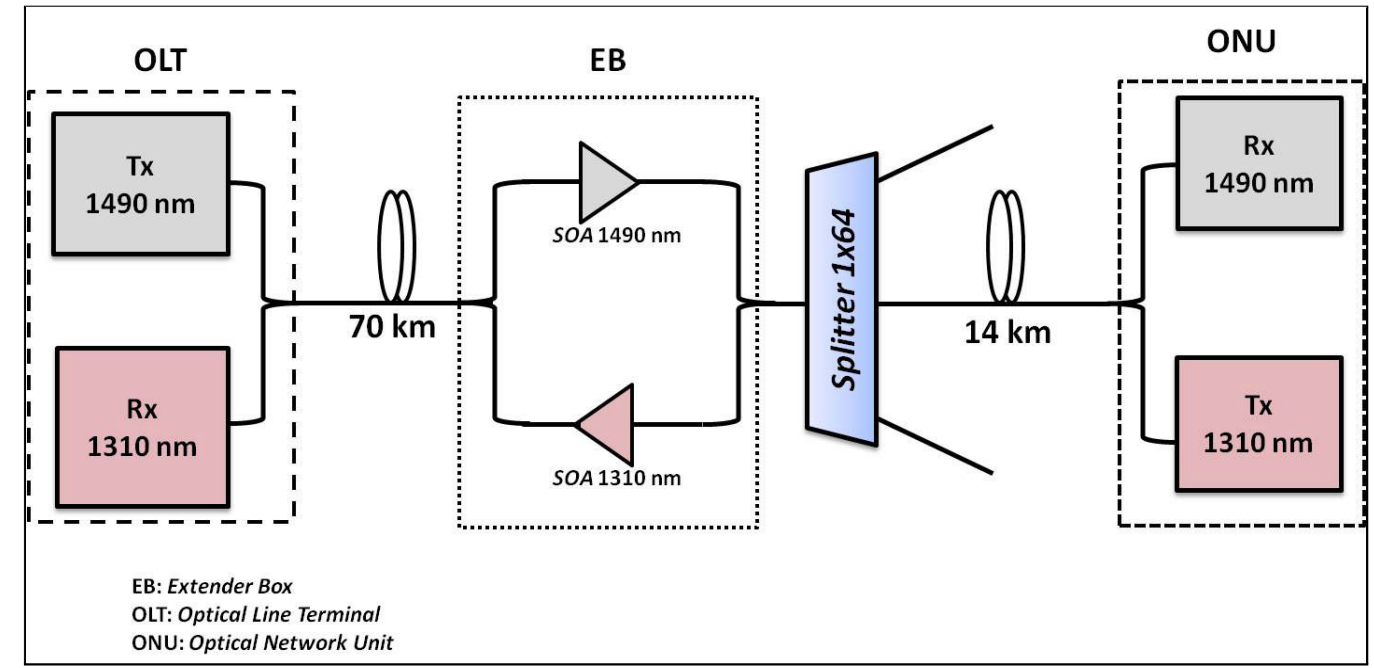

Figura 3.21: Utilização do extensor como um mid-span extender para GPON. A distância total obtida foi de $84 \mathrm{~km}$ e a taxa de divisão da potência foi 1x64.

Até o momento, o extensor foi utilizado como extensor de linha, ou seja, os SOAs presentes dentro do extensor são considerados amplificadores de linha, por estarem posicionados ao longo do enlace. Entretanto, estas arquiteturas transformam a rede passiva em rede ativa, uma vez que é necessário fornecer alimentação elétrica aos amplificadores que estão posicionados como amplificadores de linha, e, portanto, em algum ponto ao longo do enlace [29]. Uma maneira de garantir que a rede permaneça passiva, mesmo com a inserção dos amplificadores é posicionando, 
no OLT, o amplificador para o downstream como amplificador de potência e o amplificador para o upstream como pré-amplificador.

Com o objetivo de se obter uma arquitetura passiva, o extensor foi colocado antes do splitter e retirou-se a fibra da região de distribuição, de modo que todo o enlace esteja localizado no fibra de tronco.

A partir da Figura 3.21 , a fibra de $14 \mathrm{~km}$ na ODN foi retirada. Sob esta condição o sistema não apresentou perda de pacotes. A fibra da OTL foi aumentada para $80 \mathrm{~km}$ e a taxa de divisão de potência foi mantida em 1x64. O sistema não apresentou perda de pacotes. Mantendo a OTL fixa em 80km, aumentou-se a taxa de divisão para 1x128. Este sistema, 80km $+1 \times 128+0 \mathrm{~km}$, não apresenta perda de pacotes. A Figura 3.22 mostra a arquitetura obtida. Tal arquitetura pode ser interessante na utilização de um esquema do tipo Fiber-to-the-Building (FTTB), posto que o divisor de potência e os amplificadores podem ser localizados em algum armário localizado em um prédio onde 128 usuários serão atendidos [68], [69].

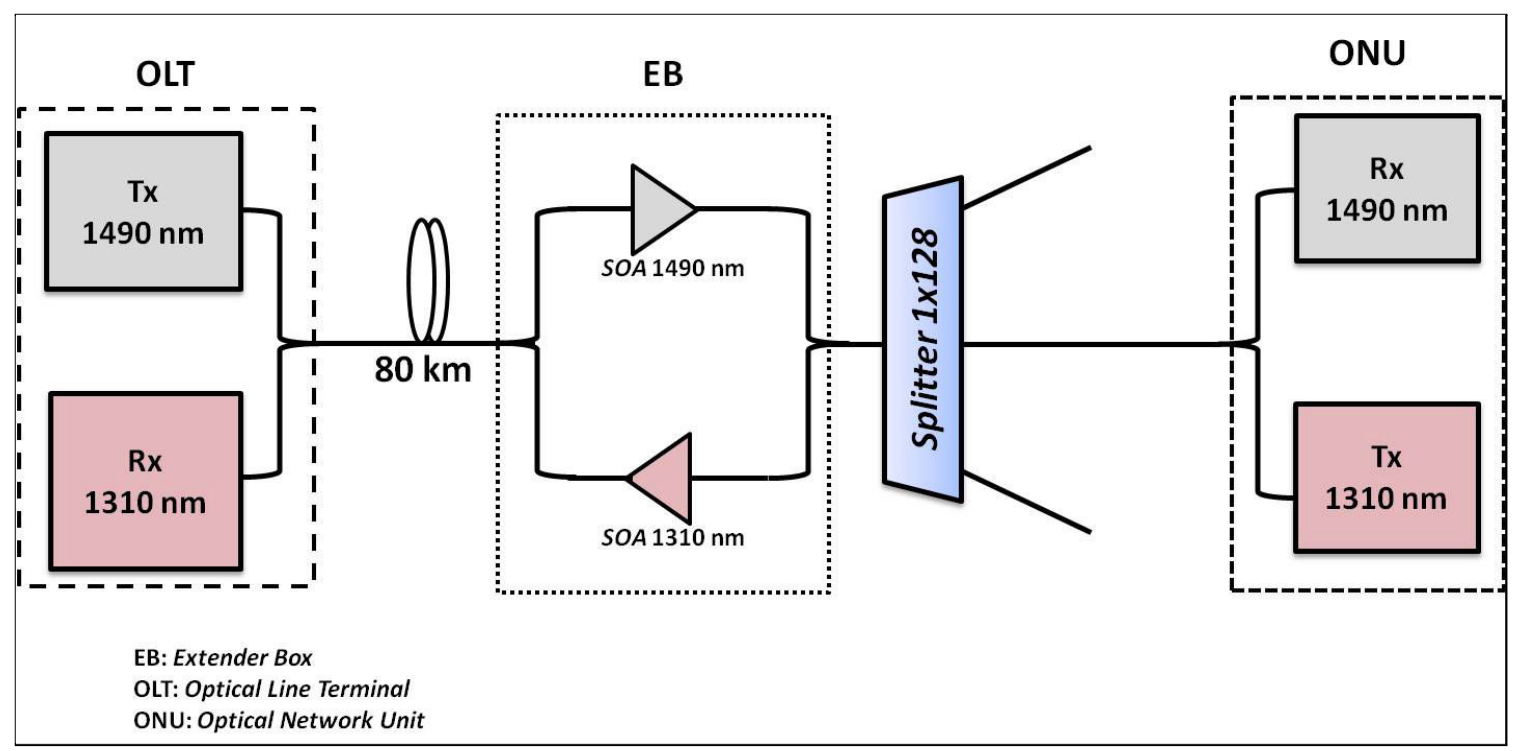

Figura 3.22: Representação esquemática do uso da EB num sistema GPON. Como todos os usuários estão a uma mesma distância do splitter, é possível a inserção do divisor de potência e do extensor num sistema do tipo FTTB (Fiber-to-the-Building). 


\subsubsection{Simulação Computacional dos Parâmetros dos Amplificadores Ópticos Semicondutores}

Esta seç̧ão consiste na avaliação computacional de amplificadores ópticos semicondutores com características otimizadas, por exemplo, figura de ruído e potência de saturação, cujo objetivo é uma previsão teórica de possíveis topologias que tenham esses SOAs como extensores. São apresentadas ainda algumas formas de otimização dessas características.

Inicialmente, será realizada a configuração e comparação dos amplificadores simulados com os que foram utilizados nos experimentos da seção anterior, visando à calibração do programa. Em seguida, serão avaliados os efeitos no orçamento de potência gerados pela introdução destes amplificadores semicondutores otimizados.

Os SOAs utilizados são amplificadores ópticos cujo meio de amplificação consiste em material semicondutor do tipo bulk [40], [41]. Novas tecnologias estão surgindo, como SOAs de quantum-dots, de modo que os dispositivos que as utilizarão produzirão ganhos mais elevados e menores níveis de ruído, como demonstrado em [67].

Tendo explorado algumas possíveis arquiteturas utilizando um extensor baseado em amplificadores ópticos semicondutores, investigou-se, a partir do simulador, um extensor composto por SOAs com diferentes características de potência de saturação, no caso do SOA de 1490nm, e figura de ruído para o SOA de 1310nm em relação aos que foram utilizados nos experimentos.

As simulações computacionais foram realizadas no software OptiSystem, desenvolvido pela empresa canadense Optiwave. O programa é um software do tipo CAD (Computer-Aided Design), que permite que seus usuários planejem, testem e simulem enlaces ópticos na camada de transmissão de redes ópticas. Dispõe de várias opções de componentes, ópticos e elétricos, presentes em suas bibliotecas, que tornam possível a configuração específica de diversos dispositivos e equipamentos. Cada um destes componentes possui vários parâmetros configuráveis conforme os objetivos de cada projeto [70].

Primeiramente, para validar o simulador, isto é, garantir que o programa está configurado corretamente, foram simulados os cenários das Figuras 3.20 a 3.22, que já haviam sido avaliadas experimentalmente. A simulação é considerada correta, refletindo a ausência de perda de pacotes, se a taxa de erro for menor ou igual a $1,0_{X} 10^{-10}$, conforme a recomendação ITU G.984.2, página 5 [24].

A Figura 3.23 mostra as janelas de transmissão das três ONUs. Todas as janelas 
temporais são iguais. A ONU2 será configurada como a ONU mais crítica do sistema, isto é, ela será a ONU posicionada à maior distância da central.

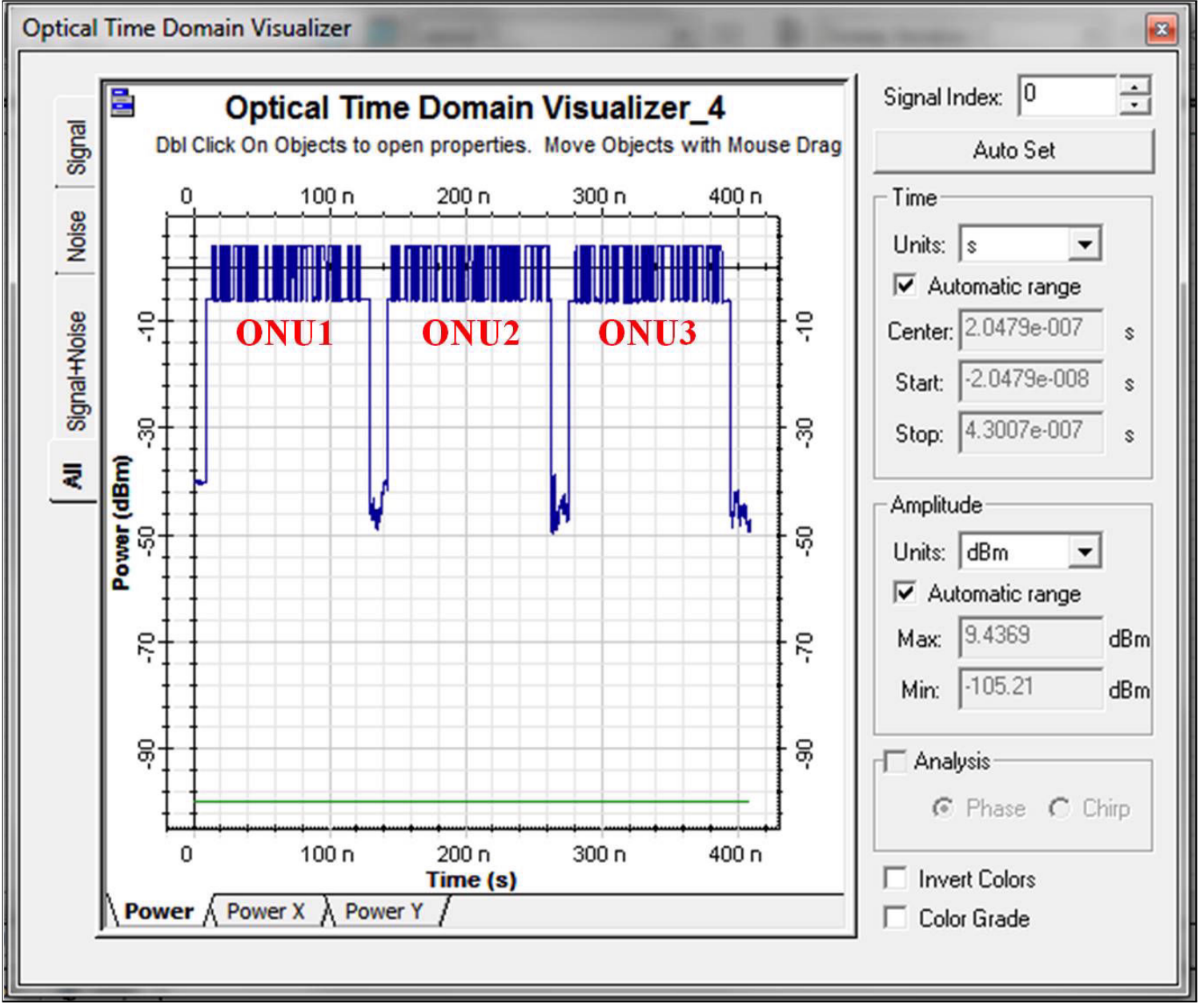

Figura 3.23: Janelas de transmissão de cada uma das ONUs. Foram atribuídas janelas temporais iguais a cada uma das ONUs.

As Figuras 3.24 e 3.25 mostram os espectros de ASE experimental e simulado para os dois amplificadores, de modo a calibrar corretamente o software de simulação. Basicamente, para garantir essa calibração, foram alterados os valores padrão fornecidos pelo programa. Os parâmetros modificados, a partir de [39], foram o valor de energia de bandgap, tendo sido considerado que o meio de ganho é constituído por $\mathrm{Ga}_{0,47} \mathrm{In}_{0,53} \mathrm{As}_{y} \mathrm{P}_{1-y}$, que para o SOA de $1310 \mathrm{~nm}$ $(\mathrm{y}=0,58)$ foi de $0,96 \mathrm{eV}$ e fator de confinamento de 0,4 e para o amplificador de $1490 \mathrm{~nm}(\mathrm{y}=$ $0,8) 0,84 \mathrm{eV}$ e 0,38 , respectivamente [38], [71] e [72]. 


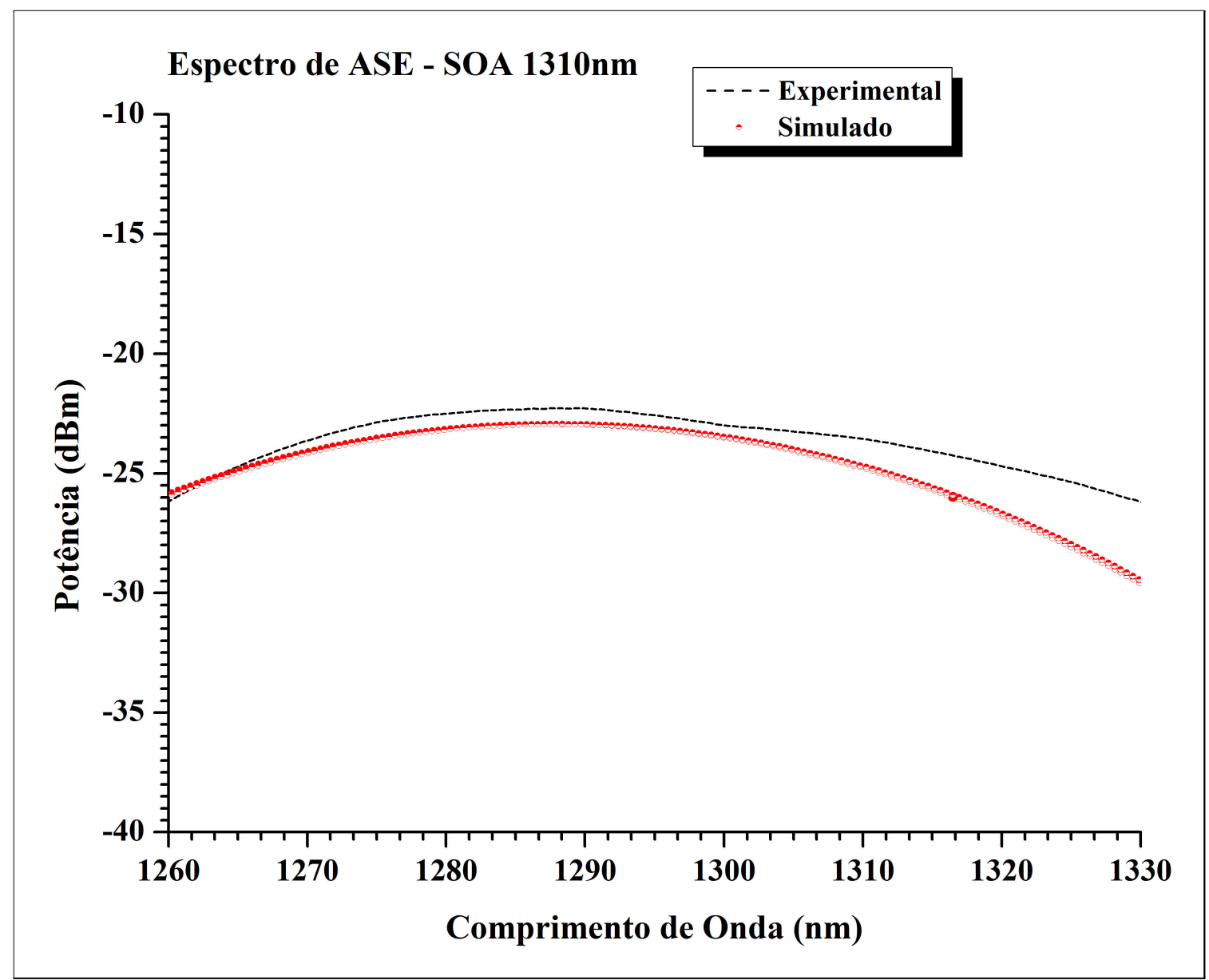

Figura 3.24: Espectros de ASE experimental e simulado para o SOA de 1310nm, sob corrente de $200 \mathrm{~mA}$. 


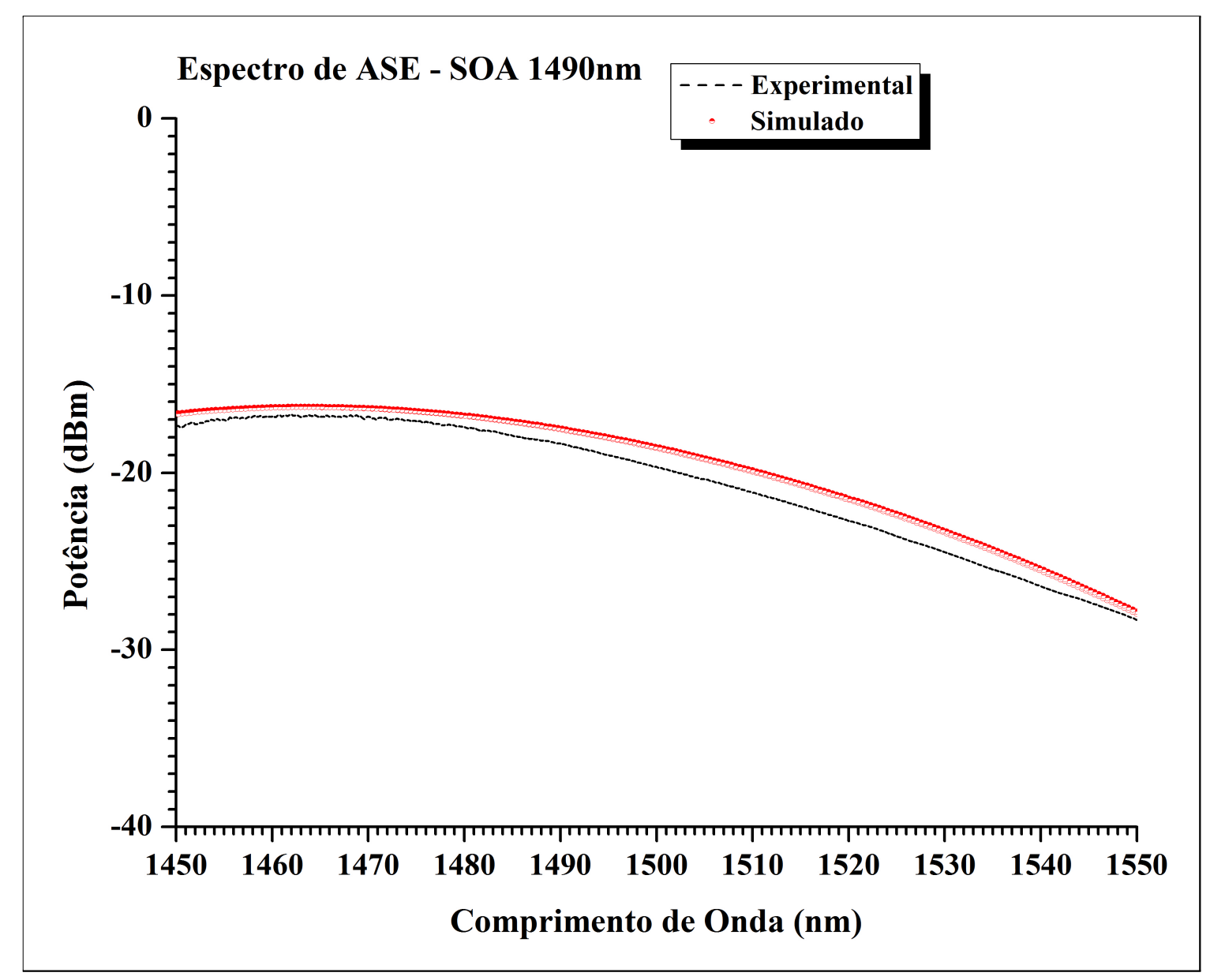

Figura 3.25: Espectros de ASE experimental e simulado para o SOA de 1490nm, alimentado com corrente de $200 \mathrm{~mA}$.

Configurados os tráfegos de downstream e upstream, bem como os amplificadores ópticos, sem otimização, avaliou-se a taxa de erro de bit para as arquiteturas das Figuras 3.20 a 3.22. No cenário referente à Figura 3.20, a BER referente ao tráfego downstream foi de $2,44_{X} 10^{-26}$. Já a taxa de erro de bit para o tráfego do usuário para a central foi de $9,82_{X} 10^{-12}$. No cenário apresentado na Figura 3.21, as taxas de erro de bit foram $1,2_{X} 10^{-29}$ e $2,86_{X} 10^{-11}$ para downstream e upstream, respectivamente. E, finalmente, para o cenário da Figura 3.22, o tráfego da central para o usuário apresentou uma BER de $4,41_{X} 10^{-41}$, ao passo que a BER do upstream foi de $7,34_{X} 10^{-11}$.

A obtenção de amplificadores com características otimizadas depende da modificação de alguns parâmetros disponíveis no software. Para obter uma figura de ruído reduzida, deve-se reduzir a perda de acoplamento na face de entrada do SOA [73], cujo valor padrão no programa 
é $3 \mathrm{~dB}$, conforme [38]. Assim, reduzindo-se a perda de acoplamento na entrada para $0,1 \mathrm{~dB}$, foi possível obter uma figura de ruído da ordem de $5 \mathrm{~dB}$, sob a mesma condição que aquela mostrada na Figura 3.3. Já a elevação da potência de saturação pode ser obtida através da redução do fator de confinamento como abordado em [38] e [73]. A partir da Figura 3.4, obtém-se que a potência de saturação é da ordem de $6 \mathrm{dBm}$. Reduzindo-se o fator de confinamento para 0,3 , a potência de saturação aumenta para, aproximadamente, 10dBm. Em conseqüência, o ganho é reduzido com a redução deste fator. Portanto, para se obter o mesmo ganho obtido anteriormente, é necessário que a corrente injetada no dispositivo aumente [38]. Outra alternativa é projetar o amplificador para operação em comprimentos de onda menores que o desejado [74]. Este projeto deve levar em conta o fato de que a elevação da corrente de injetada desloca o espectro para comprimentos de onda menores [75].

Tendo-se otimizado os amplificadores, investigou-se quais seriam os limites possíveis de ser atingidos, tomando-se como referência a arquitetura mostrada na Figura 3.15. Mantendo-se a taxa de divisão de potência em 1x64, foi possível atingir 100km, sendo $60 \mathrm{~km}$ para o comprimento L1 e 40km para o comprimento L2, obtendo-se BER de $8,99_{X} 10^{-11}$ para upstream e $1,43_{X} 10^{-12}$ para downstream. Deve-se notar que nesta configuração, a distância diferencial foi elevada em $20 \mathrm{~km}$, passando de $20 \mathrm{~km}$ para $40 \mathrm{~km}$. Aumentando-se a taxa de divisão para 1x256, foi necessário reduzir o comprimento L1 de $60 \mathrm{~km}$ para $30 \mathrm{~km}$, resultando numa arquitetura de $30 \mathrm{~km}+1 \times 256$ $+40 \mathrm{~km}$, com taxas de erro de $2,67_{X} 10^{-10}$ para o tráfego do usuário para a central e $7,5_{X} 10^{-11}$ da central para o usuário.

\subsection{EDFAs como Extensores}

Na seç̧̃̃o anterior, foram mostrados os resultados obtidos com o uso de SOAs para extensão do alcance de sistemas GPON. Nesta seção, serão realizadas investigações teóricas (computacionais) visando à investigação de alternativas, com a utilização de EDFs bombeadas remotamente, de modo a garantir o caráter passivo da rede, ainda atingindo a extensão desejada.

Os primeiros resultados apresentados serão aqueles já parcialmente mostrados na Seç̧ão 2.2.2, que serviram para compreensão do funcionamento do programa.

Inicialmente, foi estudado, no software OptiSystem, o comportamento do componente que simula uma fibra dopada com érbio configurada para atuar como a EDF - R37003, disponibilizada pela empresa OFS [76]. A Figura 3.26 mostra o componente no OptiSystem com suas 
principais características, que podem ser encontradas na Tabela 3.1. A configuração do componente foi feita com base nos trabalhos de P. Aljaff [77] e F. Mahad [78]. E foram utilizados os mesmos parâmetros disponibilizados em [76].

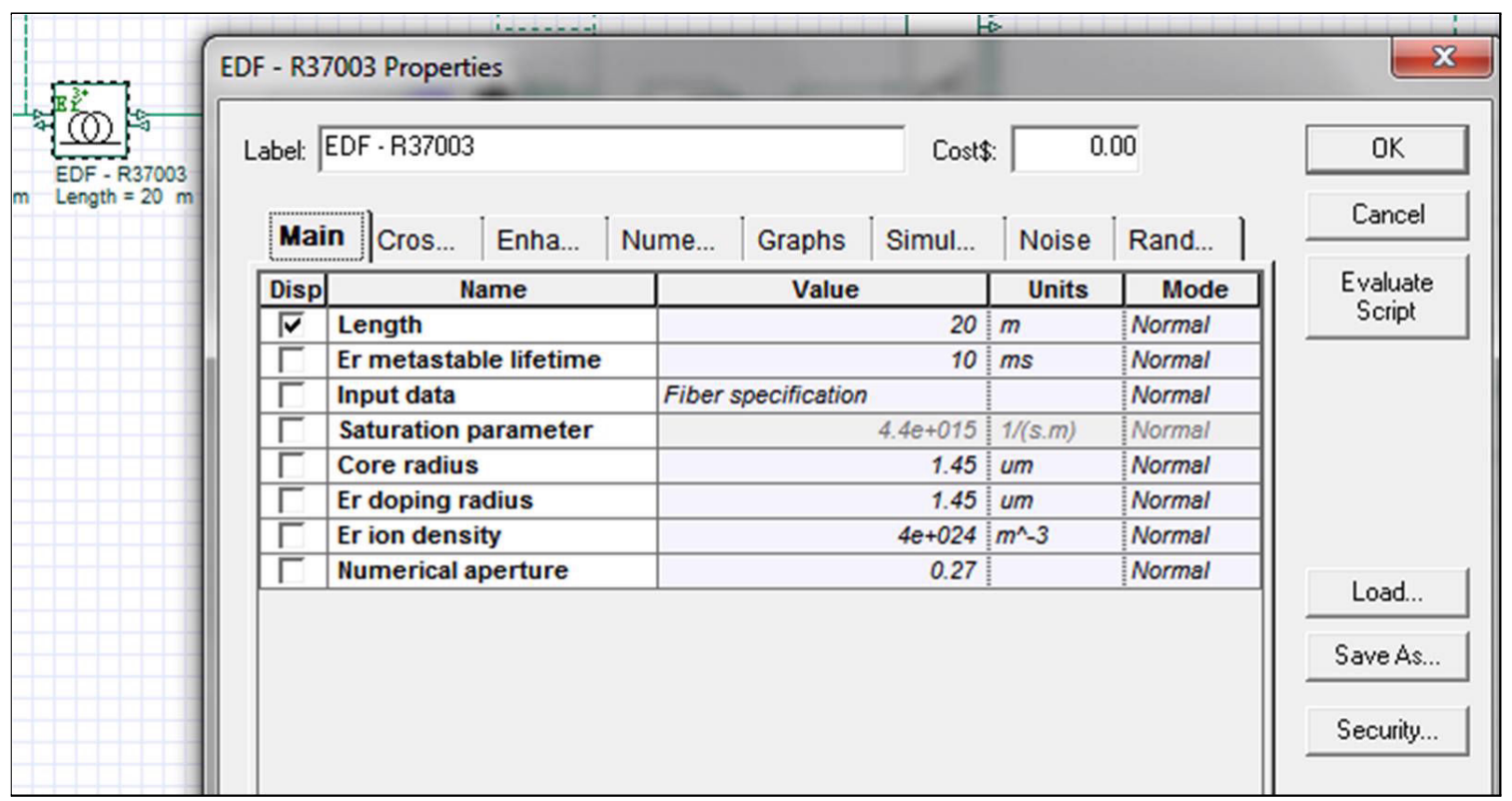

Figura 3.26: Componente, disponível no programa, representando uma fibra dopada com érbio. A caixa de diálogo ao lado do componente mostra os principais parâmetros utilizados pelo software para proceder as simulações. Estes parâmetros são os mesmos indicados em [35].

Os lasers de bombeio utilizados operam em $980 \mathrm{~nm}$ ou $1480 \mathrm{~nm}$ em esquemas co ou contra-propagante, cujas configurações estão representados nas Figuras 3.27 e 3.28, respectivamente. Entretanto, como o objetivo do trabalho é utilizar o bombeio remoto com as fontes ópticas localizadas na central de serviço, apenas as configurações co-propagante serão estudadas.

Tomando-se o esquema representado na Figura 3.27, configurou-se o transmissor emitindo 0dBm em 1550nm e que está conectado a um atenuador variável para que a potência de sinal incidente sobre a EDF seja alterada, permitindo a obtenção do ganho em função da potência de entrada. O sinal e o bombeio são introduzidos na fibra dopada através da configuração de um componente híbrido que contém um isolador e o acoplador bombeio/sinal, seguindo as especificações fornecidas em [79]. Posicionando-se um analisador de espectro óptico (Optical Spectrum Analyzer - OSA) entre o atenuador variável conectado ao transmissor e o segundo isolador, é possível obter as potências do bombeio, do sinal e do ruído, permitindo que o ganho do sinal seja calculado corretamente, de acordo com a equação 2.1. A Tabela 3.2 sumariza os parâmetros utilizados para os componentes apresentados nas Figuras 3.27 e 3.28. 


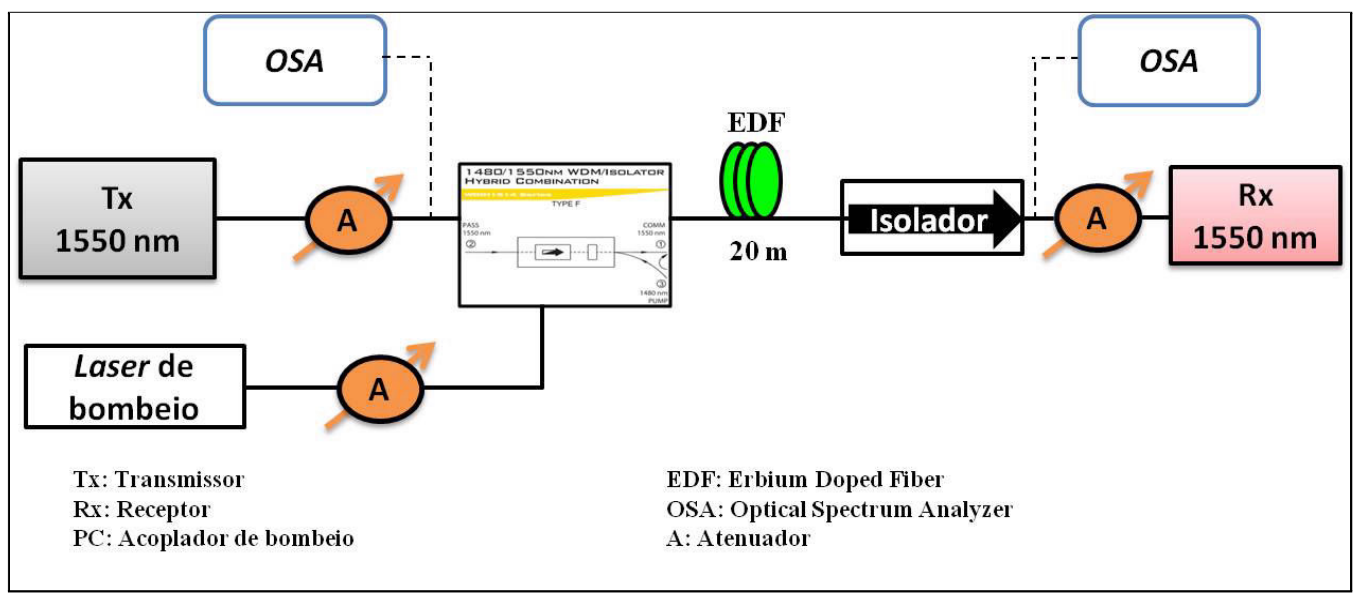

Figura 3.27: Representação esquemática de um amplificador de fibra dopada com érbio. O esquema de bombeio é co-propagante. O transmissor emite no comprimento de onda de $1550 \mathrm{~nm}$ e o laser de bombeio pode emitir em $980 \mathrm{~nm}$ ou $1480 \mathrm{~nm}$, conforme discutido na secção 2.2.4.

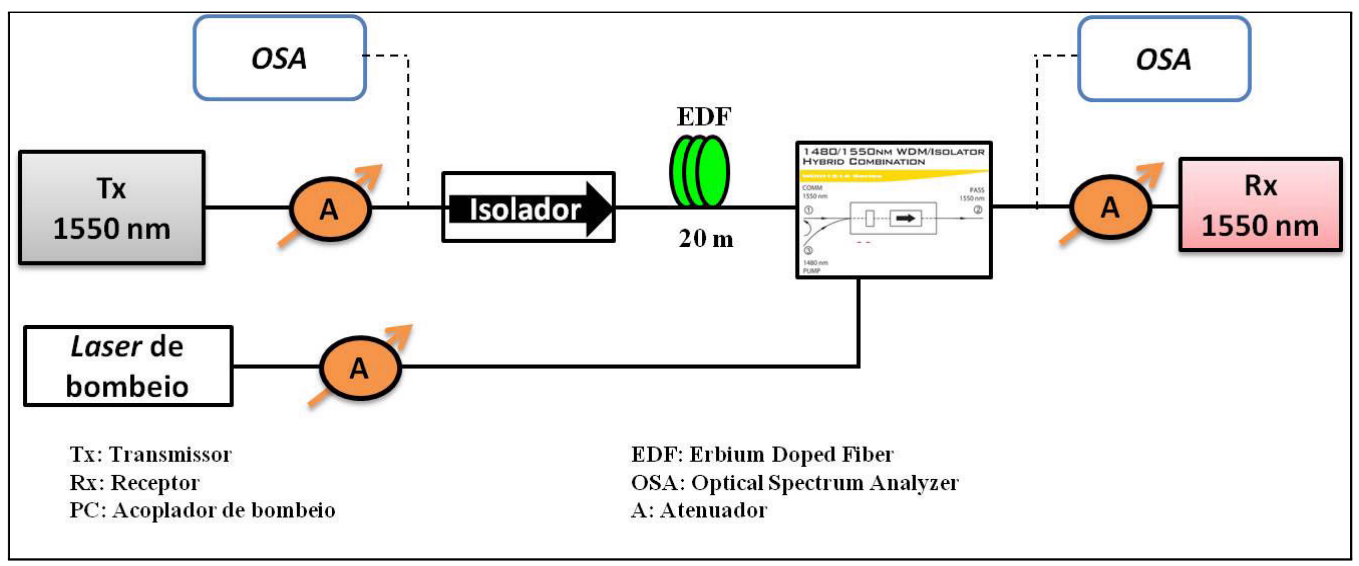

Figura 3.28: Representação esquemática de um amplificador de fibra dopada com érbio. O esquema de bombeio é contra-propagante. O transmissor emite no comprimento de onda de $1550 \mathrm{~nm}$ e o laser de bombeio pode emitir em $980 \mathrm{~nm}$ ou $1480 \mathrm{~nm}$, conforme discutido na secção 2.2.4. 


\begin{tabular}{|c|c|}
\hline Comprimento da fibra dopada $(\mathrm{m})$ & 20 \\
\hline Tempo de vida dos elétrons no nível metaestável $(\mathrm{ms})$ & 10 \\
\hline Raio do núcleo $(\mu \mathrm{m})$ & 1,45 \\
\hline Raio do núcleo dopado com érbio $(\mu \mathrm{m})$ & 1,45 \\
\hline Densidade de íons de érbio $\left(\mathrm{m}^{-3}\right)$ & $4,0 \times 10^{24}$ \\
\hline
\end{tabular}

Tabela 3.1: Principais parâmetros utilizados na simulação da fibra dopada com érbio.

\begin{tabular}{|c|c|}
\hline Potência do transmissor (dBm) & 10 \\
\hline Comprimento de onda do sinal (nm) & 1550 \\
\hline Potência do laser de bombeio 980 nm ou 1480 nm (mW) [80] & 400 \\
\hline Perda de inserção dos isoladores/acopladores (dB) [79] & $0,9 / 0,5$ \\
\hline Resolução dos analisadores de espectro (nm) & 0,5 \\
\hline
\end{tabular}

Tabela 3.2: Parâmetros dos componentes utilizados na caracterização da fibra dopada com érbio mostrada nas Figuras 3.26 e 3.27

As Figuras 3.29 e 3.30 mostram, para os bombeios de 980nm e 1480nm respectivamente, a variação do ganho e figura de ruído como função da potência de entrada para o esquema da Figura 3.27, tendo-se três valores de potência de bombeio, a saber $10 \mathrm{~mW}, 100 \mathrm{~mW}$ e $400 \mathrm{~mW}$. Nota-se que o ganho obtido para o bombeio de $980 \mathrm{~nm}$ é maior que o ganho gerado pelo bombeio de 1480nm [34]. Além disto, a figura de ruído associada ao bombeio de 980nm também é menor que aquela associada ao bombeio de 1480nm [33]. Isto pode ser explicado pelo fato de o bombeio de 980nm ser capaz de excitar os elétrons dos átomos de érbio a níveis de maior energia que o bombeio de 1480nm [55], de modo que, ao decaírem do nível de maior energia para o nível metaestável, eles permanecerão por mais tempo neste nível, isto é, seu tempo de vida neste nível metaestável será maior, reduzindo a emissão espontânea e, conseqüentemente, a figura de ruído [35]. 


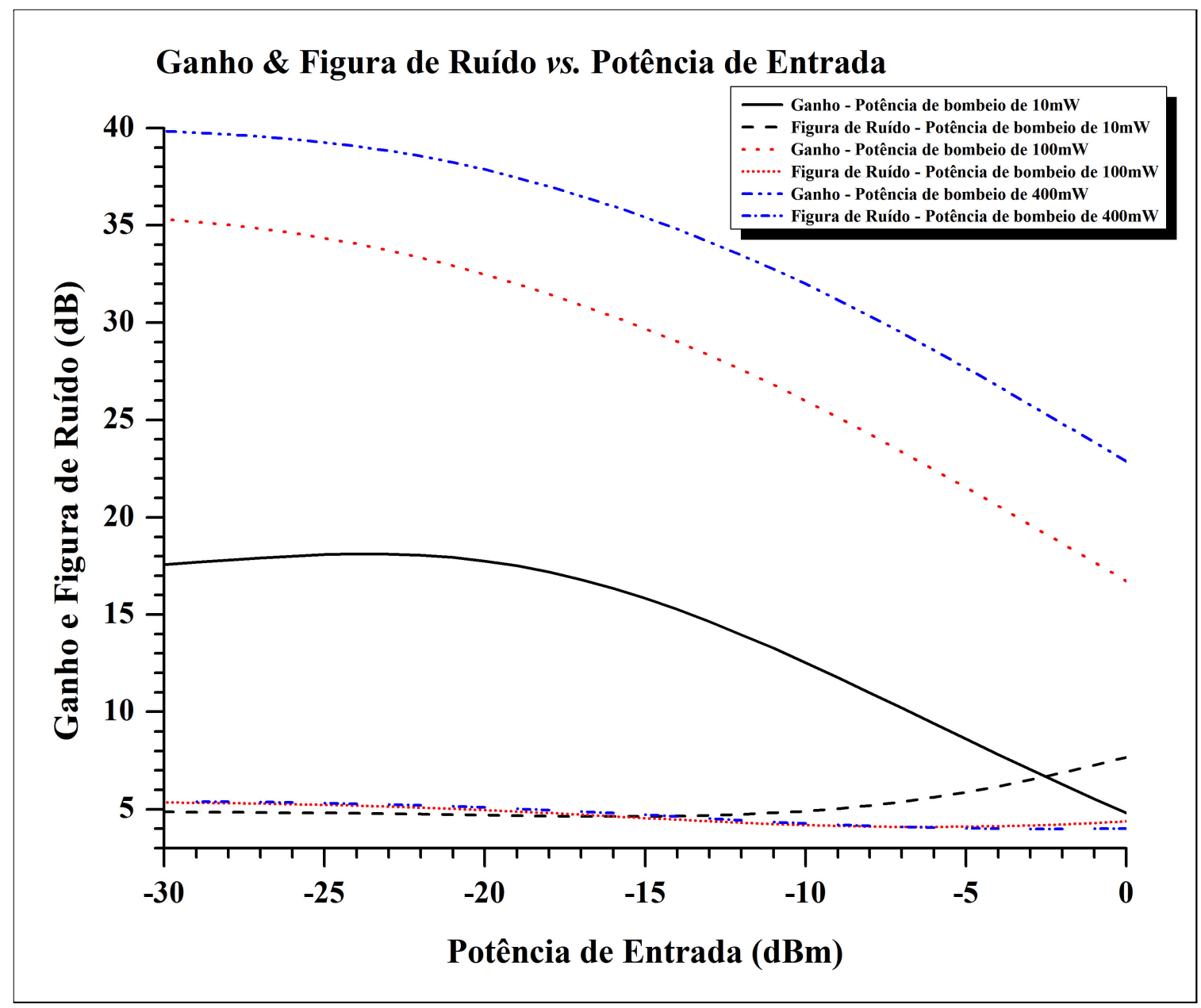

Figura 3.29: Ganho óptico e figura de ruído da fibra dopada com érbio bombeada em função da potência de entrada do sinal. A EDF é bombeada em esquema co-propagante por um laser de bombeio de $980 \mathrm{~nm}$. O comprimento de onda do sinal é de $1550 \mathrm{~nm}$. 


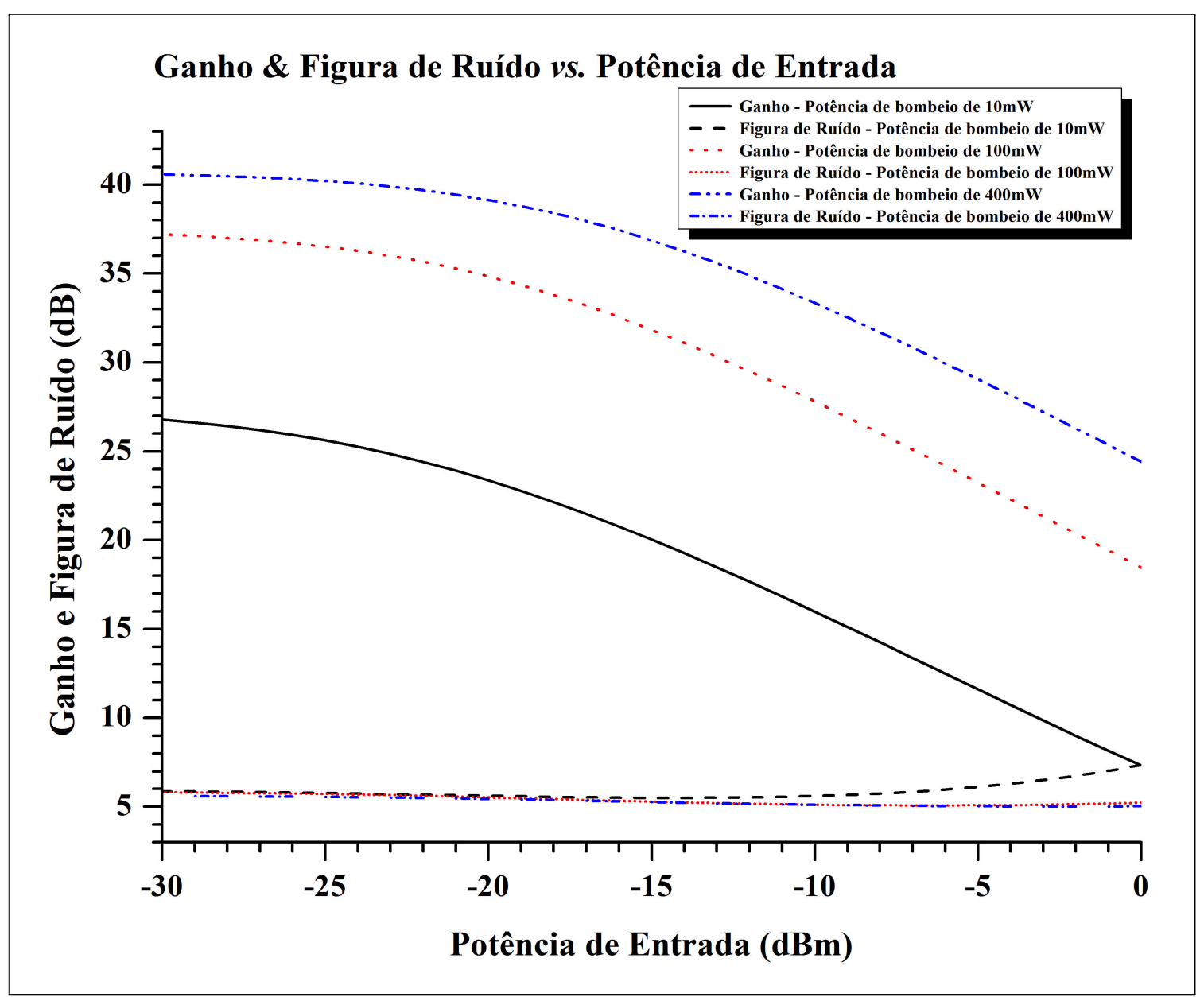

Figura 3.30: Ganho óptico e figura de ruído da fibra dopada com érbio bombeada em função da potência de entrada do sinal. A EDF é bombeada em esquema co-propagante por um laser de bombeio de $1480 \mathrm{~nm}$. O comprimento de onda do sinal é de $1550 \mathrm{~nm}$.

Outra comparação que pode ser feita consiste em avaliar a variação do ganho com o comprimento de onda do sinal de entrada. Tomando-se o o esquema co-propagante e fixando-se a potência de entrada do EDFA em $-15 \mathrm{dBm}$, varia-se o comprimento de onda do transmissor a fim de se obter o ganho como função da freqüência do sinal, o que está mostrado nas Figuras 3.31 e 3.32, para fontes de bombeio em $980 \mathrm{~nm}$ e 1480nm respectivamente. O pico de ganho está localizado em torno de 1530nm [33]. 


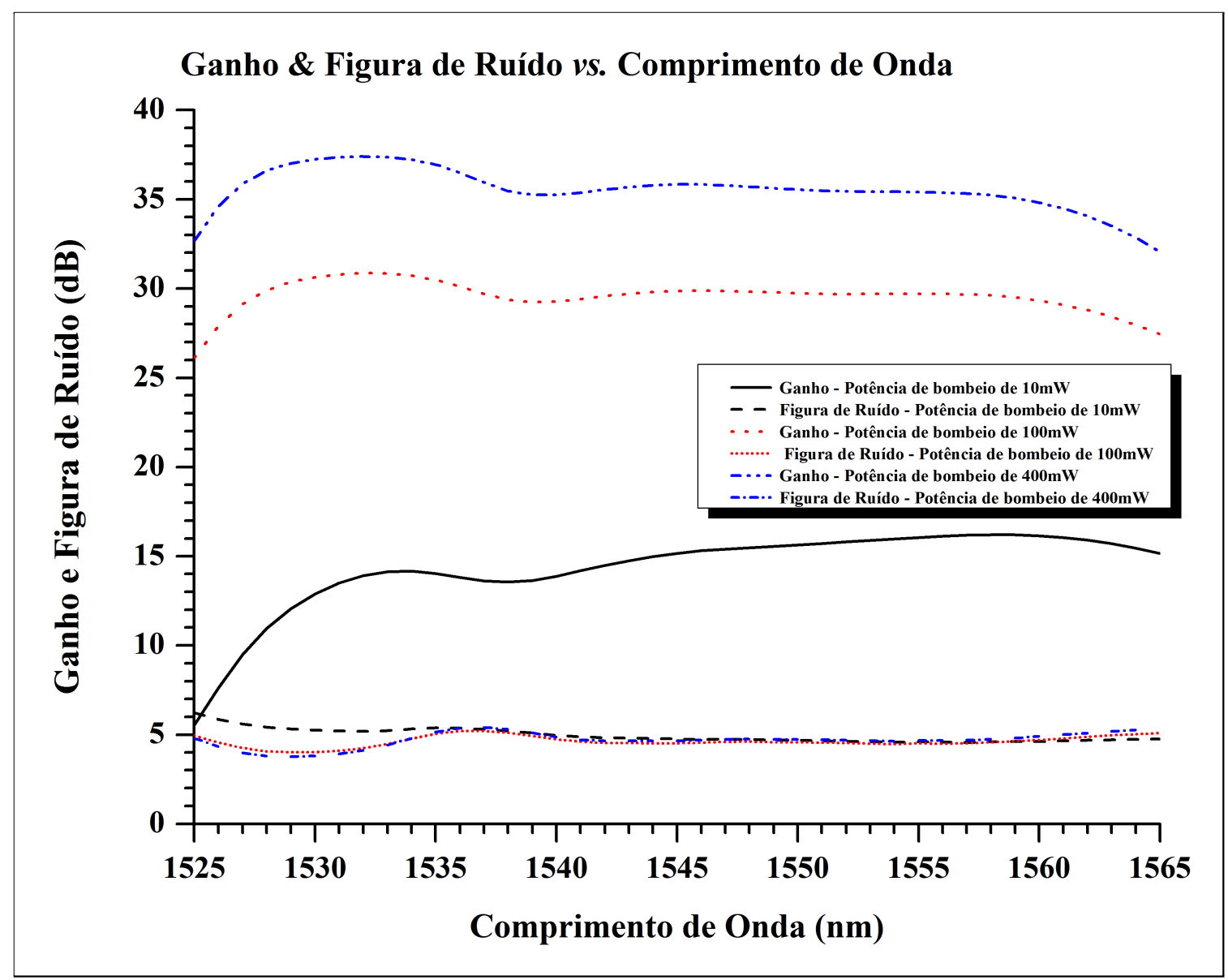

Figura 3.31: Ganho óptico e figura de ruído da fibra dopada com érbio bombeada em função do comprimento de onda do sinal. A EDF é bombeada em esquema co-propagante por um laser de bombeio de $980 \mathrm{~nm}$. O potência óptica do sinal é de $-15 \mathrm{dBm}$. 


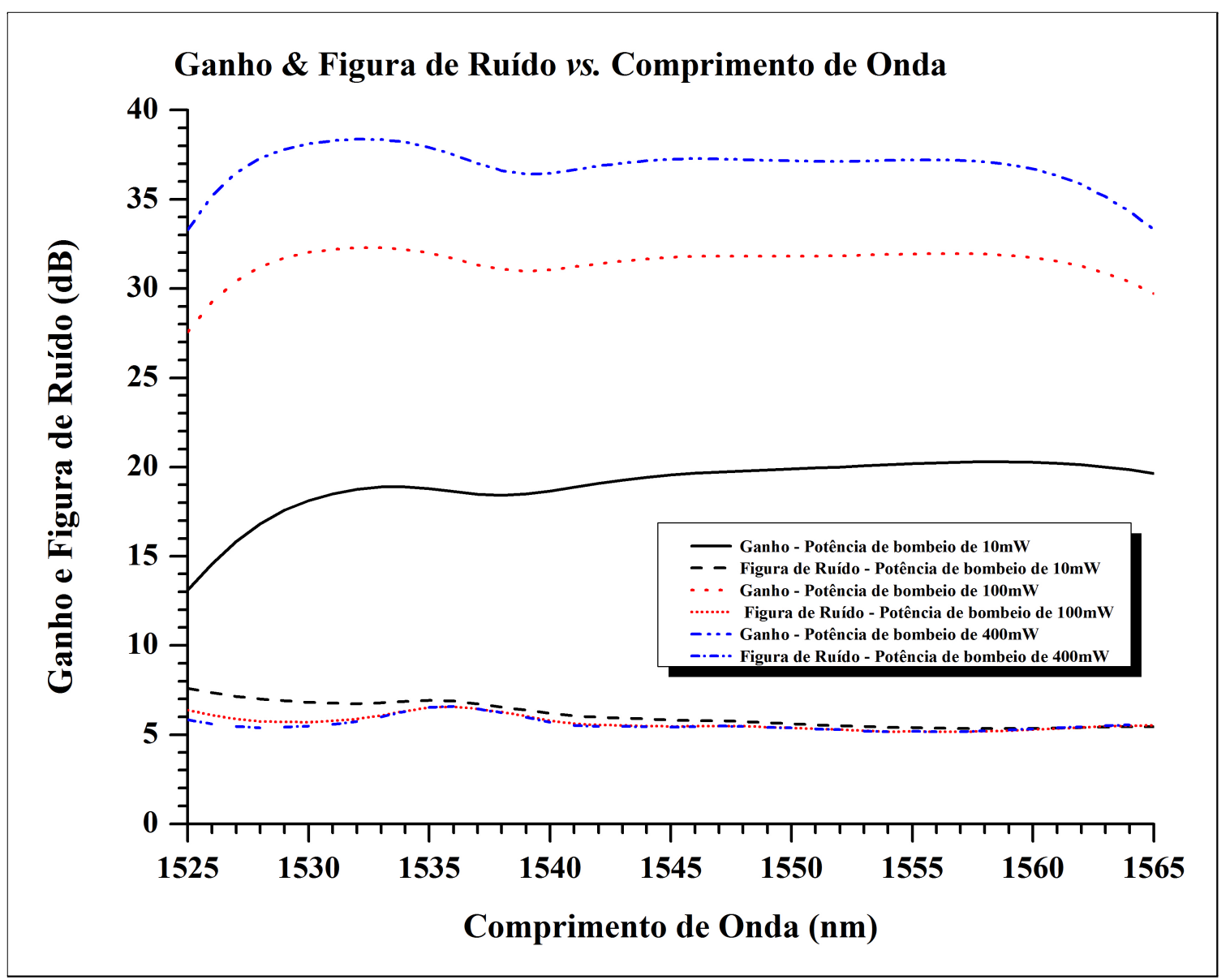

Figura 3.32: Ganho óptico e figura de ruído da fibra dopada com érbio bombeada em função do comprimento de onda do sinal. A EDF é bombeada em esquema co-propagante por um laser de bombeio de 1480nm. O potência óptica do sinal é de $-15 \mathrm{dBm}$.

Os últimos resultados referentes à configuração do software para o EDFA são a caracterização do ganho e da figura de ruído em função da potência de bombeio. As Figuras 3.33 e 3.34 mostram a variação do ganho e figura de ruído para os bombeios de 980nm e 1480nm, respectivamente. Em ambos, o comprimento de onda do sinal é de 1550nm. Foram obtidos o ganho e figura de ruído para as potências de entrada do sinal de -10dBm a -20dBm. Como esperado, para a potência de entrada mais baixa, o ganho foi mais elevado [33]. 


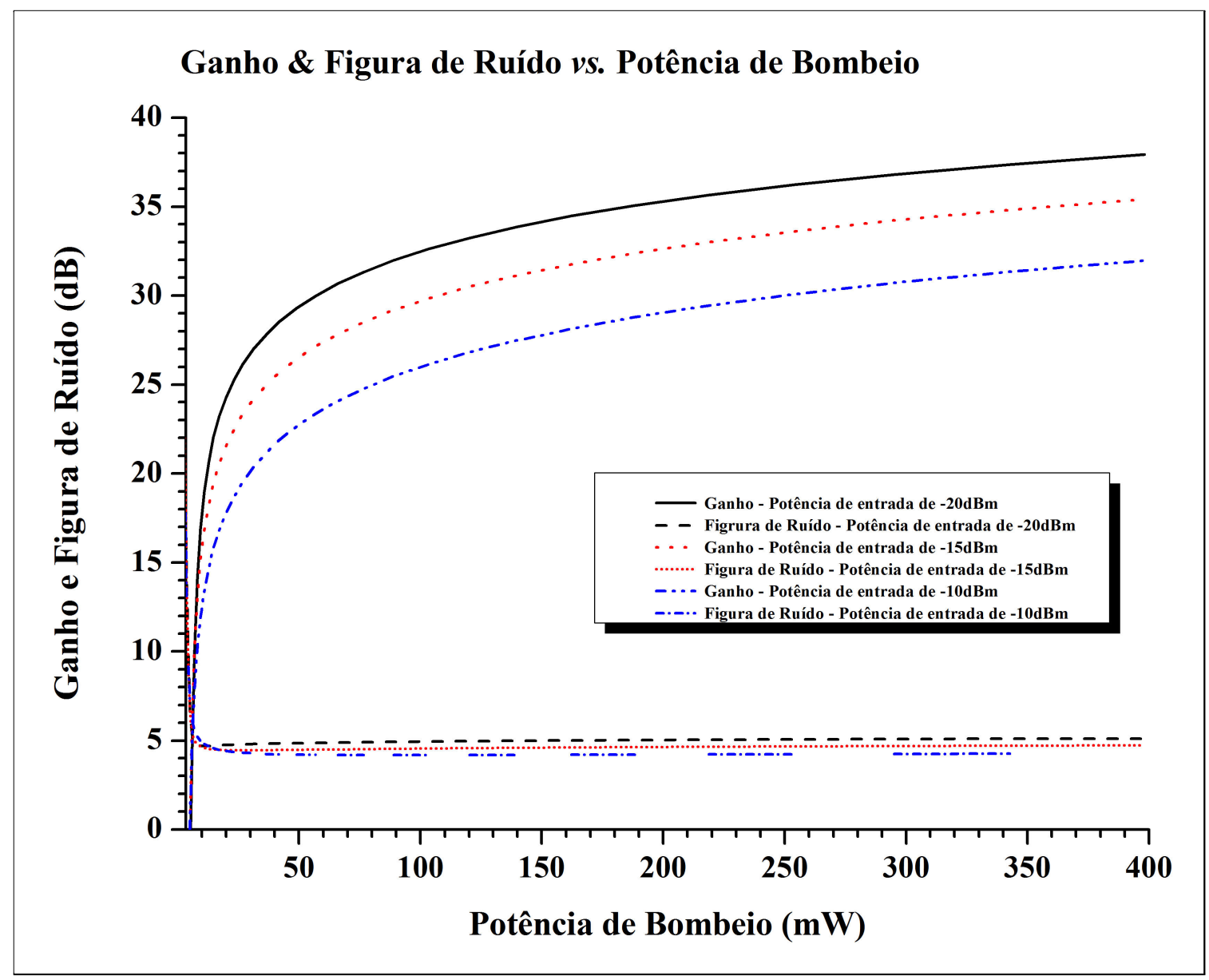

Figura 3.33: Ganho óptico e figura de ruído da fibra dopada com érbio bombeada em função da potência de bombeio. A EDF é bombeada em esquema co-propagante por um laser de bombeio de $980 \mathrm{~nm}$. O comprimento de onda do sinal é de 1550nm. 


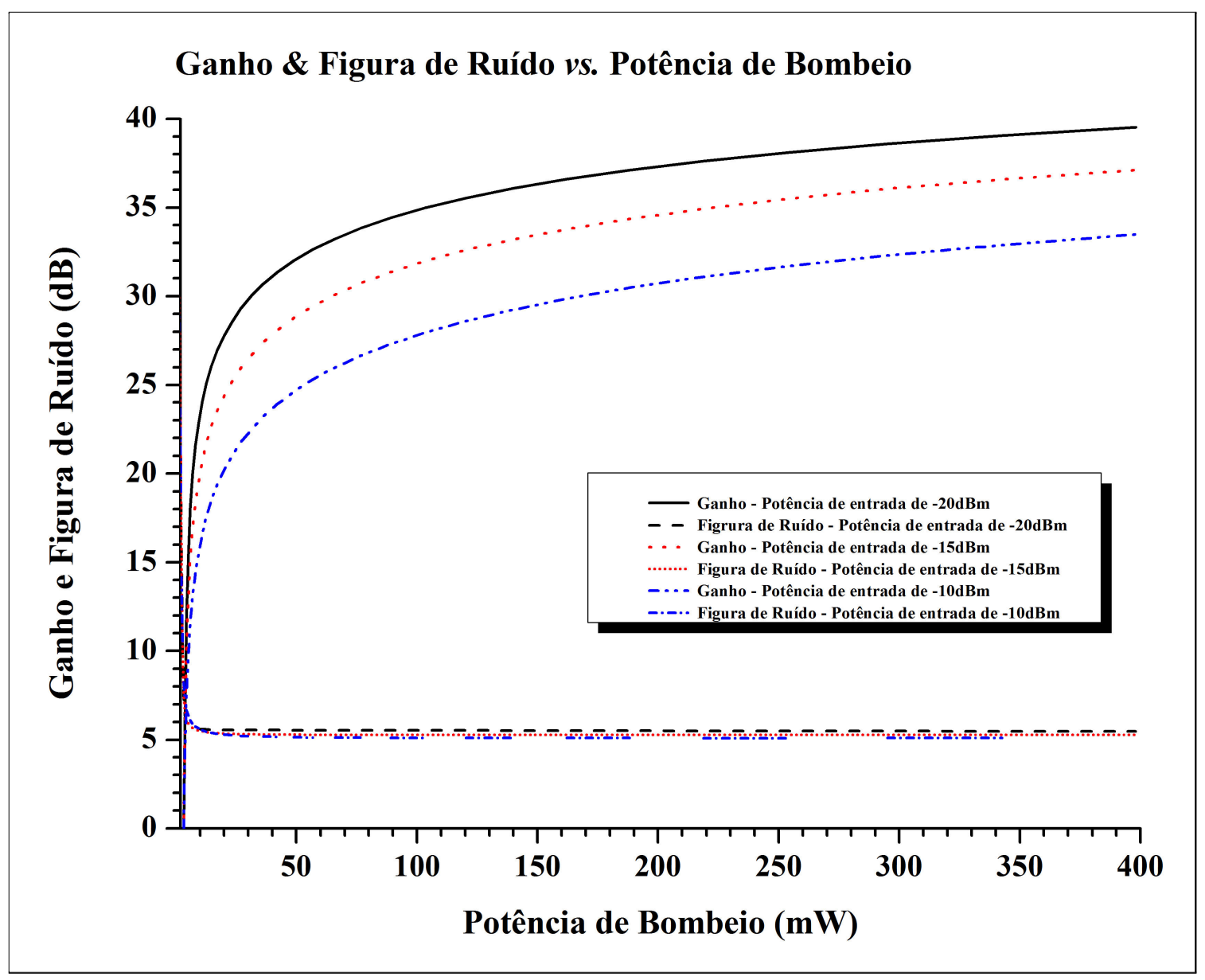

Figura 3.34: Ganho óptico e figura de ruído da fibra dopada com érbio bombeada em função da potência de bombeio. A EDF é bombeada em esquema co-propagante por um laser de bombeio de 1480nm. O comprimento de onda do sinal é de 1550nm.

Uma vez configurados os componentes para a simulação de uma EDF bombeada remotamente, foi possível simular algumas topologias para realização de testes. A primeira topologia está apresentada na Figura 3.35. Os objetivos das simulações desta topologia são a obtenção de um enlace com o maior alcance e taxas de divisão de potência possíveis, uma vez que estas representarão o número de ONUs conectadas a um mesmo OLT. No entanto, é importante se ter em mente que o aumento no número de portas dos divisores de potência representa uma redução nas taxas de transmissão atribuídas a cada ONU, o que pode ser um fator limitante no aumento do número de portas do divisor de potência passivo. Além disto, como o bombeio é realizado remotamente, não há ao longo do enlace componentes ativos, o que mantém o caráter passivo da rede [12]. 


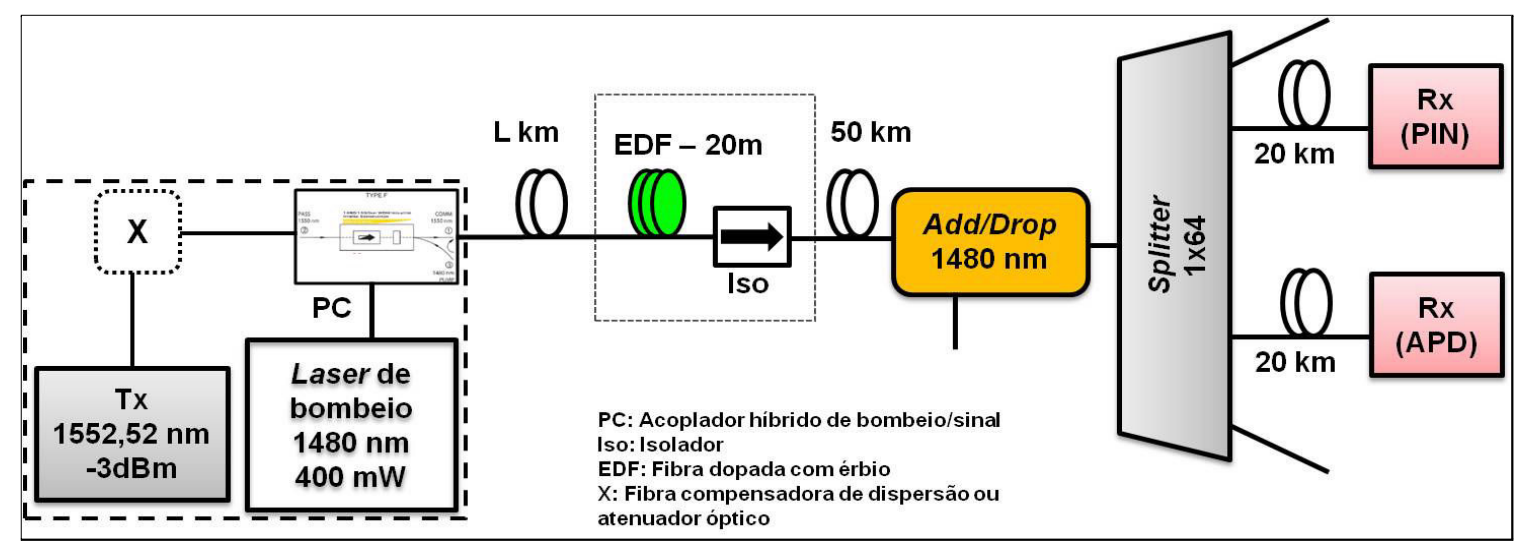

Figura 3.35: Representação esquemática da topologia utilizando amplificação por fibra dopada com érbio bombeada remotamente em esquema co-propagante. O componente representado pela letra X representa a posição onde a fibra compensadora de dispersão [81] ou atenuador óptico serão introduzidos, a fim de se comparar a influência da dispersão.

Em todas as simulações, foi utilizado somente o bombeio de $1480 \mathrm{~nm}$ pelo fato de este comprimento de onda possuir menor atenuação na fibra, quando comparado comprimento de 980nm. A atenuação utilizada para $1480 \mathrm{~nm}$ foi de $0,25 \mathrm{~dB} / \mathrm{km}$ [57], [82]. O esquema de bombeio co-propagante foi escolhido devido à possibilidade de posicionar tanto os transmissores quanto as fontes de bombeio óptico no OLT bem como a possibilidade de uso de amplificação Raman distribuída também em esquema co-propagante ao longo do enlace de comprimento L. O feixes de sinal e de bombeio são injetados na fibra através do acoplador híbrido descrito anteriormente [83].

O comprimento L desta fibra é de fundamental importância, uma vez que ele determinará a potência do bombeio que atingirá a EDF, definindo, portanto, o desempenho da rede. Logo, o estudo do desempenho da rede será realizado em função deste comprimento. A potência de bombeio injetada no acoplador híbrido é de 400mW [80].

Foi considerado um cenário contendo apenas um canal em 1550nm modulado às taxas de 1,25Gbps, 2,5Gbps e 10Gbps, conforme mostrado na Figura 3.35. Ainda na mesma figura, o componente indicado pela letra X representa a posição onde uma fibra compensadora de dispersão (Dispersion Compensation Fiber - DCF) com 10km de extensão e dispersão total de -1707ps/nm [81], o que equivale à compensação de dispersão cromática acumulada pela propagação através de 100km de fibra padrão [56] ou um atenuador óptico com atenuação de $6,4 \mathrm{~dB}$, que é equivalente a da DCF serão inseridos.

As Figuras 3.36 e 3.37 mostram os resultados obtidos, para o sistema de 1,25Gbps com 
receptores utilizando fotodetectores do tipo APD e PIN, respectivamente. Considerando-se uma taxa de erro de bit da ordem de $10^{-10}$, no sistema de com fotodetectores do tipo avalanche, o comprimento total do enlace é de $145 \mathrm{~km}$ e, aproximadamente, $126 \mathrm{~km}$ com receptores do tipo PIN. Já as Figuras 3.38 e 3.39 apresentam os resultados obtidos no sistema de 2,5Gbps, tendo sido possível atingir distâncias de $137 \mathrm{~km}$ e $121 \mathrm{~km}$ para sistemas contendo fotodetectores do tipo APD e PIN, respectivamente e sob a mesma taxa de erro avaliada. Finalmente, as Figuras 3.40 e 3.41 mostram as taxas de erro de bit em função do comprimento da fibra alimentadora para os sistemas de 10Gbps e fotodetectores APD e PIN, nesta ordem. Nestes cenários, os comprimentos totais atingidos foram de $125 \mathrm{~km}$ para os receptores com APD e $108 \mathrm{~km}$ para aqueles baseados em PIN.

Comparando-se as Figuras 3.36 a 3.41, nota-se uma inversão no cenário com melhor desempenho, isto é, para uma mesma taxa de erro de bit a configuração que é capaz de atingir o maior comprimento da fibra alimentadora. Ao passo que nos sistemas de 1,25Gbps e 2,5Gbps, em ambos os receptores, o cenário com melhor desempenho foi aquele que não possui, no transmissor, nenhum tipo de atenuação adicional, seja pela DCF seja pelo atenuador. Nos sistemas de 10Gbps foi exatamente a configuração com DCF que produziu o maior comprimento do enlace, o que mostra a necessidade de módulos compensadores de dispersão para sistemas acima de 10Gbps.

Analizando estas figuras, nota-se que é possível atingir distâncias maiores que 100km, o que caracteriza estas topologias como LR-PONs. Porém, é interessante observar que o sistema possui apenas um amplificador em um ponto ao longo do enlace e que é alimentado remotamente, mantendo o caráter passivo da rede. Além disto, como sinal e o bombeio em 1480nm compartilham a mesma fibra alimentadora, ocorre um ganho Raman $O N-O F F$ da ordem de $7 \mathrm{~dB}$, uma vez que a diferença de freqüência entre o bombeio e o sinal é de aproximadamente $10 \mathrm{THz}$ [62], [84]. Como a taxa de divisão é de 1x64, a largura de banda recebida por ONU é de, aproximadamente, 19Mbps, para o sistema transportando 1,25Gbps, de 39Mbps, para o sistema de 2,5Gbps e 156Mbps, para o sistema de 10Gbps. Taxas de divisão ainda maiores são possíveis, desde que o comprimento da segunda fibra, que é fixo em $50 \mathrm{~km}$, seja reduzido. 


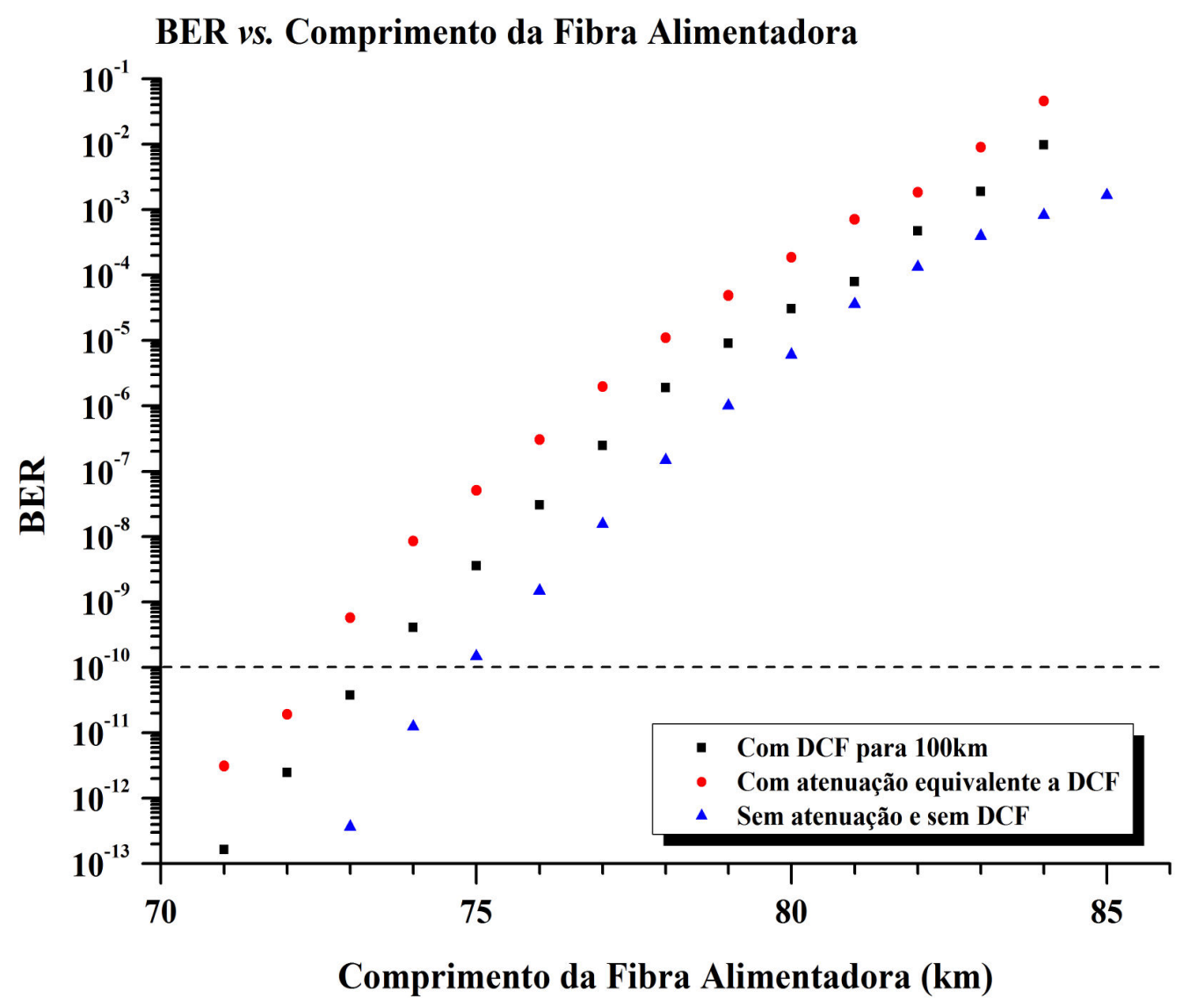

Figura 3.36: BER vs. Comprimento da Fibra Alimentadora para um sistema de 1,25Gbps com receptor baseado em APD. Observa-se que o melhor desempenho é produzido pela configuração que não utiliza nem DCF nem atenuador no transmissor. 


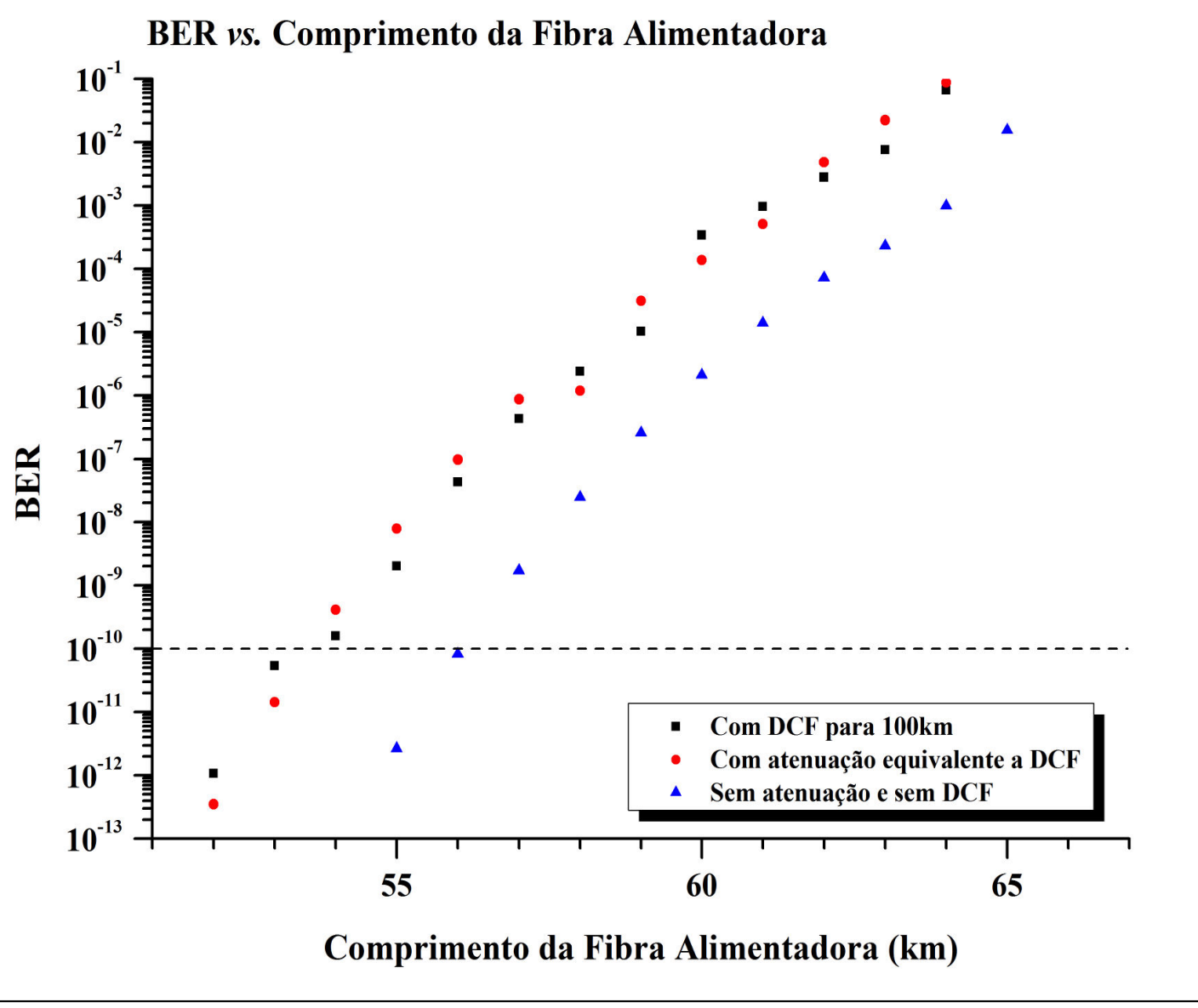

Figura 3.37: BER vs. Comprimento da Fibra Alimentadora para um sistema de 1,25Gbps com receptor baseado em PIN. Novamente, observa-se que o melhor desempenho é produzido pela configuração que não utiliza nem DCF nem atenuador no transmissor. 


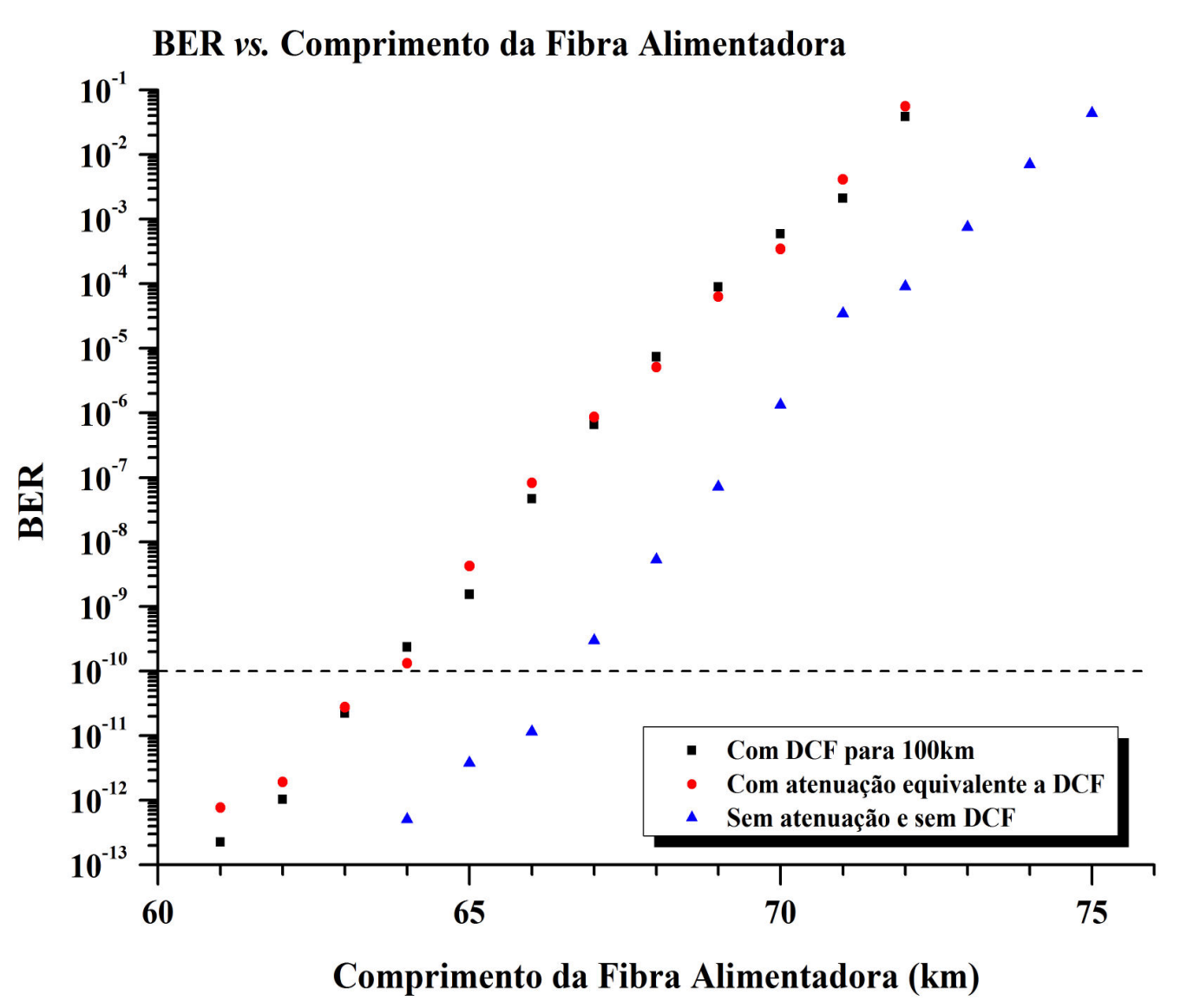

Figura 3.38: Taxa de erro de bit em função do comprimento da fibra alimentadora para receptores do tipo APD, para o sistema de 2,5Gbps. Novamente, nota-se que o cenário que atinge o maior comprimento é aquele em que não há nenhuma atenuação adicional no transmissor. 


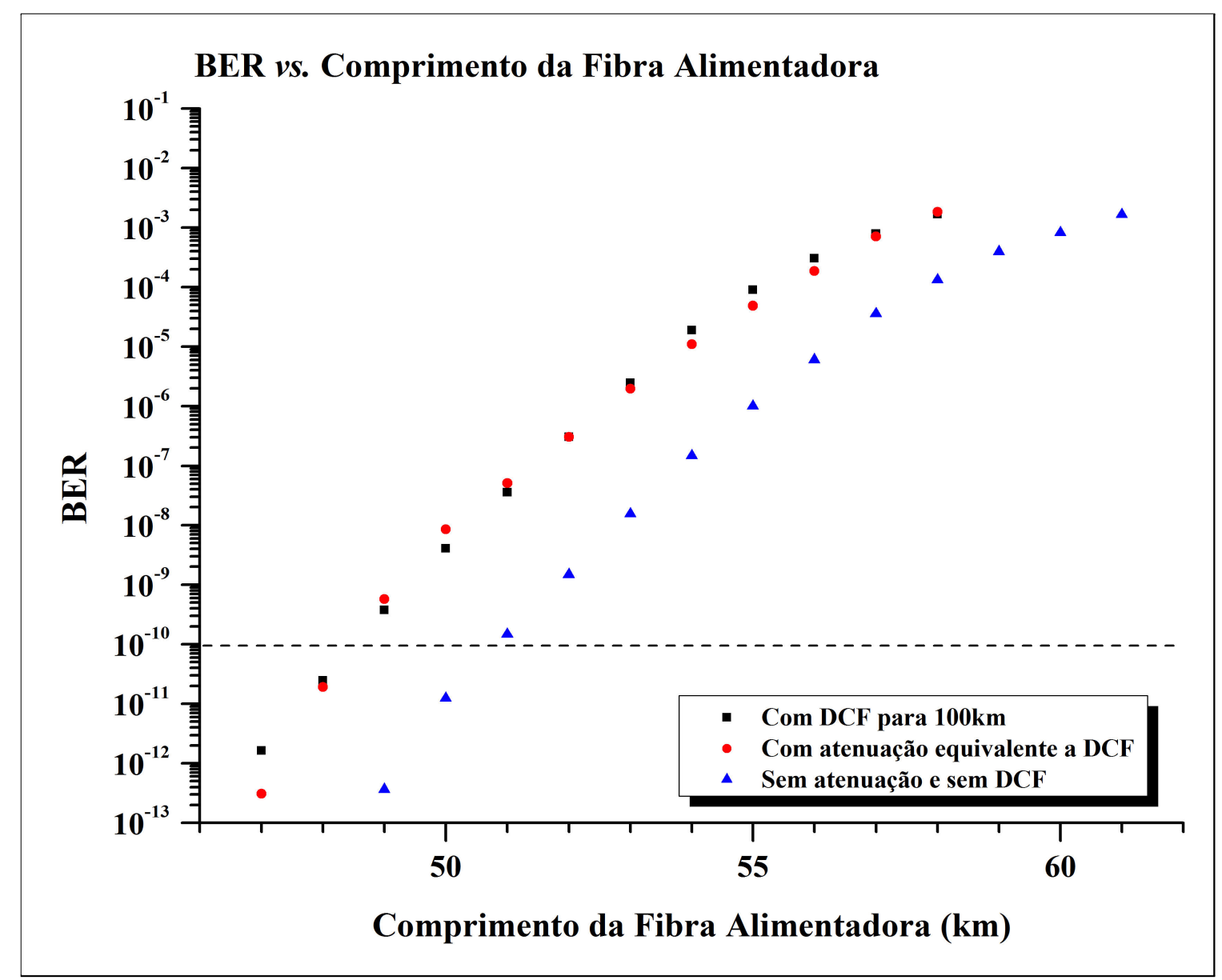

Figura 3.39: Taxa de erro de bit em função do comprimento da fibra alimentadora para receptores do tipo PIN, para o sistema de 2,5Gbps. Novamente, nota-se que o cenário que atinge o maior comprimento é aquele em que não há nenhuma atenuação adicional no transmissor. 


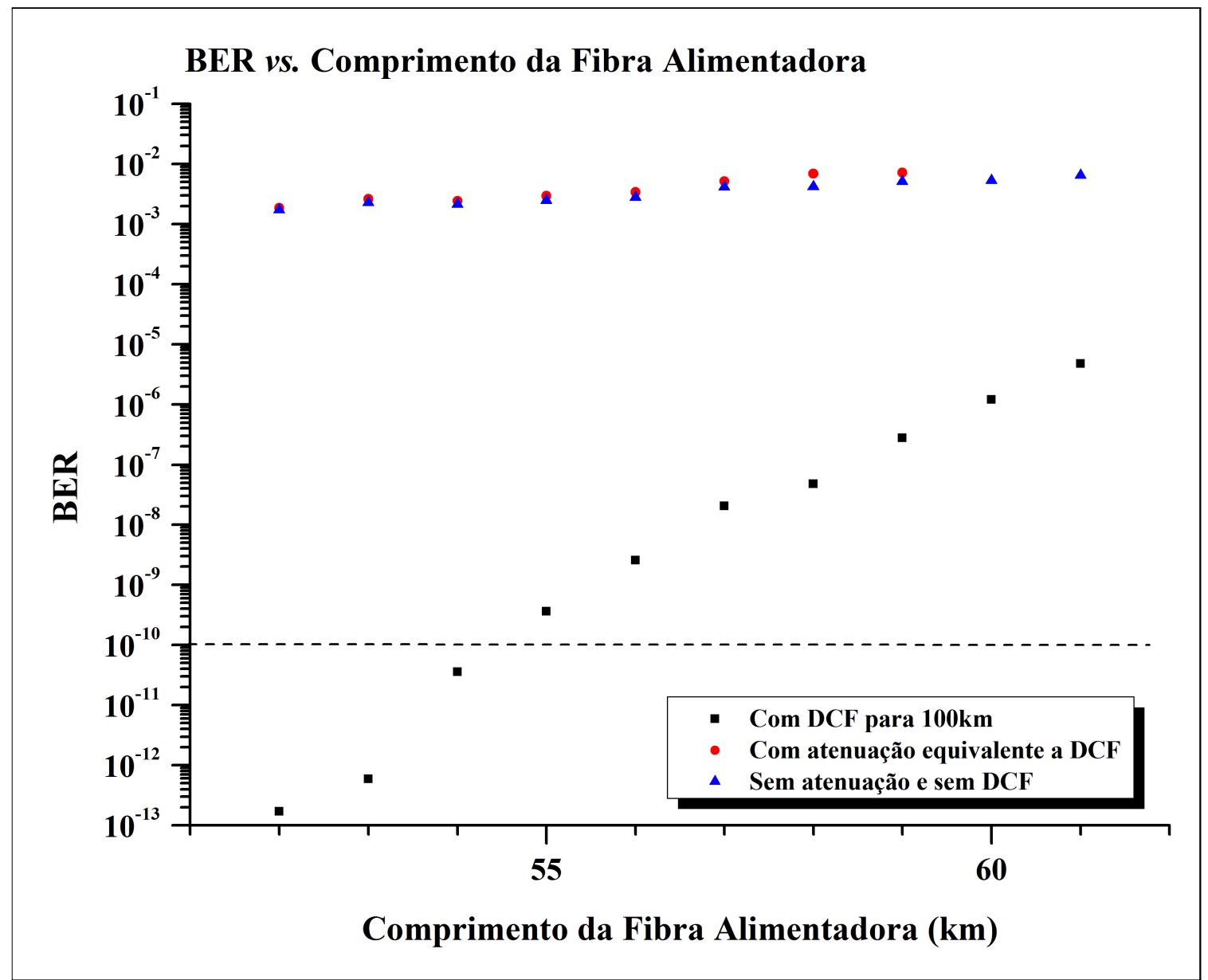

Figura 3.40: BER vs. Comprimento da Fibra Alimentadora para receptores baseados em APD, considerando uma taxa de 10 Gbps. Diferentemente dos cenários obtidos até o momento, aquele contendo a fibra compensadora de dispersão apresentou o melhor desempenho para uma mesma BER. 


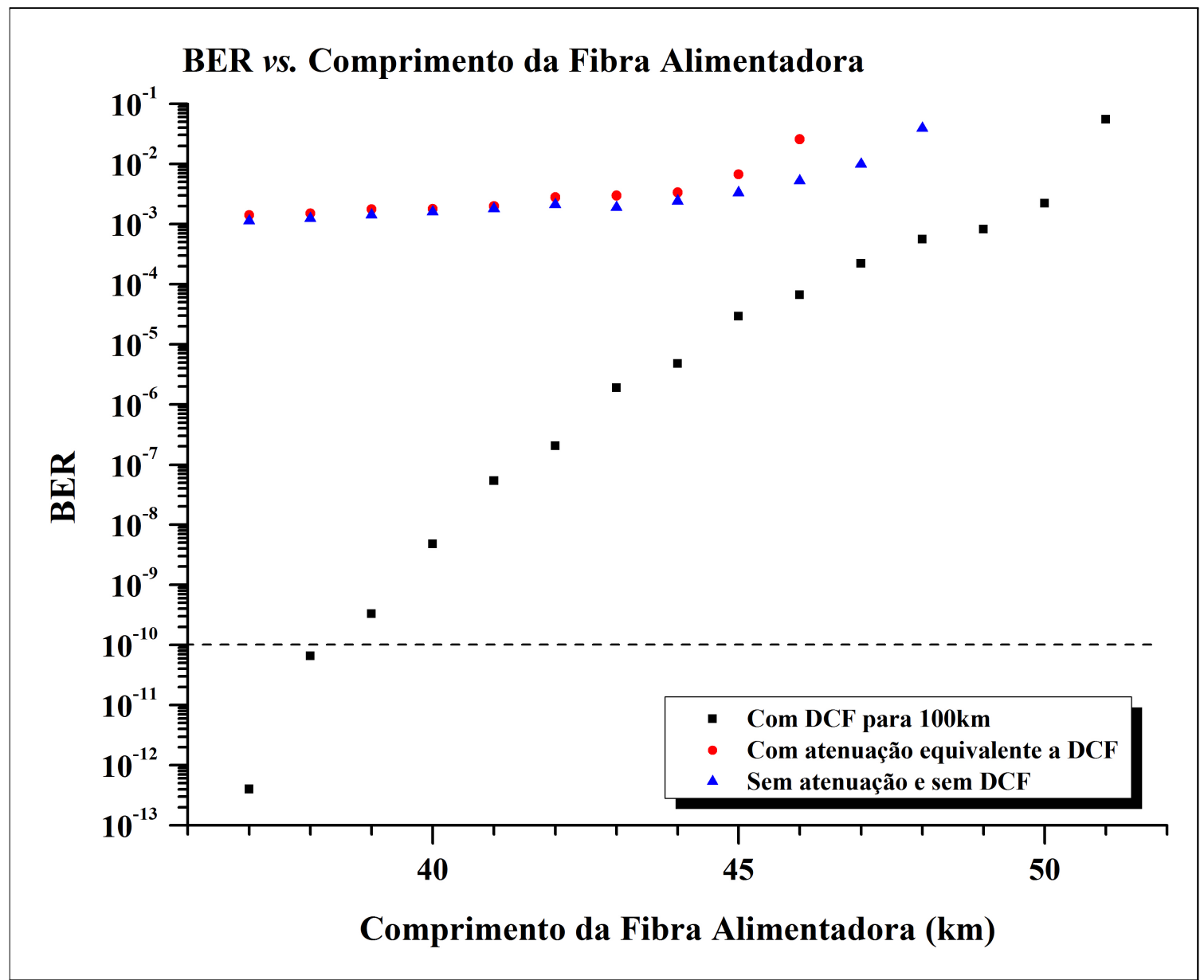

Figura 3.41: BER vs. Comprimento da Fibra Alimentadora para receptores com fotodetector do tipo PIN, em sistemas de 10Gbps. Nota-se, mais uma vez, que o cenário contendo a compensação da dispersão, através da DCF, atingiu um comprimento maior que aqueles que não possuíam nenhuma compensação. 


\section{Capítulo 4}

\section{Conclusões}

Buscou-se investigar ao longo do trabalho os diversos tipos de amplificadores e esquemas de amplificação que podem ser utilizados nas redes de acesso. O objetivo em desenvolver sistemas eficientes de amplificação óptica é permitir a redução de custos de instalação e operacionais para as operadoras de telecomunicações, uma vez que será necessário um menor número de estações, isto é, nós na rede, já que um maior número de usuários, que podem estar distribuídos em uma vasta região geográfica, são atendidos por uma mesma central [12].

Além disto, foram discutidas algumas arquiteturas de longo alcance [26], nas quais foi possível observar uma evolução dos sistemas de amplificação partindo das arquiteturas que utilizavam um número proibitivo de amplificadores [49] até aquelas que usam dois amplificadores para cada árvore TDM [62].

Métodos de amplificação óptica indicados para sistemas instalados atualmente, ou seja, redes ópticas do padrão GPON, foram investigadas tanto experimentalmente quanto teoricamente, a partir da utilização de amplificadores ópticos semicondutores. Com a transformação da rede passiva em uma rede ativa foi possível atender 64 usuários localizados a uma distância de $84 \mathrm{~km}$ da central de serviço. Alternativamente, um sistema do tipo FTTB pode ser implantado com a utilização do extensor, baseado em amplificadores semicondutores, desenvolvido no $\mathrm{CPqD}$, atendendo a 128 usuários de um prédio localizado a $80 \mathrm{~km}$ do OLT.

Ainda em sistemas de amplificação para o padrão GPON, foram realizadas simulações computacionais visando à obtenção de SOAs com características, como figura de ruído e potência de saturação, otimizadas. Com estas abordagens, foi possível estender ainda mais o alcance da rede, chegando a 100km com 64 usuários conectados e separados entre si de uma distância de $40 \mathrm{~km}$ ou atendendo a 256 ONUs numa distância de $70 \mathrm{~km}$. A otimização de amplificadores 
semicondutores é capaz de produzir bons resultados na extensão do orçamento de potência, entretanto, alguns cuidados devem ser tomados, uma vez que, conforme a otimização realizada, por exemplo, elevação da potência de saturação, pode resultar num maior consumo energético do dispositivo, embora, o consumo energético da rede possa ser reduzido, já que este dispositivo seria capaz de suportar potências de entrada mais elevadas e, conseqüentemente, maiores distâncias.

Arquiteturas híbridas como a proposta SARDANA são alternativas de migração entre as redes atuais e possíveis arquiteturas do tipo WDM-PON [62], [60]. Desta forma, esquemas de amplificação utilizando EDFAs também foram investigados teoricamente. Porém, a fim de manter o caráter passivo da rede, utilizou-se o bombeio remoto por um laser de 1480nm.

Mantendo a taxa de divisão de potência fixa em 1x64, sistemas de 1,25Gbps, 2,5Gbps e 10Gbps foram estudados, considerando-se três cenários: presença de DCF, com $10 \mathrm{~km}$ de extensão, para compensar a dispersão relativa a 100km de propagação, atenuador óptico com atenuação idêntica à da DCF e uma configuração em que nem a DCF nem o atenuador estão presentes. Em todos os cenários, receptores com fotodetectores do tipo PIN e APD foram utilizados.

Foi possível verificar, a partir das simulações, que para sistemas até 2,5Gbps não é necessária a utilização de fibras compensadoras de dispersão, tendo sido atingido um enlace da ordem de 140km para receptores com APD. Entretanto, para sistemas com 10Gbps, a utilização de um módulo de compensação de dispersão é obrigatória, tendo sido atingido um comprimento total de $120 \mathrm{~km}$, aproximadamente.

Como proposta para trabalhos futuros, sugerem-se o estudo de esquemas de amplificação óptica voltados para tráfego upstream do padrão GPON que utilizem bombeio Raman em 1240nm ou possíveis formas de se integrar amplificadores ópticos que operem nas bandas dos padrões GPON/XG-PON, dado que os comprimentos de onda do tráfego do usuário para a central ocorrem na na banda O. Além disto, podem ser pesquisadas maneiras de amplificação óptica híbrida que utilizem amplificação Raman e amplificadores de fibra dopada com érbio para amplificar os sinais do padrão GPON. 


\section{Referências Bibliográficas}

[1] Ovídio Barradas, Você e as Telecomunicações. Interciência: Rio de Janeiro, Brasil, 1995.

[2] Andrew Wheen, Dot-Dash to Dot.Com: How Modern Telecommunications Evolved from the Telegraph to the Internet. Springer-Praxis: Chicester, Reino Unido, 2011.

[3] Cópia do artigo original publicado por Charles Kao, em 1966, disponível em http://www.ieee.org/netstorage/spectrum/pdfs/KaoHockham.pdf, acesso em 20/12/2010.

[4] História da criação experimental da fibra óptica, disponível em http://www.corning.com/opticalfiber/innovation/index.aspx, acesso em 01/08/2011.

[5] Lista de laureados com o Prêmio Nobel de Física no ano de 2009, disponível em http://nobelprize.org/nobel_prizes/physics/laureates/2009/, acesso em 20/12/2010.

[6] Premiação dos pesquisadores da Corning sobre a descoberta da fibra óptica, disponível em http://www.corning.com/opticalfiber/innovation/discovery/maurerschultzkeck/index.aspx, acesso em 01/08/2011.

[7] Estimativa do volume de dados trafegados por redes de fibra óptica, disponível em http://www.teleco.com.br/tutoriais/tutorialfoI/Default.asp, acesso em 30/11/2010.

[8] Pesquisa disponibilizada em www.internetworldstats.com/emarketing.htm, acesso em $21 / 05 / 2011$.

[9] Dimitri Leino, 10 Gigabit-capable Passive Optical Network Transmission Convergence layer design. Dissertação de mestrado, Faculty of Electronics, Communications and Automation, Aalto University, Finland, 2010.

[10] C.-H. Lee, S.-M. Lee, K.-M. Choi, J.-H. Moon, S.-G. Mun, K.-T. Jeong, J. H. Kim e B. 
Kim, WDM-PON experiences in Korea [Invited]. Journal of Optical Networking, 6, 5, p. 451-464, Maio 2007.

[11] Pesquisa disponibilizada pela empresa Cisco em www.cisco.com/en/US/solutions/ collateral/ns341/ns525/ns537/ns705/ns827/VNI_Hyperconnectivity_WP.html, acesso em $21 / 05 / 2011$.

[12] R. P. Davey, D. Nesset, A. Rafel, D. B. Payne e A. Hill, Designing long reach optical access networks. BT Technology Journal, 24, 2, p. 13-19, Abril 2006.

[13] C. P. Larsen, A. Gavler e K. Wang. Comparison of active and passive optical access networks. $9^{\text {th }}$ Conference on Telecommunications, Internet and Media Techno Economics (CTTE), 2010.

[14] A. Banerjee, Y. Park, F. Clarke, H. Song, S. Yang, G. Kramer, K. Kim e B. Mukherjee, Wavelength-division-multiplexed passive optical network (WDM-PON) technologies for broadband access: a review [Invited]. Journal of Optical Networking, 4, 11, p. 737-758 Novembro 2005.

[15] K. A. Hinton, D. Neilson e M. Pickavet (Organizadores), IEEE Journal of Selected Topics in Quantum Electronics. 17, 2, 2011.

[16] D. Nowak e J. Murphy, FTTH: The overview of existing technologies. Proceedings SPIE Optoelectronics, Photonic Devices, and Optical Networks, 5825, p. 500-509, 2005.

[17] F. Saliou, P. Chanclou, F. Laurent, N. Genay, J. A. Lazaro, F. Bonada e J. Prat, Reach Extension Strategies for Passive Optical Networks [Invited]. Journal of Optical Communication Networks, 1, 4, p. c51-c60, Setembro 2009.

[18] D. Mestdagh e C. M. Martin, The Super-PON concept and its technical challenges. Proceedings of the International IFIP-IEEE Conference on Broadband Communications, p. 333-345, Abril 1996.

[19] G. Talli e P. D. Townsend, Hybrid DWDM-TDM Long-Reach PON for Next-Generation Optical Access. Journal of Lightwave Technology, 24, 7, p. 2827-2834, Julho 2006.

[20] B. Sartorius, 3R regeneration for all-optical networks. Proceedings of 2001 3rd International Conference on Transparent Optical Networks (ICTON), p. 333-337, Junho 2001. 
[21] R. P. Davey, P. Healey, I. Hope, P. Watkinson, D. B. Payne, O. Marmur, J. Ruhmann e Y. Zuiderveld, DWDM extension of a GPON to $135 \mathrm{~km}$. Optical Fiber Conference (OFC), 6 , Março 2005.

[22] R. P. Davey, D. B. Grossman, M. Rasztovits-Wiech, D. B. Payne, D. Nesset, A. E. Kelly, A. Rafel, S. Appathurai e S.-H. Yang. Long-Reach Passive Optical Networks. Journal of Lightwave Technology, 27, 3, Fevereiro 2009.

[23] Suplemento 39 da série $G$ de recomendações, disponível em http://www.itu.int/itut/recommendations/index.aspx?ser=G, acesso em 15/06/2011.

[24] Recomendação ITU-T G.984.x, disponível em http://www.itu.int/itut/recommendations/index.aspx?ser=G, acesso em 15/01/2011.

[25] João Batista Rosolem, Amplificadores Ópticos de Dupla Passagem Incorporando Fibras Compensadoras de Dispersão. Tese de Doutorado, Escola de Engenharia de São Carlos, Universidade de São Paulo, 2005.

[26] H. Song, B.-W. Kim e B. Mukherjee, Long-Reach Optical Access Networks: A Survey of Research Challenges, Demonstrations, and Bandwidth Assignment Mechanisms. IEEE Communications Surveys \& Tutorials, 12, 1, p. 112-123, $1^{\circ}$ trimestre 2010.

[27] N. Suzuki, S. Yoshima e J. Nakagawa, Extended Reach Bidirectional Optical Amplified GEPON with a high 46 dB Span-budget for 64 far-end user ONUs. Conference on Optical Internet-Australian Conference on Optical Fibre Technology (COIN-ACOFT), Junho 2007.

[28] F. Saliou, P. Chanclou, F. Laurent, B. Landousies, N. Genay e Z. Belfqih. Class B+ GPON extended to $44 \mathrm{~dB}$ while maintaining $15 \mathrm{~dB}$ optical budget difference. European Conference on Optical Communications (ECOC), Setembro 2008.

[29] K.-I. Suzuki, Y. Fukada, D. Nesset e R. Davey, Amplified gigabt PON systems [Invited]. Journal of Optical Networking, 6, 5, p. 422-433, Maio 2007.

[30] D. Nesset e P. Wright, Raman Extended GPON using 1240 nm Semiconductor QuantumDot Lasers. Optical Fiber Conference (OFC), 10, Março 2010.

[31] B. Zhu, Entirely passive reach extended GPON using Raman amplification. Optics Express, 18, 22, p. 23428-23434, Outubro 2010. 
[32] Página central dos datasheets das fibras AllWave ${ }^{(R)}$ produzidas pela empresa OFS, disponível em http://www.ofsoptics.com/fiber/category.php?txtCategoryID=1022260265461, acessado em 20/04/2012.

[33] Goving P. Agrawal, Fiber-Optic Communication Systems. John Wiley \& Sons: New York, 2002.

[34] Gerd Keiser, Optical Communications Essentials. McGraw-Hill NETWORKING: New York, 2003.

[35] C. R. Giles e E. Desurvire, Modeling Erbium-Doped Fiber Amplifiers. Journal of Lightwave Technology, 9, 2, p. 271-283, Fevereiro 1991.

[36] Gerd Keiser, Optical Fiber Communications. McGraw-Hill Books: New York, 2000.

[37] D. M. Baney, P. Gallion e R. S. Tucker, Theory and Measurement Techniques for the Noise Figure of Optical Amplifiers. Optical Fiber Technology, 6, 2, pp. 122-154, Abril 2000.

[38] Michael J. Connelly, Semiconductor Optical Amplifiers. Kluwer Academic Publishers: New York, 2004.

[39] M. J. Connelly, Wideband Semiconductor Optical Amplifier Steady-State Numerical Model. IEEE Journal of Quantum Electronics, 37, 3, p. 439-447, Março 2001.

[40] Lista de amplificadores ópticos semicondutores, e respectivos datasheets, produzidos pela empresa Kamelian, disponível em http://www.kamelian.com/products.html, acesso em $12 / 12 / 2010$.

[41] Lista de amplificadores ópticos semicondutores, e respectivos datasheets, produzidos pela empresa InPhenix, disponível em http://www.inphenix.com/soa_devices.html, acesso em $12 / 12 / 2010$.

[42] Lista de amplificadores ópticos semicondutores, e respectivos datasheets, produzidos pela empresa Covega, disponível em http://www.covega.com/Products/?catID=2, acesso em $12 / 12 / 2010$.

[43] A. Borghesani, Semiconductor Optical Amplifiers for Advanced Optical Applications. International Conference on Transparent Optical Networks (ICTON), p. 119-122, Novembro 2006. 
[44] Fabricante de dispositivos optoeletrônicos para redes ópticas passivas, disponível em www.alphion.com, acesso em 15/01/2011.

[45] White paper sobre a extensão do padrão GPON, disponinível em http://www.alphion.com/img/pdf/Extended_PON_Whitepaper.pdf, acesso em $15 / 01 / 2011$.

[46] K.-I. Suzuki, M. Fujiwara, T. Imai, N. Yoshimoto e H. Hadama, $128 \times 8$ Split and $60 \mathrm{~km}$ Long-Reach PON Transmission Using 27 dB-Gain Hybrid Burst-Mode Optical Fiber Amplifier and Commercial Giga-Bit PON System. National Fiber Optic Engineers Conference (NFOEC), Março 2010.

[47] Especificação técnica do amplificador óptico semicondutor com dupla banda de amplificação, disponível em http://www.alphion.com/img/pdf/Alphion\%20Dual\%20Band\%20PON\%20Amplifiers.pdf, acesso em 15/01/2011.

[48] I. Van de Voorde, C. M. Martin, J. Vandewege e X. Z. Qiu, The SuperPON Demonstrator: An Exploration of Possible Evolution Paths for Optical Access Networks. IEEE Communications Magazine, p. 74-82, Fevereiro 2000.

[49] Relatório contendo os resultados obtidos pelo projeto ACTS-PLANET, disponível em ftp://ftp.cordis.europa.eu/pub/infowin/docs/fr-050.pdf, acesso em 21/08/2010.

[50] D. P. Shea e J. E. Mitchell, A 10-Gb/s 1024-Way-Split 100-km Long-Reach Optical-Access Network. Journal of Lightwave Technology, 25, 3, p. 685-693, Março 2007.

[51] Biblioteca digital sobre tópicos em fotônica e optoeletrônica, disponível em http://www.rpphotonics.com/raman_gain.html, acesso em 15/04/2010.

[52] C. E. S. Castellani, S. P. N. Cani, M. E. V. Segatto, M. J. Pontes, and M. A. Romero, Design methodology for multi-pumped discrete Raman amplifiers: case-study employing photonic crystal fibers. Optics Express, 17, 16, p. 14121-14131, Agosto 2009.

[53] Y. Emori e S. Namiki, $100 \mathrm{~nm}$ bandwidth flat-gain Raman amplifiers pumped and gainequalised by 12-wavelength-channel WDM laser diode unit. Electronics Letters, 35, 16, p. 1355-1356, Agosto 1999. 
[54] C. Barnard, P. Myslinski, J. Chrostowski e M. Kavehrad, Analytical model for rare-earthdoped fiber amplifiers and lasers. IEEE Journal of Quantum Electronics, 30, 8, p. 1817-1830, Agosto 1994.

[55] A. A. M. Saleh, R. M. Jopson, J. D. Evankow e J. Aspell, Modeling of Gain in ErbiumDoped Fiber Amplifiers. IEEE Photonics Technology Letters, 2, 10, p. 714-717, Outubro 1990.

[56] Recomendação ITU-T G.652, disponível em http://www.itu.int/itut/recommendations/index.aspx?ser=G, acesso em 18/10/2010.

[57] A. W. Naji, M. S. Zainal Abidin, M. H. Al-Mansoori, F. R. Mahamd Adikan e M. A, Mahdi, Optimisation of remotely-pumped $\mathrm{Er}^{3+}{ }_{-}$doped fibre amplifier location in repeaterless tranmission systems. Optics Communications, 272, p. 205-210, Abril 2007.

[58] Página da internet referente ao projeto PIEMAN, disponível em http://www.istpieman.org/techap.htm, acesso em 21/08/2010.

[59] Relatório contendo os principais resultados obtidos no projeto PIEMAN, disponível em https://biblio.ugent.be/input/download?func=downloadFile\&fileOId=586755, acesso em $21 / 08 / 2010$.

[60] S. Smolorz, H. Rohde, P. Ossieur, C. Antony, P. D. Townsend, T. DeRidder, B. Baekelandt, X. Z. Qiu, S. Appathurai, H.-G. Krimmel, D. Smith e A. Poustie, Next generation access networks: PIEMAN and beyond. International Conference on Photonics Switching, Setembro 2009.

[61] Página da internet referente ao projeto SARDANA, disponível em http://www.ictsardana.eu/index.php, acesso em 21/08/2010.

[62] B. Schrenk, F. Bonada, J. A. Lazaro e J. Prat, Remotely Pumped Long-Reach Hybrid PON With Wavelength Reuse in RSOA-Based ONUs. Journal of Lightwave Technology, 29, 5, p.635-641, Março 2011.

[63] Apresentação dos resultados parciais obtidos no projeto SARDANA, disponível em http://iscte.pt/ rhcl/material/NGON/NGON_ATeixeira.pdf, acesso em 12/08/2010. 
[64] W. Mathlouthi, F. Vacondio e L. A. Rusch, High-Bit-Rate Dense SS-WDM PON Using SOA-Based Noise Reduction With a Novel Balanced Detection. Journal of Lightwave Technology, 27, 22, p. 5045-5055, Novembro 2009.

[65] Rich Seifert e Jim Edwards, The All-New Switch Book: The Complete Guide to LAN Switching Technology Second Edition. Wiley Publishing: Indianapolis, 2008.

[66] Gilbert Held, Ethernet Networks: Fourth Edition. John Wiley \& Sons: Chichester, 2003.

[67] R. Bonk, R. Brenot, C. Meuer, T. Vallaitis, A. Tussupov, J. C. Rode, S. Sygletos, P. Vorreau, F. Lelarge, G. H. Duan, H.-G. Krimmel, T. Pfeiffer, D. Bimberg, W. Freude e J. Leuthold. 1.3 / $1.5 \mu \mathrm{m} Q D$-SOAs for WDM/TDM GPON with extended reach and large upstream / downstream dynamic range. Optical Fiber Conference (OFC) post deadline papers, Março 2009.

[68] Página principal da internet do consórcio de emrpesas que regulamentam o acesso do tipo FTTx, disponível em http://www.ftthcouncil.org/, acesso em 13/09/2011.

[69] White-paper sobre sistemas do tipo FTTH, disponível em http://www.corning.com/WorkArea/downloadasset.aspx?id=10889, acesso em $13 / 09 / 2011$.

[70] Página da internet contendo informações sobre o programa OptiSystem, disponível em http://www.optiwave.com/products/system_overview.html, acesso em 20/06/2011.

[71] Sadao Adachi, Peter Carper, Safa Kasap e Arthur Willoughby, Properties of Semiconductor Alloys: Group-IV, III-V and II-VI Semiconductors. Wiley Publishing: Indianapolis, 2009.

[72] Página da internet que contém informações físicas sobre compostos semicondutores, disponível em http://www.ioffe.rssi.ru/SVA/NSM/Semicond/, acesso em 10/11/2011.

[73] Página da internet sobre características e figuras de mérito dos SOAs, disponível em http://www.inphenix.com/pdfdoc/Application_Notes_for_SOAs.pdf, acesso em $12 / 11 / 2011$.

[74] Página da internet sobre característcas e figuras de mérito dos SOAs, disponível em http://www.kamelian.com/techarticles/App_Note_No_0001.pdf, acesso em 12/11/2011. 
[75] K. Morito, S. Tanaka, S. Tomabechi e A. Kuramata, A Broad-Band MQW Semiconductor Optical Amplifier With High Saturation Output Power and Low Noise Figure. IEEE Photonics Technology Letters, 17, 5, p. 974-976, Maio 2005.

[76] Página da internert contendo datasheets das fibras dopadas com érbio fabricadas pela empresa OFS, disponível em http://www.specialtyphotonics.com/products/specialty_fiber_optics.php, acesso em $20 / 08 / 2010$.

[77] P. M. Aljaff e B. O. Rasheed, Design Optimization for Efficient Erbium-Doped Fiber Amplifiers. World Academy of Science, Engineering and Technology, 46, p. 40-43, 2008.

[78] F. D. B. Mahad e A. S. B. M. Supa'at, EDFA Gain Optimization for WDM System. Elektrika, Faculty of Electrical Engineering, Universiti Teknologi Malaysia, 11, 1, p. 34-37, 2009.

[79] Página central dos datasheets dos componentes híbridos, disponível em http://www.oplink.com/product/productdetail.asp?pcategory=Amplifications\& psubcategory=Isolators\%2FHybrid+Amp+Components, acesso em 20/08/2010.

[80] Datasheet do laser de bombeio modelo FOL14xx Series, disponível em http://www.furukawa.co.jp/fitel/eng/active/pdf/14xx/ODC-9A001B_FOL14xx_B.pdf, acesso em 20/08/2010.

[81] Datasheet da fibra compensadora de dispersão de $100 \mathrm{~km}$, disponível em http://ofscatalog.specialtyphotonics.com/Asset/OFS_SMFDK_S.pdf, acesso em $20 / 08 / 2010$.

[82] N. Hossain, A. W. Naji, V. Mishra, F. M. Abbou, A. "A. R. Hairul e A. R. Faidz, Theoretical Analysis, Optimization, and Experimental Evaluation of Dual Function DP R-EDFA. Journal of Russian Laser Research, 28, 3, p. 293-303, 2007.

[83] Datasheet do acoplador de bombeio modelo $1480 \mathrm{~nm} / 1550 \mathrm{~nm}$, disponível em http://www.furukawa.co.jp/fitel/eng/active/pdf/14xx/ODC-9A001B_FOL14xx_B.pdf, acesso em 20/08/2010.

[84] Clifford Headley e Goving P. Agrawal, Raman Amplification in Fiber Optical Communication Systems. Elsevier: San Diego, Estados Unidos, 2005. 